\title{
IMPROVING HEALTHCARE DELIVERY WITH LEAN THINKING:
}

\author{
ACTION RESEARCH IN \\ AN EMERGENCY DEPARTMENT
}

Remco Willem Rosmulder 


\section{PhD dissertation committee:}

Chairman and Secretary:

Prof. dr. R.A. Wessel, Universiteit Twente

Promotores:

Prof. dr. ir. J.J. Krabbendam, Universiteit Twente

Prof. dr. A.H.M. Kerkhoff, Universiteit Twente

Referee:

Drs. J.S.K. Luitse, AMC Amsterdam

Members:

Prof. dr. H.G. Bijker, Universiteit Twente

Prof. dr. ir. P.C. de Weerd-Nederhof, Universiteit Twente

Prof. dr. G. Turchetti, Scuola Superiore Sant'Anna, Pisa

Prof. dr. P. Coughlan, Trinity College, Dublin

Prof. dr. J.J. van Muijen, Nyenrode Business Universiteit

Opmaak en vormgeving: Dolf Trieschnigg

Omslagontwerp: Peter Rosmulder

Druk: Wöhrmann Print Service, Zutphen

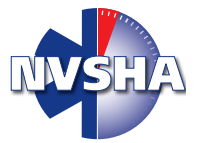

De verspreiding van dit proefschrift is mede mogelijk gemaakt door een bijdrage van de Nederlandse Vereniging van Spoedeisende Hulp Artsen

(c) 2011 Remco Rosmulder, Utrecht, The Netherlands.

ISBN: 978-90-365-3258-7

DOI: $10.3990 / 1.9789036532587$ 


\title{
IMPROVING HEALTHCARE DELIVERY WITH LEAN THINKING:
}

\author{
ACTION RESEARCH IN \\ AN EMERGENCY DEPARTMENT
}

\section{PROEFSCHRIFT}

ter verkrijging van

de graad van doctor aan de Universiteit Twente, op gezag van de rector magnificus, prof. dr. H. Brinksma, volgens besluit van het College voor Promoties in het openbaar te verdedigen op donderdag 13 oktober 2011 om 14.45 uur

door

\section{Remco Willem Rosmulder}

geboren op 27 februari 1981

te Geldrop 


\section{Promotores:}

Prof. dr. ir. J.J. Krabbendam, Universiteit Twente

Prof. dr. A.H.M. Kerkhoff, Universiteit Twente

(C) 2011 Remco Rosmulder, Utrecht, The Netherlands ISBN: 978-90-365-3258-7 
No man is an island

—John Donne, Meditation XVII, 1624 

Voor Anne Rosmulder-Gorissen 



\section{Summary}

The healthcare sector faces a challenge to deliver more and better patient care with less manpower and less financial resources. This thesis deals with the question if industrial engineers can contribute to this by applying process improvement concepts that were successful in industry. In this research, the principles of lean thinking were used. In a nutshell, these imply that all activities that do not add value are removed from a production process, and that the remaining activities should run as smoothly as possible.

An excellent opportunity to apply lean thinking occurred when the Academic Medical Centre in Amsterdam wished to address certain problems in the flow of patients in the hospital's emergency department (ED). Delivering healthcare obviously is something different than industrial production. Therefore we carried out an exploratory research first. In this pilot project, a new scheduling system was tested that allowed general practitioners to schedule arrival times for patients they referred to the ED. The goal was to match the variable number of patients better to the available resources in the ED. Based on the encouraging results from the pilot, it was decided to perform further empirical research using a soft systems approach. This implied that we first formed a team with the managers of the ED and healthcare professionals from all disciplines contributing to the care delivery. We invited them to take a critical look at the care delivery from a lean thinking perspective. Then we defined feasible actions together to make the healthcare delivery run more smoothly. Experiments were set up to test these new ways of working and measure the effects on the patient flow. This process of action and research, to which we as researchers contributed, became the subject of investigation for this $\mathrm{PhD}$ research. This centred around two main questions: 1) Are healthcare managers and healthcare professionals willing and able to apply the principles of lean thinking? 2) Do eventual applications indeed produce effects in the flow of patients in the ED?

Five action research (AR) projects were carried out:

1. Radiology project. In this project, the patient flow was analysed for ED patients who needed x-rays. The project goal was to improve patient flow between the ED and the radiology department and to reduce waiting times.

2. Planning board project. In this project, a central planning board was developed 
and implemented. The project goal was to increase the overview of patient flow and the feeling of control over the department for ED staff.

3. Computer simulation project. In this project, a computer simulation model was designed of the care delivery process for self-referred ED patients. The model enabled us to predict the effects of interventions on the patient flow. The project goal was to design a simulation model as a tool to facilitate action taking in the AR process.

4. Advanced triage project. In this project, an advanced triage protocol was developed and tested for self-referred ED patients. In advanced triage, emergency nurses initiate additional diagnostic examinations independently, directly from the triage. The project goal was to reduce patient waiting times while maintaining the quality of medical care. The computer simulation model mentioned before was used in this project.

5. Nursing wards project. In this project, the patient flow was analysed for ED patients who were admitted to one of the nursing wards of the internal medicine specialty. The project goal was to inform hospital management about implementing a special observation unit to improve patient flow.

In all five projects, the industrial engineers were able to have the other participants in the AR look at the healthcare delivery from the perspective of lean thinking. It proved to be a substantially different perspective than what the ED managers and other healthcare professionals were used to. Together, we developed a shared closer understanding of the patient flow and the inherent activities that did not add to the patient care. On the whole, the direct participants in the AR were able to experiment successfully with making the healthcare delivery run more smoothly. Other healthcare professionals, who had not directly participated in the AR, were, by contrast, not always willing to support the new ways of working. This complicated the experimentation in the projects. This probably is the main explanation of the fact that a clear improvement of patient flow could be demonstrated with hard figures in only one of the five projects. Fortunately, the other projects produced data that may be labelled as promising clues of improvement.

The general conclusion of this thesis is that industrial engineers, through careful application of lean thinking principles, can contribute to the improvement of healthcare delivery in hospitals. The soft systems approach deserves further application for this purpose. This approach was, to our knowledge, not used before by industrial engineers to apply lean thinking in healthcare. The same can be observed in relation to the use of computer simulation models in hospitals. Contrary to the opinion of many, these models can successfully be applied in the testing of new ways of working in the healthcare delivery. 


\section{Samenvatting}

\section{Verbeteren van de zorgverlening door lean thinking: actieonderzoek op een afdeling spoedeisende hulp}

De gezondheidszorg staat voor de uitdaging om meer en betere zorg te verlenen met minder menskracht en minder financiële middelen. Dit proefschrift gaat over de vraag of technisch bedrijfskundigen hieraan een bijdrage kunnen leveren door het toepassen van verbeterconcepten die afkomstig zijn uit de industrie. In dit onderzoek gebruikten wij de principes van lean thinking. Deze houden kort samengevat in dat alle activiteiten die geen waarde toevoegen, worden verwijderd uit een productieproces en dat men de resterende activiteiten zo vloeiend mogelijk laat verlopen.

Een goede gelegenheid om de beginselen van het lean thinking toe te passen ontstond toen het Academisch Medisch Centrum te Amsterdam bepaalde problemen met de doorloop van patiënten op de afdeling spoedeisende hulp (SEH) wilde gaan aanpakken. Het verlenen van patiëntenzorg is uiteraard iets heel anders is dan de industriële productie. Daarom verrichtten we eerst een verkennend onderzoek. Dit hield in dat een nieuw planningssysteem werd uitgeprobeerd om huisartsen aankomsttijden te laten afspreken voor patiënten die zij naar de SEH verwezen. Doel was om hiermee het variabele aanbod van patiënten beter af te stemmen op de beschikbare mensen en middelen in de SEH. Op basis van de bemoedigende resultaten van de voorstudie werd besloten om vanuit een soft systems-benadering verder empirisch onderzoek te doen. Concreet betekende dit dat wij allereerst een team vormden met de managers van de SEH en zorgverleners van alle disciplines die bijdragen aan de patiëntenzorg. Wij nodigden hen uit om de zorgverlening eens kritisch te bezien vanuit een lean thinking-perspectief. Samen formuleerden wij vervolgens nieuwe werkwijzen om de zorgverlening vloeiender te laten verlopen. Daarna werden experimenten opgesteld om deze in de praktijk uit te proberen en de effecten daarvan te bepalen op de patiëntenstroom. Dit proces van actie en onderzoek, waaraan wij als onderzoekers deelnamen, was het onderwerp van dit promotieonderzoek. Dit centreerde zich rond twee hoofdvragen: 1) Zijn hulpverleners en managers in de gezondheidszorg bereid en in staat om de beginselen van het lean thinking toe te passen? 2) Levert het eventuele toepassen inderdaad effecten op in de doorloop van patiënten op de SEH? 
Vijf actieonderzoeksprojecten werden uitgevoerd:

1. Radiologie project. Dit project betrof een analyse van de stroom van patiënten van de SEH naar de afdeling radiologie en terug. Doel was om de patiëntenstroom tussen beide afdelingen te verbeteren en wachttijden te verminderen.

2. Planbord project. Dit project betrof het ontwerpen en invoeren van een centraal overzichtsbord. Doel was om het personeel van de SEH meer zicht te geven op de patiëntenstroom en hun gevoel van controle daarover te verbeteren.

3. Computer simulatie project. In dit project werd een computersimulatie ontworpen van het zorgproces voor zelfverwezen patiënten op de SEH. Het computermodel maakte het mogelijk om de effecten van interventies op de patiëntenstroom te voorspellen. Doel was om een computermodel te ontwerpen voor gebruik als hulpmiddel in het actieonderzoek, om het daadwerkelijk nemen van actie te bevorderen.

4. Advanced triage project. Hier ging het om het ontwikkelen en uitproberen van een advanced triage-protocol voor zelfverwezen patiënten. Advanced triage hield in dat de SEH-verpleegkundige direct bij de triage zelfstandig aanvullend diagnostisch onderzoek aanvraagt. Doel was om de wachttijden van patiënten te verkorten terwijl de kwaliteit van de medische hulpverlening behouden bleef. De eerder genoemde computersimulatie werd bij dit project gebruikt.

5. Opname project. Dit project betrof een analyse van de stroom van patiënten die vanaf de SEH werden opgenomen op verpleegafdelingen van de interne geneeskunde. Doel was om het ziekenhuismanagement te informeren over het invoeren van een speciale observatorium-afdeling om de patiëntenstroom te bevorderen.

In alle vijf de projecten waren de technisch bedrijfskundigen in staat om de andere deelnemers aan het actieonderzoek vanuit een lean thinking perspectief naar de zorgverlening te laten kijken. Dit bleek een wezenlijk ander perspectief dan de afdelingsmanagers en zorgverleners gewend waren om te hanteren. Samen ontwikkelden wij een gedeeld nader inzicht in de patiëntenstroom en de daarin aanwezige activiteiten die niet bijdroegen aan de patiëntenzorg. Over het geheel genomen bleken de rechtstreekse deelnemers aan het actieonderzoek heel wel in staat om succesvol te experimenteren met het vloeiender laten verlopen van de zorgverlening. Andere hulpverleners, die niet direct deelnamen aan het actieonderzoek, bleken daarentegen lang niet altijd bereid om de nieuwe werkwijzen te ondersteunen. Dit bemoeilijkte de uitvoering van de projecten. Waarschijnlijk schuilt hierin de belangrijkste verklaring van het feit dat een duidelijke verbetering van de patiëntenstroom slechts in één van de vijf projecten met harde cijfers kon worden aangetoond. Gelukkig leverden de andere projecten tal van gegevens op die als hoopvolle aanwijzingen voor verbetering kunnen worden bestempeld.

De algemene conclusie van dit proefschrift luidt dan ook dat technisch bedrijfskundigen door zorgvuldige toepassing van de principes van lean thinking een bijdrage 
kunnen leveren aan het verbeteren van de zorgverlening in ziekenhuizen. De soft systems benadering verdient hierbij verdere toepassing. Zij werd, voor zover ons bekend is, niet eerder door technisch bedrijfskundigen gebruikt om lean thinking toe te passen in de gezondheidszorg. Hetzelfde kan worden geconstateerd in verband met het gebruik van computersimulatiemodellen in het ziekenhuis. Anders dan velen van mening zijn, blijken deze modellen met succes te kunnen worden toegepast bij het uitproberen van nieuwe werkwijzen in de zorgverlening. 



\section{Contents}

Summary vii

Samenvatting $\quad$ ix

1 Lean thinking in healthcare $\quad 1$

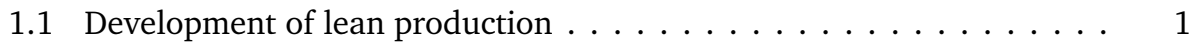

1.2 Promise and principles of lean thinking $\ldots \ldots \ldots 2$

1.3 A first encounter with the problem $\ldots \ldots \ldots \ldots$

1.3.1 Brief description of the pilot project .......... 3

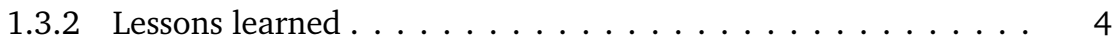

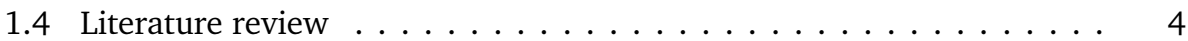

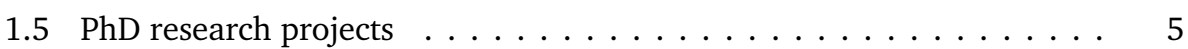

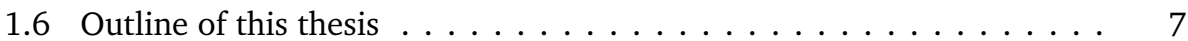

2 Literature review $\quad 11$

2.1 An industrial engineering model of a production system . . . . . . . . 11

2.1.1 Central elements of organisations . . . . . . . . . . . 11

2.1.2 Functional combination into a transformation process . . . . . . 12

2.2 Lean production at Toyota . . . . . . . . . . . . . . 13

2.2.1 Architecture of the transformation process . . . . . . . . . . 14

2.2 .2 Organisational arrangements . . . . . . . . . . . . 15

2.3 Implementing lean production in other organisations . . . . . . . . 16

2.3.1 Principles of lean thinking . . . . . . . . . . . . 16

2.3 .2 Critiques of lean . . . . . . . . . . . . . 17

2.4 Differences between the production systems of Toyota and a hospital . 18

2.4.1 Different types of organisations . . . . . . . . . . . . 19

2.4.2 Different configurations of organisational arrangements . . . . 20

2.4.3 Different goals in different worlds of management . . . . . . . . 22

2.5 Possible arrangements for lean healthcare delivery . . . . . . . . . 23

2.5.1 Based on the arrangements at Toyota . . . . . . . . . . 23

2.5.2 Described in empirical studies . . . . . . . . . . . . 24 
2.6 Appropriate strategies for industrial engineers to help organise lean

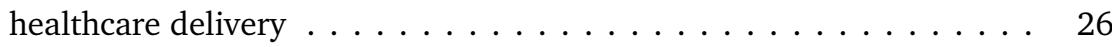

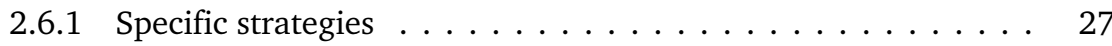

2.6.2 Systems engineering and soft systems methodology . . . . . 27

2.6.3 An appropriate choice for our research problem . . . . . . . 29

3 Research context 33

3.1 An emergency department in general . . . . . . . . . . . 33

3.2 The ED in the Academic Medical Centre . . . . . . . . . . . 34

3.2.1 Numbers of patients and main patient flows . . . . . . . . 34

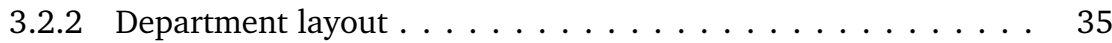

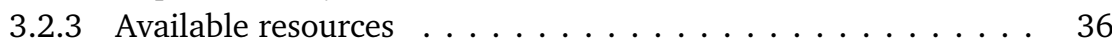

3.3 Organisational arrangements for emergency care delivery in the AMC . 38

3.3.1 Task division and coordination in the ED . . . . . . . . . 38

3.3.2 Dependencies in the value stream . . . . . . . . . . 39

3.3.3 How complex arrangements create waiting . . . . . . . . . . 39

3.4 Trends in professional domains involved in emergency care delivery . 42

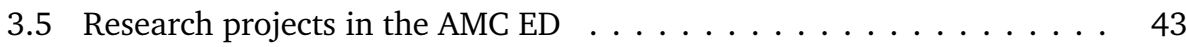

4 Planning emergency patients: an attempt to change the nature of the $\begin{array}{ll}\text { emergency department } & 47\end{array}$

4.1 Can we defy chance? . . . . . . . . . . . . . . . . . . . . 49

4.2 The scheduling idea $\ldots \ldots \ldots \ldots \ldots \ldots \ldots \ldots \ldots$

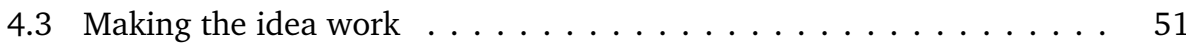

4.4 Reasons for the limited success . . . . . . . . . . . . . . . . 51

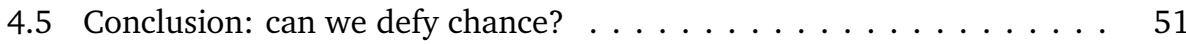

5 Action research and soft systems methodology for studying problems in emergency care delivery 53

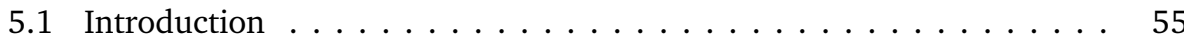

5.2 Lessons from an attempt to schedule emergency patients . . . . . . . 55

5.3 Theoretical perspectives . . . . . . . . . . . . . . 56

5.4 Three implications, calling for an action mode of research . . . . . . 58

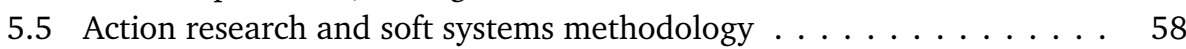

5.6 Toward a methodology for studying and improving problematic ED

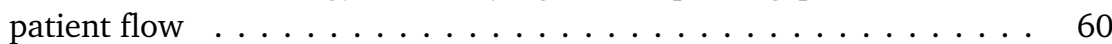

5.7 The methodology illustrated $\ldots \ldots \ldots \ldots \ldots \ldots \ldots \ldots \ldots$

5.8 Conclusion and implications $\ldots \ldots \ldots \ldots \ldots \ldots \ldots \ldots$

6 Computer simulation within action research: a promising combination $\begin{array}{ll}\text { for improving healthcare delivery? } & 69\end{array}$

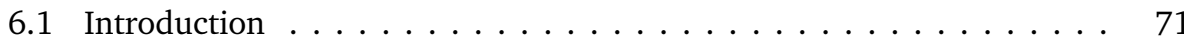

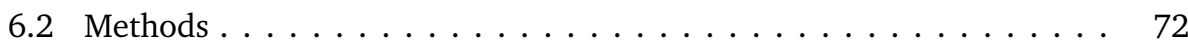

6.2 .1 Study setting and research situation $\ldots \ldots \ldots \ldots \ldots \ldots$ 
6.2 .2 The subject of the simulation model . . . . . . . . . . 73

6.2.3 Strategy to design and use the simulation model . . . . . . . 73

6.2 .4 Evaluation of the outcomes . . . . . . . . . . . 75

6.3 Execution of the experiment $\ldots \ldots \ldots \ldots \ldots \ldots$

6.3.1 Preparations; defining the primary outcome measure . . . . . 75

6.3 .2 Making the conceptual model . . . . . . . . . . 76

6.3 .3 Designing the computer model . . . . . . . . . . . 76

6.3 .4 Exploring improvement scenarios . . . . . . . . . . . . 80

6.3 .5 Implementing the scenario . . . . . . . . . . . . . . 81

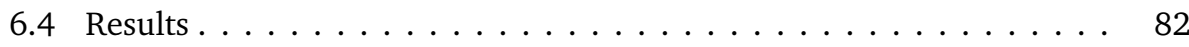

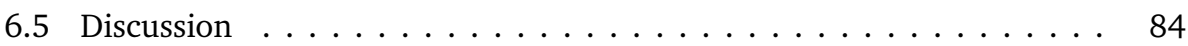

7 'Advanced triage' improves patient flow in the emergency department $\begin{array}{ll}\text { without affecting the quality of care } & 91\end{array}$

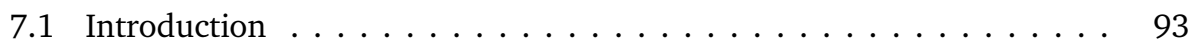

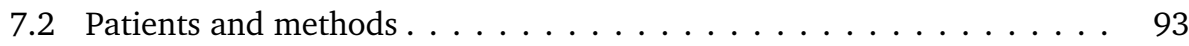

7.2.1 Study setting and design . . . . . . . . . . . . . 93

7.2.2 Emergency department care delivery process . . . . . . . . . . 94

7.2 .3 Data collection . . . . . . . . . . . . . . . . . 95

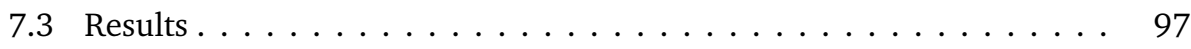

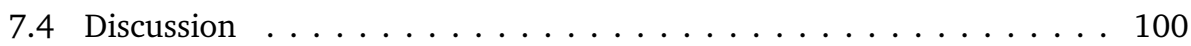

7.5 Conclusion ......................... 101

8 The role of operations management in improving emergency department $\begin{array}{ll}\text { outflow } & 103\end{array}$

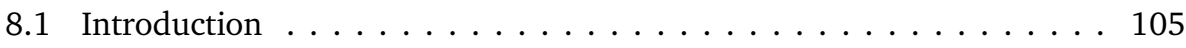

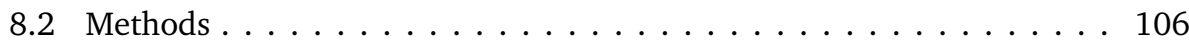

8.2.1 Study setting and patient population . . . . . . . . . 106

8.2.2 Theoretical model of the research problem . . . . . . . . . . 106

8.2 .3 Research approach . . . . . . . . . . . . . . . . 108

8.2.4 Methods of measurement. . . . . . . . . . . . . . . 109

8.3 Results . . . . . . . . . . . . . . . . . . . . . . 110

8.3.1 Emergency patient flow to the wards . . . . . . . . . . . 110

8.3.2 Patient volume and meaningful time differences . . . . . . . 113

8.3.3 Bed availability in the wards in relation to patient outflow from the ED . . . . . . . . . . . . . . . . 113

8.3.4 Interviews with management in the wards and the ED . . . . . 114

8.3.5 Presentation of key insights and follow-up decisions in the study setting ........................ 114

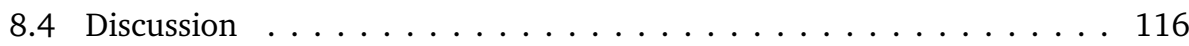


9 Conclusions 121

9.1 Conclusion and discussion for central question one . . . . . . . . . . 122

9.1.1 Main findings from the AR projects . . . . . . . . . . . . . . . . . . . . . . . . . . . . . . .

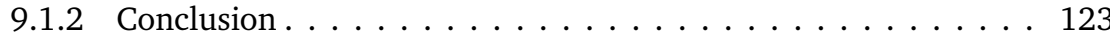

9.1 .3 Discussion . . . . . . . . . . . . . . . 123

9.2 Conclusion and discussion for central question two . . . . . . . . . . . . . . 124

9.2.1 Main findings from the AR projects . . . . . . . . . . . . . . . . . . . . . . . . . . . . . . . .

9.2 .2 Conclusion . . . . . . . . . . . . . . . . . . . . . . . . . . . . . 125

9.2 .3 Discussion . . . . . . . . . . . . . . . . 125

9.3 Conclusion and discussion for central question three . . . . . . . . . . 127

9.3.1 Main findings from the AR projects . . . . . . . . . . . . . 127

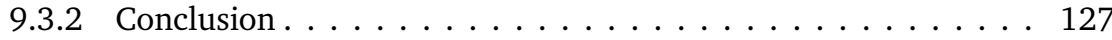

9.3 .3 Discussion . . . . . . . . . . . . . . . . . 128

9.4 A new set of lean thinking principles for use in healthcare . . . . . . . 129

9.5 Recommendations . . . . . . . . . . . . . . . . . . . . . . 129

9.5 .1 Further research . . . . . . . . . . . . . . . . . . . . . . . . . . . . . . . . . . . . . . . . . .

9.5 .2 Improving practice . . . . . . . . . . . . . 130

$\begin{array}{ll}\text { Dankwoord } & 133\end{array}$

$\begin{array}{ll}\text { Over de auteur } & 135\end{array}$

$\begin{array}{ll}\text { Index } & 137\end{array}$ 


\section{1}

\section{Lean thinking in healthcare}

The healthcare sector is under stress. Demands are rising and expenditures increasing. Healthcare workers are in short supply; they experience high work pressure and unpleasant working conditions. Waiting times for patients nevertheless get longer. After years of open-end financing, governments turn towards budgeting actions with sharp efficiency cuts. Healthcare insurers also expect a much more rational delivery of cure and care. The healthcare sector, thus, faces a big challenge: delivering more and better patient care with the same means. This thesis investigates if the healthcare sector can adopt certain new techniques pioneered in industry to help meet this challenge.

\subsection{Development of lean production}

The sector of car production faced a comparable challenge in the 1980s. It was started by the Japanese Toyota Motor Company, which brought cars to the market that were at the same time cheaper, more reliable and more fuel-efficient than others. The established car makers in America and Europe did not have an answer-they were rapidly losing market share (Holweg, 2007). A large international research operation was started to discover what caused Toyota's competitive advantage. It proved to be based on Toyota's production system (Womack et al., 1990). The people at Toyota produced cars of higher quality, in a larger variety, and with far less effort than their competitors. What is more, Toyota produced and delivered cars more rapidly to respond to changing customer demands, and was also able to design new models faster with less effort. This unique ability originated after World War II, when Toyota decided to serve the tiny Japanese automobile market by producing a wide range of vehicles in small numbers (Ohno, 1988; Hopp and Spearman, 2000; Womack et al., 1990; Holweg, 2007). As Toyota could not exploit economies of scale to reduce costs, it focused instead on eliminating the waste of all resources-human effort, materials, and time-required to make final products. This continuous emphasis on reliability, speed 
and flexibility paid off decades later in the global car market. Toyota's manufacturing approach soon became a model for many other companies in many different industries. Thus it developed into a new paradigm for industrial production: mass productionwhich had replaced craft production methods-now became lean production (Womack et al., 1990; Jaffee, 2001; Hayes et al., 2005).

\subsection{Promise and principles of lean thinking}

Naturally, it is appealing to apply lean production in healthcare-the physicians and nurses would be able to cure more patients and care for them better at a lower cost to society. A large range of lean techniques and methods is available to choose from. Unfortunately, this range resembles a loose collection rather than an integrated system (Hopp and Spearman, 2000). Moreover, the techniques and methods were designed to solve specific production problems at Toyota or in other specific organisations. Fortunately, however, Womack and Jones continued the international research to develop a thought process for guiding the implementation of lean techniques. This process, called lean thinking, was intended for managers in any company in any industry wishing to make their mass-production organisations more lean (Womack and Jones, 1996a;b).

Lean thinking consists of five principles (Lean Enterprise Institute, 2009):

1. Specify value from the standpoint of the end customer in terms of a specific product.

2. Identify all the steps in the value stream for each product family, eliminating whenever possible those steps that do not create value.

3. Make the value-creating steps occur in tight sequence so the product will flow smoothly toward the customer.

4. As flow is introduced, let customers pull value from the next upstream activity.

5. As value is specified, value streams are identified, wasted steps are removed, and flow and pull are introduced, begin the process again and continue it until a state of perfection is reached in which perfect value is created with no waste.

It is by no means reasonable, however, to expect that healthcare managers can simply use lean thinking to improve healthcare delivery in their organisations. Healthcare delivery does not equal industrial mass production. The value produced is more or less untouchable, difficult to specify and unclearly priced; the products worked on are the customers themselves; and the operators at work are professionals with considerable autonomy (Mintzberg, 1980; Porter and Teisberg, 2004; Hayes et al., 2005). How difficult it is follows not only from these theoretical considerations but also from our first experiences in a research we carried out in Amsterdam. 


\subsection{A first encounter with the problem}

The Academic Medical Centre (AMC) had offered an excellent opportunity to acquire firsthand knowledge about implementing lean thinking. The managers of the hospital's emergency department wished to address the increasingly problematic patient flow. Tired of seeing their staff improvising continuously to solve problems, they expressed a need for theory about organising the care delivery in a better way. They also wanted improvement ideas to be based on analysis instead of gut feelings as usual. A collaboration was started to carry out a pilot project as part of a MSc thesis research in industrial engineering at the University of Twente (Rosmulder, 2004).

\subsubsection{Brief description of the pilot project}

An emergency department (ED) is a unique healthcare context; it is one of few hospital departments open to patients 24 hours per day, 7 days a week. The number of new patients is rather unpredictable and varies throughout the day. Their symptoms are always different. In an ED, the most important type of waste is waiting (Dickson et al., 2009). Waiting is directly life-threatening for some patients and places all at risk for poor outcomes (Derlet and Richards, 2000; Chalfin et al., 2007). Moreover it is tedious, which sometimes results in aggression toward staff (Bindman et al., 1991; Kyriacou et al., 1999; Derlet and Richards, 2000).

One of the causes of waiting in the ED is the continuous mismatch between the varying number of patients and the relatively fixed number of staff and treatment rooms (Slack et al., 1998; Derlet and Richards, 2000; Asplin et al., 2003). During quiet times, staff are waiting for patients; during busy times, patients are waiting for staff. In the pilot, we used lean thinking to design a new planning system that allowed ED staff to control part of the patient inflow. A smoothened flow reduces waiting lines for patients and disturbances for staff (Hopp and Spearman, 2000). Our analysis of ED inflow revealed that the arrivals of one patient group could, in principle, be scheduled. This concerned patients referred by their general practitioner (GP). They comprise about 20 percent of total ED inflow at the AMC. A GP-referred patient generally requires medical treatment within 24 hours. Before sending the patient to a nearby ED, the GP needs to consult with a specialist in that hospital. The specialist then contacts a coordinating nurse in the ED to start diagnostic examinations when the patient arrives.

We redesigned the referral procedure together with ED management, emergency nurses, specialists and GPs. The idea was simple and cost nothing: after consulting with the GP on the phone, the specialist would put the GP through to the coordinating nurse in the ED. The nurse could then talk directly to the GP to schedule arrival times based on the condition of the patient and the situation in the ED. It was decided that the two main referral specialties-surgery and internal medicine-try this new procedure for a few weeks. We informed hospital staff extensively about the pilot in presentations, emails, and posters. They received especially designed pocket cards 
explaining the new procedure. A planning board was installed in the ED to record scheduled arrival times. All GPs in the area were notified by the hospital.

Soon after the new procedure was begun, it turned out that the specialists hardly put any of the GPs through to the coordinating emergency nurse. Their arguments were: "These are emergency patients, you should not postpone their arrival"; "The GPs cannot adequately judge whether the patients can wait"; and "It's extra work for me." A good and simple idea proved surprisingly difficult to implement.

\subsubsection{Lessons learned}

We experienced that the principles of lean thinking were easily explained to healthcare managers and workers. However, the principles proved useless because not all of the groups involved adopted the new procedure. The group that was crucial for the new planning system to succeed stuck to their old way of working. This made it impossible for us to study if the new procedure would benefit patient waiting times and ED flow. How did this happen?

In our opinion, there were two causes. First, the procedure of referring patients from the GP to the ED is complex and historically ill-structured. The specialists accepting the call from the GP neither work for the ED nor in it, but their actions impact the patient flow considerably. Their decision to accept a referral actually has to do with the availability of beds in the nursing wards. Second, they did not accept the new procedure we offered, in spite of the support for it from ED management and the other co-designers (among whom several residents from surgery and internal medicine). Surely enough, this must have had something to do with our own actionsthe way in which we, as industrial engineers, had offered the lean principles and to whom. We realised that this also had to do with our perspective on engineering production systems in healthcare contexts.

\subsection{Literature review}

Starting from the lessons learned in the pilot project, we set out to study the following questions in the literature:

1. What are the differences between the production systems of Toyota and a hospital?

2. What are the organisational arrangements used by Toyota to implement lean production?

3. What are possible organisational arrangements for hospitals to organise lean healthcare delivery?

4. What are appropriate strategies for industrial engineers to help healthcare managers and workers organise lean healthcare delivery? 
Looking ahead to chapter 2, in which the results of the literature review are described, we briefly provide our tentative answers here:

1. There are a number of notable differences. For example, healthcare delivery cannot be standardised in the same way as car production, and healthcare managers can exert far less control over the operations than their colleagues at Toyota (Mintzberg, 1980; Vermaak and Weggeman, 1999; Glouberman and Mintzberg, 2001).

2. Toyota's organisational arrangements are well-documented. Lean production was implemented by arranging multi-skilled workers in functional teams, where they rotated through each different task (Womack et al., 1990; Hopp and Spearman, 2000; Jaffee, 2001; Hayes et al., 2005). There were numerous other arrangements.

3. Comparing the answers to the previous questions yields several possible organisational arrangements for hospitals. There are a few studies describing organisational arrangements that have been used successfully. The Karolinska hospital in Stockholm reorganised its functional, specialist departments around the patient flow (Brown-Humes, 1994). New functions of nurse coordinators were created to manage patient flow; physicians reported to these coordinators. Organisational arrangements for emergency departments include implementing teamwork, new communication and decision policies, and sharing best practices (Kyriacou et al., 1999; Risser et al., 1999; Hoffenberg et al., 2001; Spaite et al., 2002; Cardin et al., 2003).

4. We found no answer to this question in the literature. More generally speaking, a distinction can be made between systems engineering-the basis of all engineering sciences-and soft systems methodology. Systems engineering takes the world to contain systems that can be engineered for achieving certain objectives (Checkland and Scholes, 1990). Soft systems methodology is suitable for unstructured problem situations in which people disagree on goals and means (Checkland and Scholes, 1990; Hicks, 1991). The latter was most appropriate for our research problem.

\section{5 $\mathrm{PhD}$ research projects}

We decided to perform further empirical research about using lean thinking to improve patient care delivery in the ED. Based on the literature review and the experiences in the pilot project, our strategy started from a soft systems approach in which we collaborated with ED managers and healthcare professionals in the ED to diagnose the problematic patient flow, find feasible actions to take and study the effects. It was essential in our strategy to involve the professionals from all disciplines contributing to the care delivery and to ensure their agreement with an action before starting implementation efforts. The joint process of enquiry and action, to which we as 
researchers contributed, became the subject of investigation for a $\mathrm{PhD}$ research. This method for generating knowledge is known as action research.

Action research (AR) aims to contribute both to the practical concerns of people in an immediate problematic situation and to the goals of social science by joint collaboration within a mutually acceptable ethical framework (Rapoport, 1970; Susman and Evered, 1978). The research takes place in ongoing cycles of action planning, action taking and evaluating, leading to further action planning and so on (French and Bell Jr, 1990; Coughlan and Coghlan, 2002). Action researchers enter a social situation, take part in the action going on, and use the involvement as a research experience focused on the change process (Boonstra, 2000; Checkland and Poulter, 2006).

We carried out a number of AR projects in the ED. In each project, certain lean principles were used to target that part of the patient flow deemed promising for improvement by the people involved. The evaluation of one project and the responsiveness to other opportunities in the study setting determined which project to start next (Dick, 1993; Westbrook, 1994). Muddling through from project to project in this way (Lindblom, 1959; 1979), we were able to cover the entire patient flow in the ED from entry to exit.

The following AR projects were executed:

1. (The pilot project had covered the inflow of GP-referred patients.)

2. Radiology project. The participants in the AR team considered this a promising way to start the collaboration and they expected to achieve improvement easily. The team mapped patient flow between the ED and radiology and identified waste. Interventions were designed to improve patient flow and information flow between both departments and to reduce waiting time. Several proposed changes were implemented, but patient length of stay was unaffected. It proved difficult to gain the support for actions from members of the radiology department.

3. Planning board project. The team decided to limit the next project to something that could be done by healthcare professionals working in the ED only. The improvised planning board from the pilot project provided an excellent opportunity. The participants designed a new and improved planning board for the entire ED. This action successfully increased the overview of patient flow and the feeling of control for the ED staff.

4. Computer simulation project. The previous project improved the overview of flow, which created an opportunity to improve the flow itself. This implied having the physicians and nurses discuss their professional task division. Because the step toward actually taking action had proven difficult earlier, a project was started to design a computer simulation model. This model would be used to facilitate action taking. We modelled the care delivery for self-referred patients together with the medical director of the ED. The modelling assumptions were shared with the entire ED staff. They considered the final computer simulation model a valid representation of the actual work situation. 
5. Advanced triage project. The participants in the AR team used the computer simulation model to discuss the professional task division for self-referred patients, design improvement actions and compute the effects. The model projected a promising reduction of patients' length of stay in the ED. The AR team successfully implemented the new task division, in which the triage nurses ordered diagnostic examinations directly upon patient arrival. The project generated a lot of concerns and discussion in the ED. The use of the simulation model promoted action taking nevertheless.

6. Nursing wards project. After these projects, insight was still lacking into the outflow of patients who were admitted after treatment in the ED. Questions were raised in the AMC about implementing an observation unit to improve this flow. We started a project to analyse the patient flow into the nursing wards of the internal medicine specialty. This revealed a large amount of waste. The analysis provided other and less extensive options to address the problem situation. Implementing an observation unit implied treating symptoms, not causes. Hospital management decided to change the configuration of the nursing wards for each of the major specialties receiving admissions from the ED.

\subsection{Outline of this thesis}

The next chapter presents the findings from the literature review. It also describes the background of lean thinking. Chapter 3 presents the research context. It describes the emergency department of the Academic Medical Centre in detail, including the organisational arrangements and professional domains involved in the care delivery. Chapter 4 (Rosmulder et al., 2006) describes the pilot project in the ED. In chapter 5 (Rosmulder et al., 2009), we describe the design of the collaboration between researchers and practitioners in the action research. The chapter provides backgrounds of action research and soft systems methodology. It includes brief descriptions of the radiology project, the planning board project and the advanced triage project. Chapter 6 (Rosmulder et al., 2011) presents the computer simulation project. It describes how the model was designed and then used to facilitate implementation of advanced triage. Chapter 7 (Rosmulder et al., 2010) describes the advanced triage project in full detail. Chapter 8 (Rosmulder and Luitse, 2011) describes the nursing wards project. Chapter 9 presents the conclusions of the research. We describe and discuss the main findings from the AR projects. We also propose a new set of lean thinking principles, specially intended for use in healthcare. This thesis ends with recommendations for further research and for practice. 


\section{References}

Asplin B, Magid D, Rhodes K, Solberg L, Lurie N, Camargo C (2003). A conceptual model of emergency department crowding. Annals of Emergency Medicine. 42:173-80.

Bindman A, Grumbach K, Keane D, Rauch L, Luce J (1991). Consequences of queuing for care at a public hospital emergency department. Journal of the American Medical Association. 266:1091-96.

Boonstra J (2000). Lopen over water: over dynamiek van organiseren, vernieuwen en leren. Vossiuspers AUP, Amsterdam.

Brown-Humes C (1994). Production line treatment for patients. Financial Times. 7 January.

Cardin S, Afilalo M, Lang E, Collet J, Colacone A, Tselios C, Dankoff J, Guttman A (2003). Intervention to decrease emergency department crowding: does it have an effect on return visits and hospital readmissions? Annals of Emergency Medicine. 41:173-85.

Chalfin D, Trzeciak S, Likourezos A, Baumann B, Dellinger R (2007). Impact of delayed transfer of critically ill patients from the emergency department to the intensive care unit. Critical Care Medicine. 35:1477-83.

Checkland P, Poulter J (2006). Learning for action. John Wiley \& Sons, Chichester.

Checkland P, Scholes J (1990). Soft systems methodology in action. John Wiley \& Sons, Chichester.

Coughlan P, Coghlan D (2002). Action research for operations management. International Journal of Operations \& Production Management. 22:220-40.

Derlet R, Richards J (2000). Overcrowding in the nation's emergency departments: complex causes and disturbing effects. Annals of Emergency Medicine. 35:63-8.

Dick B (1993). You want to do an action research thesis? http://www.scu.edu.au/schools/gcm/ ar/art/arthesis.html.

Dickson E, Anguelov Z, Vetterick D, Eller A, Singh S (2009). Use of lean in the emergency department: a case series of 4 hospitals. Annals of Emergency Medicine. 54:504-10.

French W, Bell Jr C (1990). Organization development: behavioral science interventions for organization improvement. Prentice-Hall International, Englewood Cliffs, 4th edn.

Glouberman S, Mintzberg H (2001). Managing the care of health and the cure of disease. Part I: differentiation. Health Care Management Review. 26:56-69.

Hayes R, Pisano G, Upton D, Wheelwright S (2005). Operations, strategy, and technology: pursuing the competitive edge. Wiley, Hoboken.

Hicks M (1991). Problem solving in business and management: hard, soft and creative approaches. Chapman \& Hall, London.

Hoffenberg S, Hill M, Houry D (2001). Does sharing process differences reduce patient length of stay in the emergency department? Annals of Emergency Medicine. 38:533-40.

Holweg M (2007). The genealogy of lean production. Journal of Operations Management. 25:42037.

Hopp W, Spearman M (2000). Factory physics. McGraw-Hill, Singapore, 2nd edn.

Jaffee D (2001). Organization theory: tension and change. Mc Graw-Hill Higher Education, Singapore.

Kyriacou D, Ricketts V, Dyne P, McCollough M, Talan D (1999). A 5-year time study analysis of emergency department patient care efficiency. Annals of Emergency Medicine. 34:326-35. 
Lean Enterprise Institute (2009). Principles of lean. http://www.lean.org/WhatsLean/Principles. $\mathrm{cfm}$.

Lindblom C (1959). The science of 'muddling through'. Public Administration Review. 19:79-88.

Lindblom C (1979). Still muddling, not yet through. Public Administration Review. 39:79-88.

Mintzberg H (1980). Structure in 5's: a synthesis of the research on organization design. Management Science. 26:322-41.

Ohno T (1988). Toyota production system: beyond large-scale production. Productivity Press, Cambridge.

Porter M, Teisberg E (2004). Redefining competition in healthcare. Harvard Business Review. 82:64-76.

Rapoport R (1970). Three dilemmas of action research. Human Relations. 23:499-513.

Risser D, Rice M, Salisbury M, Simon R, Jay G, Berns S (1999). The potential for improved teamwork to reduce medical errors in the emergency department. Annals of Emergency Medicine. 34:373-83.

Rosmulder R (2004). Organisatieverbetering spoedeisende hulp AMC Amsterdam. Evaluatie van driewegoverleg: gepresenteerde patiënten sneller behandeld? Unpublished MSc thesis, University of Twente, Enschede.

Rosmulder R, Krabbendam J, Kerkhoff A, Houser C, Luitse J (2011). Computer simulation within action research: a promising combination for improving healthcare delivery? Systemic Practice and Action Research. Published Online First.

Rosmulder R, Krabbendam J, Kerkhoff A, Luitse J (2009). Action research and soft systems methodology for studying problems in emergency care delivery. International Journal of Healthcare Technology and Management. 10:289-302.

Rosmulder R, Krabbendam J, Kerkhoff A, Schinkel E, Beenen L, Luitse J (2010). 'Advanced triage' improves patient flow in the emergency department without affecting the quality of care. Nederlands Tijdschrift voor Geneeskunde. 154:A1109.

Rosmulder R, Krabbendam J, Luitse J (2006). Planning emergency patients: an attempt to change the nature of the emergency department. European Journal of Emergency Medicine. 13:377-9.

Rosmulder R, Luitse J (2011). The role of operations management in improving emergency department outflow. International Journal of Healthcare Technology and Management. 12:293306.

Slack N, Chambers S, Harland C, Harrison A, Johnston R (1998). Operations management. Pearson Education, Harlow, 2nd edn.

Spaite D, Bartholomeaux F, Guisto J, Lindberg E, Hull B, Eyherabide A, Lanyon S, Criss E, Valenzuela T, Conroy C (2002). Rapid process redesign in a university-based emergency department: decreasing waiting time intervals and improving patient satisfaction. Annals of Emergency Medicine. 39:168-77.

Susman G, Evered R (1978). An assessment of the scientific merits of action research. Administrative Science Quarterly. 23:582-603.

Vermaak H, Weggeman M (1999). Conspiring fruitfully with professionals: new management rols for professional organisations. Management Decision. 37:29-44.

Westbrook R (1994). Action research: a new paradigm for research in production and operations management. International Journal of Operations \& Production Management. 15:6-20. 
Womack J, Jones D (1996a). Beyond Toyota: how to root out waste and pursue perfection. Harvard Business Review. 74:140-58.

Womack J, Jones D (1996b). Lean thinking. Simon \& Schuster, London.

Womack J, Jones D, Roos D (1990). The machine that changed the world. Rawson Associates, New York. 


\section{2}

\section{Literature review}

This chapter provides a review of the literature relevant to the research problem in this thesis. It describes lean production at Toyota (section 2.2), implementing lean techniques in other organisations with lean thinking (2.3), differences between the production systems of Toyota and a hospital (2.4), possible arrangements for hospitals to organise lean healthcare delivery (2.5), and appropriate strategies for industrial engineers to help healthcare managers and workers achieve this (2.6). We start with defining a model of a production system.

\subsection{An industrial engineering model of a production system}

Industrial engineers are concerned with ways about how people work together to create products and services. Industrial engineers are concerned with the transformation function of organisations. Organisations are essentially viewed as production systems, consisting of several central elements arranged in a certain way.

\subsubsection{Central elements of organisations}

People work together in organisations to achieve things that are beyond the reach of individuals. An organisation is made up of several central, interrelated elements (Scott, 1998):

- Social structure: the patterned or regularised aspects of the relationships among participants in an organisation. The social structure can be analytically separated in a normative and a behavioural structure, and in a formal and informal structure. The social structure is the fundamental building block of organisation; it is what distinguishes a spontaneous and temporary collection of people from an 
actual organisational entity that comes together on a regular bases for a specific purpose (Jaffee, 2001, p.2).

- Participants: those individuals, who, in return for a variety of inducements, make contributions to the organisation. The human resource is unique: it is conscious, reactive and reflective, and it cannot be owned by the organisation. Extracting physical and mental human energy is a persistent organisational problem. Participants are social actors; the social structure is at the same time a medium for their actions and the outcome of it (Giddens, 1984; Bhaskar, 1998). Social structures do not exist unless-and only exist to the extent thatsocial actors carry out their requisite activities; at the same time, social actors are the instruments of both continuity-the reproduction of structure-and change (Scott, 1998, p.20).

- Goals: the conceptions of desired ends that participants attempt to achieve through their performance of task activities. The goals are often referred to as the reason of an organisation's existence. It is important to note that the goals of an organisation are human goals (Jaffee, 2001), often those of a dominant coalition (Cyert and March, 1963; Thompson, 1967; Child, 1972).

- Technology: the means used by the organisation to transform raw materialsphysical, informational, human-into some final product (Perrow, 1967; Hickson et al., 1969; Jaffee, 2001). Technology includes machines and equipment, knowledge, methods, and skills (Veen, 1980). Technology shapes many other aspects of the organisation such as the labour process, social structures, and participants (Jaffee, 2001).

- Environment: every organisation exists in a specific physical, technological, cultural, and social environment to which it must adapt. The environment provides the resources for an organisation to fulfil its function (Parsons, 1960; Miller and Rice, 1967). Exchange relations rest on domain consensus: expectations for organisational members and others with whom they interact about what the organisation will and will not do (Thompson, 1967). Most relevant to organisational goal attainment is the task environment, which includes customers, suppliers, competitors, and regulatory groups (ibid). Naturally, organisations also shape their environments (Scott, 1998).

\subsubsection{Functional combination into a transformation process}

Industrial engineers do not consider an organisation's central elements as elements in themselves or in isolation - they always consider how their combination relates to the function of transformation. In other words, we are concerned with the architecture in which transformational activities are grouped and linked with regard to customer orders (de Sitter, 2000). Organisations are essentially viewed as production systems.

The transformation process of an organisation changes inputs-materials, customers, and information-into outputs: products and services. It consists of inter- 


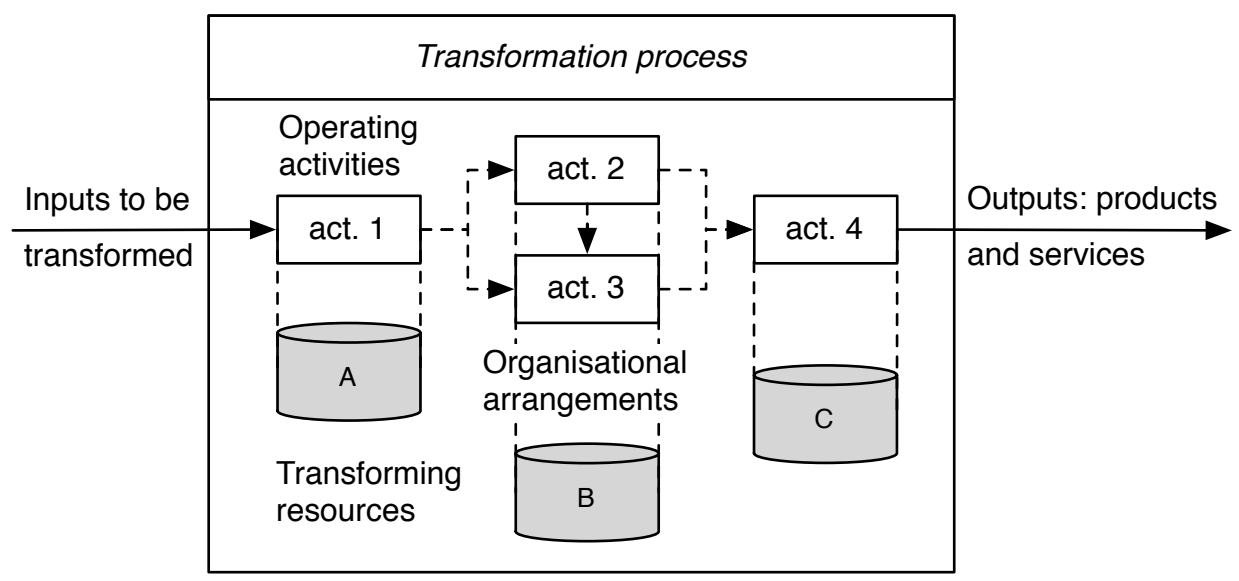

Figure 2.1: An industrial engineering model of a transformation process in a production system

related operating activities that are needed to complete the transformation (Miller and Rice, 1967) and transforming resources that perform or enable the operating activities (Slack et al., 2004). These include people, machines, equipment, and facilities. Organisational arrangements are required to initiate, maintain, and control the transformation process (Boer and Krabbendam, 1996). These are relatively enduring arrangements about the division and coordination of tasks, and their alignment toward the goals of the organisation (ibid). See figure 2.1.

When we consider an emergency department for example, the transformation process involves turning patients who arrive with an acute medical problem into patients recovering from treatment. Medical and nursing staff use treatment rooms, equipment and materials to perform physical examinations, $\mathrm{x}$-rays, and various kinds of treatment. The symptoms of the patient designate the exact combination of operating activities that is needed; the healthcare professionals decide how, when, and in which order these activities are performed.

\subsection{Lean production at Toyota}

Toyota's lean production system was popularised by a group of researchers and consultants studying automakers in Japan, Europe and the United States to find the reasons for Toyota's competitive success (Womack et al., 1990). Their book-entitled The machine that changed the world-declared Toyota's production system as best and explained how it worked. Lean production concerns a specific architecture of the transformation process, which is made possible by certain organisational arrangements. 


\subsubsection{Architecture of the transformation process}

In the 1980s, production of cars in the United States was based on the mass production paradigm pioneered by Ford. It featured both a vertical distinction between workers doing the work and managers designing the work and solving problems, and a horizontal distinction between different workers performing specialised tasks on the assembly line (Jaffee, 2001). Quality inspection occurred after the production was finished. Making profits was based on achieving economies of scale: as much product as possible was squeezed out of the production process in long production runs. There were long setup times to change the line to produce a different product. Capital investment in machines was high, and machines were dedicated to each process stage. Loading the machines and the workers to full utilisation was imperative. The different process stages were buffered with inventory to keep the production process going at all times-just in case (Hopp and Spearman, 2000). This configuration fit the then dominating market principle of mass markets with little choice (Jaffee, 2001; Hayes et al., 2005).

The configuration of the production system at Toyota was very different. Teams of multi-skilled workers rotated through groups of tasks (Hayes et al., 2005). Workers were involved with management in continuously improving the production process by reducing materials waste and production errors. Quality was built into the production process to discover and address problems when they occurred. The production process carried minimal levels of inventory to produce what was needed at the moment-just in time. The setup times to change the line were much shorter and there was an emphasis on cleanliness of the workplace (Imai, 1997; Hopp and Spearman, 2000; Swank, 2003). Making profits was based on relentlessly eliminating waste to reduce costs, improve quality and productivity (Womack et al., 1990). This made Toyota able to produce more reliable cars in smaller numbers and more varieties, and introduce new cars to the market more rapidly (Hopp and Spearman, 2000; Womack et al., 1990; Jaffee, 2001). Preventing exceptions from becoming the norm and removing disturbances was imperative to keep the production process balanced at a steady pace at all times. Toyota also involved suppliers and dealers in this effort. Balance was also achieved through standardised social norms, achieved by guaranteeing long-term employment and promoting worker identification with the company (Lincoln and Kalleberg, 1985; Jaffee, 2001). The Toyota production system eventually became a new paradigm for mass production-lean production (Jaffee, 2001; Hayes et al., 2005).

In terms of the transformation process, the architecture at Toyota was designed to carry out all the operating activities required to create a complete product without interruption. This was a fragile system, because the whole production line would stop upon a problem, and there were far fewer buffers to compensate for disturbances. It was therefore vulnerable to variability. The benefit of this design was that it required quality to function effectively. It exposed problems directly when they occurred, allowing the causes to be tackled and creating an incentive to prevent them from 
happening at all.

\subsubsection{Organisational arrangements}

Womack et al. (1990, p.99) state the two key organisational features of the Toyota factory: it transferred the maximum number of tasks and responsibilities to those workers actually adding value to the car on the line, and it had in place a system for detecting defects that quickly traces every problem to the source once discovered. This in turn meant teamwork among line workers and an information display system that made it possible for everyone to respond to problems and understand the factory's overall situation (ibid). The dynamic work team emerged as heart of the factory. To build these teams, workers were first rotated through the various jobs in their work group. Every aspect of the work process was standardised; there was a precise and commonly understood way to conduct every essential step in every process (Womack et al., 2007). Once multi-skilled, they were rotated on a daily basis to keep multiple skills sharp, foster an appreciation of the overall picture, and increase the potential for new idea generation (Hopp and Spearman, 2000). One worker could operate several machines arranged in a U-shaped layout. Each had the ability to stop the entire production line. Workers were also taught skills of basic machine repair, quality checking, housekeeping, materials ordering and problem solving (Womack et al., 1990; Jaffee, 2001). Time was set apart periodically to discuss ways of improving the work with management. The managers at Toyota were also rotated through all of the different production tasks at the beginning of their careers. Problem solving in their area of management was a large fraction of their jobs (Womack et al., 2007, p.290).

Lincoln and Kalleberg (1985) summarised the structural components of the arrangements at Toyota as follows:

1. Structures facilitating participation. Workers were integrated into areas of managerial concern. There were formal channels to raise, discuss and act on production-related issues with managers. This made the workers' tacit knowledge explicit (Nonaka and Takeuchi, 1995).

2. Cross-cutting divisions and hierarchies served to integrate workers into the organisation. These defused potential worker solidarity and class polarisation (Jaffee, 2001).

3. A constellation of career and mobility ladders. These stimulated long-term organisational attachment, motivation and loyalty. Workers received seniority-related bonuses and were guaranteed lifetime employment.

4. Corporate citizens. Members of the organisation had mutual obligations within the factory but were also encouraged to form social and recreational ties outside of it. This helped to promote a cooperative culture and strong identification with the organisation. 


\subsection{Implementing lean production in other organisations}

In 1996, Womack and Jones introduced the lean thinking concept after studying implementations of lean techniques in other production industries. Lean thinking is a thought process to guide the implementation of lean techniques (Womack and Jones, 1996b). It is intended for managers in any company in any industry who wish to make their mass-production organisations more lean (i.e., produce more and better outputs with less effort). It centres around changing people's conceptions about the current operation of the transformation process in their organisation-they should learn to see how to add value and eliminate waste (Rother and Shook, 1999). Although several organisations successfully applied lean thinking or claim they did, many more have failed.

\subsubsection{Principles of lean thinking}

The basic principle of lean thinking is minimising activities that consume resources but do not add value for the customer-muda in Japanese, meaning unproductive or waste. Examples of waste in a production process are products with errors, scrap, storage of products, transport of products, overproduction, waiting of people and machines to perform a task, and searching for tools (Ohno, 1988). There are five principles in lean thinking:

1. Define value from the perspective of the end customer. Value is defined as a specific product (good, service, or combination) which meets the customer's needs at a specific price at a specific time (Womack and Jones, 1996b). Another way to illustrate value is asking the following question for every step in a transformation process: is the customer willing to pay for this?

2. Identify the entire value stream and eliminate waste. The value stream includes all the actions required to bring a specific product through three critical tasks of any business: the problem-solving task, which involves product and process design, the information management task, which proceeds from order taking through detailed scheduling to delivery, and the physical transformation task, which proceeds from raw materials to finished product in the hands of the customer. Waste can be uncovered with value stream and process mapping tools (Rother and Shook, 1999; NHS Institute for Innovation and Improvement, 2005), but also, equally important, by going to the production process yourself as manager, to understand what is going on (genchi genbutsu). Once waste has been uncovered, we must recognise that it comprises non-value adding activities that must be done under the present work conditions. Type one waste is unavoidable at present; the current process layout, machines, need for transport or safety stock prevent it from being removed. Type two waste is immediately avoidable, and can be removed with minimal changes to current procedures and practices. 
The value stream typically involves many different companies adding value to a product.

3. Make the remaining value-creating steps flow. This means working on each design, order, and product continuously from beginning to end so that there is no waiting, downtime, or scrap within or between the steps (Womack and Jones, 1996a, p.141). Flow is taken as a long-term goal, to be achieved in a process of continuous, incremental improvement (kaizen), which involves all workers continuously learning by doing and standardising the best activities. The first step towards flow is often counter-intuitive, requiring a conceptual leap, a breakthrough (Womack and Jones, 1996b). It often involves radically changing (kaikaku) parts of the existing organisation and technology of the production process. Existing layouts are typically designed around process stages, where large batches are processed in each step and then pushed on to the next, or where customers get sent from one location to the other and have to wait in between (job shop configuration). This layout is changed by rearranging equipment and staff around families of products or services that require similar resources or have similar needs. Teams of workers are put in place that use general-purpose equipment in production cells to produce arrays of products at a constant pace (takt time).

4. Design and provide what the customer wants only when the customer wants it. When continuous flow is achieved, customers can consume the product when they need it. This pull from the end of the value stream triggers activities upstream, so that there is no need to push orders through the production system using forecasts that turn out to be wrong (Womack and Jones, 1996a).

5. Pursue perfection. The reasoning here is that the improvement effort builds on itself. Removing waste from the value stream frees up resources that can be used to further improve flow. For instance, when people are freed from doing non-value adding activities, they have more time to help improve the process (Womack and Jones, 1996b). Typical benefits to expect from applying lean thinking to pursue perfection are reductions of at least 50 percent in production lead times, inventories, errors reaching the customer, and floor space requirements—and doubled labour productivity (Womack and Jones, 2003).

Lean thinking paints a challenging ideal picture of a smooth value stream in which value flows continuously at the pull of the customer, with no waste of human effort, materials and time. This ideal can never be reached; it is meant to promote creativity.

\subsubsection{Critiques of lean}

Inspired by reported successes and the romantic philosophy of lean, many companies started to examine and improve their transformation processes. Naturally, some were successful, but there were also many failures. Hayes et al. (2005) provide an overview of studies revealing that only about one third of the companies trying to 
implement lean production achieved the results expected. Many companies failed to adequately implement the lean techniques. This is hardly surprising, because Toyota developed the wide range of techniques over a period of 30 years to solve its own specific problems (Ohno, 1988; Shingo, 1989). One cannot simply proceed from one organisational form to another without hybrid forms, conflicts and constraints (Jaffee, 2001).

One critique argues that too much credit is given to the production principles and management techniques as the reasons for Toyota's success (Jaffee, 2001). Things worked out for Toyota under its specific conditions, but these were set within larger structural and economic forces. These helped fuel the growth of the Japanese economy and competitiveness of Japanese companies in the 1980s altogether (Jaffee, 2001; Hayes et al., 2005). Perhaps the oil crisis in came at the right time for Toyota's fuelefficient cars. Another critique argues that Toyota was successful precisely because of the exceptionally large management influence. The managers of Toyota owned the company; they could do what they wanted and had a great urgency to do so after the war (Hopp and Spearman, 2000). In this view, Toyota "imprisoned" its workforce for life by agreeing with other companies (keiretsu) not to compete on the labour market and paying seniority-related bonuses as part of workers' income (de Sitter, 2000). A stable workforce greatly helped to achieve the ideal of balanced, continuous production. Toyota also had executives in the boards of directors of its suppliers, which ensured that they carried the inventory and delivered to Toyota directly when needed (Hopp and Spearman, 2000). Finally, there are reports about the reality of work under the lean system, which indicate that workers experienced stress and injuries (Graham, 1995) and suffered from extreme fatigue (de Sitter, 2000). The participative structures of lean production acted simply as sophisticated and insidious forms of labour control (Barker, 1993; Jermier, 1998). Workers were "chained" to the production line not physically but psychologically, with every member of the multidisciplinary teams supervising and controlling the others (Ezzamel and Willmott, 1998). Compared with workers in traditional Fordist-style factories, those at lean companies reported their workload was heavier and faster (Lewchuk and Robertson, 1996).

\subsection{Differences between the production systems of Toyota and a hospital}

The production systems of Toyota and a hospital are quite different. In this section we describe several differences, first by comparing manufacturing and healthcare organisations in general. We then turn to different configurations of their organisational arrangements. Finally, the alignment and integration of different goals in a hospital is contrasted to Toyota's production system. 


\subsubsection{Different types of organisations}

Manufacturing organisations produce physical products that can be inventoried. After placing the order, the customer only interacts with the product after purchase (Slack et al., 1998; Hopp and Spearman, 2000). Product quality can be directly measured at the moment of consumption. Healthcare organisation produce professional service. Production and consumption are simultaneous - as if the customer is already in the car being made (van den Heuvel, 2006). Value is created in direct interaction with the patients. They are an essential part of the transformation process and may perceive the quality of the service in different ways (Slack et al., 1998). The outcomes of the transformation may also still be uncertain at the moment of production, making it difficult to measure (Mintzberg, 1980; Hayes et al., 2005). Manufacturing produces products in mass, often using an assembly line. The basic different product variants do not affect the basic process of production (Slack et al., 2004). Service delivery in healthcare depends highly on the patients' needs. Service cannot be produced to stock of course; the production process can only start when the patient is present (Slack et al., 1998; Daft, 2000). The transformation process depends largely on what the patients need. Production volume is lower and variety is higher compared to manufacturing (Slack et al., 1998).

In manufacturing, the dominant technology is best understood as the longlinked type (Thompson, 1967). There is a logical sequence between the different activities. Once started, the sequence can function without interruption, provided that resources and supplies are sufficient. In healthcare, the dominant technology is the intensive type. A variety of techniques is drawn upon to achieve a change in some specific object; the selection, combination and order of application are determined by feedback from the object itself (Thompson, 1967, p.17). Success depends on the availability of all capacities potentially needed, and also on the appropriate custom combination as required by the individual patient. Naturally, this technology type is more complex and it allows much less control over the environment. Competition in manufacturing is based on a clear relation between price and product. There is a strong trigger to improve the price, quality, speed, possibilities of products and processes; if companies do not improve, they are out of business. This positive-sum competition means than customers get more value for money over time (Porter and Teisberg, 2004). In healthcare the competitive mechanism is much less clear. There is no direct relation between price and performance. Service delivery is often paid for by healthcare insurers or governments; in addition, social aspects play a role such as making services accessible to the population. The trigger for improvement is smaller; at the same time, changes have a direct impact on patients and involve more risk. Competition generally takes place as zero-sum, with different parties shifting the costs to each other, instead of working together to reduce them and increase customer value (Porter and Teisberg, 2004). Patients end up paying more or receiving a reduced quality of service. Table 2.1 summarises the general differences between manufacturing and healthcare organisations. 
Table 2.1: General differences between manufacturing and healthcare organisations

\begin{tabular}{lll}
\hline $\begin{array}{l}\text { Item of } \\
\text { comparison }\end{array}$ & Manufacturing & Healthcare \\
\hline $\begin{array}{l}\text { Value } \\
\text { creation }\end{array}$ & $\begin{array}{l}\text { Physical products: inventoried } \\
\text { before consumption; low customer } \\
\text { interaction; quality directly } \\
\text { measured }\end{array}$ & $\begin{array}{l}\text { Service: simultaneous production } \\
\text { and consumption; customer fully } \\
\text { involved; quality is perceived and } \\
\text { difficult to measure }\end{array}$ \\
Process type & $\begin{array}{l}\text { Mass production: production } \\
\text { process not affected by different }\end{array}$ & $\begin{array}{l}\text { Professional service: production } \\
\text { process tailored to "product"; lower }\end{array}$ \\
& product variants & volume and higher variation \\
Technology & Long-linked: actions follow each & Intensive: actions based on \\
type & other logically once started & $\begin{array}{l}\text { combination of capabilities based on } \\
\text { feedback from "product" }\end{array}$ \\
Competitive & Clear price-product relation; & Unclear price-service relation; \\
mechanism & positive-sum competition triggers & zero-sum competition; access to \\
& improvement & service important \\
\hline
\end{tabular}

\subsubsection{Different configurations of organisational arrangements}

We use the ideal-type configurations developed by Mintzberg (1980) to describe the differences between the organisational arrangements used by Toyota and a hospital. Mintzberg described five basic organisational configurations, based on five basic organisational parts, five basic mechanisms of coordination, several design parameters and contingency factors. Each of the five configurations relies on one of five coordinating mechanisms and tends to favour one of its five basic parts (ibid). Toyota, as a manufacturing organisation, is represented by the machine bureaucracy configuration; a hospital is represented by the professional bureaucracy configuration (see Fehse, 2002). We restrict ourselves to describing the differences between the elements of these two configurations, adapted from table 1 in Mintzberg's article (1980:330). See table 2.2.

Coordination of work in the machine bureaucracy is achieved through standardising the work itself. Standardised operating procedures are established for individual actions and entire processes; deviations are often quickly noticed and permanently solved. The continuous improvement of standards (Ohno, 1988) was precisely the strength of the lean production system. In the professional bureaucracy, coordination is achieved through standardisation of skills. The work itself cannot be standardised because it involves complex tasks that require nuanced judgement as well as complex knowledge and skills (Mintzberg, 1980; Dessler, 1986; Scott, 1998; Glouberman and Mintzberg, 2001a). The skills of healthcare professionals are standardised through years of education and training, often outside of the organisation in which they work. 
Table 2.2: Differences between the machine bureaucracy and professional bureaucracy configurations of organisations, adapted from (Mintzberg, 1980, p.330)

\begin{tabular}{lll}
\hline Item of comparison & Machine bureaucracy & Professional bureaucracy \\
\hline Key coordinating mechanism & Standardisation of work & Standardisation of skills \\
Design parameters: & & \\
Vertical specialisation of jobs & High & Low \\
Training & Low & High \\
Indoctrination & Low & High (retraining) \\
Formalisation of behaviour & High & Low \\
Planning and control system & Action planning & Little \\
Decentralisation & Limited horizontal & Horizontal and vertical \\
& decentralisation & \\
Contingency factors: & & \\
Technical system regulation & High & Low \\
Environment complexity & Low & High \\
Power focus & Technostructure, often & Professional operators \\
& external & \\
\hline
\end{tabular}

The focus of power in the machine bureaucracy lies with the technostructure: the (industrial) engineers and analysts out of the formal line structure. They design the work of everyone else, seeking to impose their standards. Behaviour in the machine bureaucracy is highly formalised; decision-making in jobs is typically narrow (vertically specialised). There is great regulation of the technical system (long-linked technology); actions are planned and outputs are controlled to a high degree. The formal power remains with management at the strategic apex of the organisation. In the professional bureaucracy, the professional operators are in the focus of power. They seek to minimise the influence of administrators, managers (claiming to have formal power) and analysts over their work. Relying on outside training that enhances their skills, the professionals determine their way of working themselves to a large extent (Mintzberg, 1980; Glouberman and Mintzberg, 2001a; Ham, 2003; Weggeman, 2007). Highly trained medical specialists by definition only perform and control that part of the production process within their professional domain, which renders cross-training and multi-skilling efforts impossible. Technical system regulation is low because of the individual operator autonomy. The actual coordination of the transformation process takes place through rather standardised exchanges between the different spheres of professional expertise. If every member of a professional group behaves as expected by the others, everything should work fine (Glouberman and Mintzberg, 2001b). If not, the healthcare professionals feel great improvising their way to making it work. 


\subsubsection{Different goals in different worlds of management}

Toyota was able to aim the goals of workers to join with those of management in an ingenious way (Jaffee, 2001). Over a period of many years, a production system was developed that produced cars of high quality efficiently, but which also improved the process of producing continuously. This was achieved because the managing owners and engineers had the power to integrate both the individual actions and the organisational arrangements of workers into one production system-one lean machine ("that changed the world"). In a hospital, management does not control the process of service delivery-the professionals do. The strict professional task division and the professional nature of the activities also trouble the view on shared goals.

Glouberman and Mintzberg (2001a) provide a useful classification of the different goals in a hospital. They describe how different groups of people have a stake in the delivery of healthcare within different worlds of management.

- The physicians' goal is to cure; they make interventions based on knowledgemedical technology - to change the condition of a patient in a certain manner. These interventions occur typically in short, often scheduled bursts: in operating rooms, in outpatient departments, on clinical rounds. Then they leave, leaving much of the remaining care to the nursing staff. The physicians are organised by specialist chimneys around some part or organ of the patient. Physicians climb their own hierarchical specialist ladder of medical achievement. In most hospitals, the physicians work in the hospital but not for it; they have their own private practices. We wish to add that for physicians who are training to become medical specialists, the goal is education just as much as cure. In an emergency department, they treat patients to get the required training and experience (and then hardly work there anymore).

- The nurses' goal is to care; they coordinate the operating workflow around the patients. This includes their own activities but also the work of physicians and other caregivers. They also assist the physicians, for example by arranging diagnostic examinations, while being functionally subordinate to them (Glouberman and Mintzberg, 2001a). They try their best to reconcile all other needs around and on behalf of patient.

- The managers' goal is to control the resources for which they are formally responsible such as beds, budgets and jobs. This poses constraints on the demands of the medial and nursing staff. The managers also represent the hospital to the outside world, advocating for funds and resources. Managers control by interventions also: they tend to (continuously) restructure and reorganise their administrative hierarchy of formal authority-all without much affecting the direct delivery of service (Glouberman and Mintzberg, 2001a). To the physicians, the managerial hierarchy is far less important than their own hierarchy of medical achievement. Management may have formal authority, but the professional work cannot be controlled technocratically (Berwick, 1994; Glouberman and 
Mintzberg, 2001a).

Within each of their separated worlds of management, everyone-the physicians, the nurses, the managers-is taking purposeful action to treat patients or facilitate doing this. The problem is that these worlds are not connected. No stakeholder group is formally responsible for coordinating the entire care delivery process-although the nurses come closest to effecting it (Glouberman and Mintzberg, 2001a). Subjecting all the stakeholders in these disconnected hierarchies (Ham, 2003) to the one goal of delivering patient care and continuously improving the delivery process is not to be expected naturally. This means that transformation processes cannot be engineered in the same way as the production system of Toyota. For process improvement to happen in healthcare, all of the groups need to accept it as a goal to contribute to (Berwick, 1989). We return to this issue in section 2.6.

\subsection{Possible arrangements for lean healthcare delivery}

The differences between the production systems of Toyota and a hospital have major consequences for possible ways in which hospitals can organise lean healthcare delivery. We first describe possible organisational arrangements pointed out theoretically by Toyota. Then we provide an overview of arrangements reported in empirical healthcare studies.

\subsubsection{Based on the arrangements at Toyota}

Almost all of the organisational arrangements at Toyota-see section 2.2.2-provide possible ways for hospitals to organise lean healthcare delivery. Naturally, these need to be adapted for the differences between the production systems described in the previous section.

- The maximum number of tasks and responsibilities for those workers actually adding value to the patients. It is the nature of healthcare that the professional operators have considerable autonomy and responsibility to carry out many different tasks as they see needed.

- Teamwork. Toyota used cross-training, multi-skilling and job switching to build dynamic work teams. Each of the workers could carry out all of the required tasks and had an understanding of the overall picture. By definition, these arrangements are practically impossible in healthcare. These arrangements, however, do point at the importance of having different healthcare professionals working together in the room around the patient. They can generate ideas from seeing each other work and also better understand the entire transformation process for the patient. In chapter 3, we describe how teamwork enables the emergency department to treat its most critical and complex patients within an hour. 
- Workers who are also trained in areas of quality checking and problem solving. Healthcare workers concentrate on carrying out their medical and nursing tasks. Enhancing their skills in other areas can potentially improve patient flow. Many healthcare improvement programs start with teaching in these areas, which may include the principles of lean thinking. Healthcare managers also need these skills, much to the same way as Toyota's managers possessed them.

- Participation of workers and managers in improving the healthcare delivery. Training healthcare workers and healthcare managers in areas of problem solving is not sufficient. Participation and communication channels need to be established to discuss and act on issues concerning the healthcare delivery. Of course, hospitals already discuss these issues in many places during different meetings. The question is, however, how often all three worlds of management are involved in these meetings. Mintzberg (1997) showed how this was initially not the case in a Canadian hospital-the subject of problematic patient flow in the emergency department turned up over and over in different meetings. The problems were not resolved until all worlds came together.

- A system for detecting defects that quickly traces every problem to the source once discovered. With specialisation being the heart of healthcare, integration of the different activities of the healthcare professionals is key (Glouberman and Mintzberg, 2001b). Errors occur, many of which are preventable (e.g. Risser et al., 1999; Nolan, 2000). It would be a great asset to have an information display system that enables everyone to respond to problems and understand the overall situation in the care delivery process. It would be even better to give everyone the ability to stop the care delivery upon discovery of an error.

\subsubsection{Described in empirical studies}

When we reviewed the literature in 2004, we found a number of healthcare studies describing organisational arrangements that were successfully used. It is important to note that most studies were not explicitly aimed at improving healthcare delivery with lean thinking - they aimed to improve healthcare delivery efficiency in general. Since 2004, many studies became available on applications of lean in healthcare (see chapter 9). The inexhaustive list of studies below includes organisational arrangements applied in emergency departments, predominantly in the United States. It also includes more popular articles about applying manufacturing insights in healthcare. Most of the practices described can be directly related to the arrangements at Toyota.

- The Karolinska hospital in Stockholm used manufacturing insights to reorganise its functional, specialist departments around the patient flow (Brown-Humes, 1994; also: Peppard and Rowland, 1994, p.33). Instead of bouncing their patient from department to department, hospital staff were asked to look at illness to recovery as a process with pit stops in admission, surgery, and a recovery ward. New functions of nurse coordinators were created to manage and improve 
patient flow, with physicians actually reporting to these coordinators. As a result, patients met a surgical and internal medicine specialist together, instead of separately, and received all diagnostic tests in one visit instead of up to five. The hospital could close 4 of its 16 operating rooms while increasing the number of operations. Hospital-wide changes were needed because of pressing financial problems.

- Kyriacou et al. (1999) conducted a 5-year time study analysis of emergency department (ED) patient care efficiency. The effects of several administrative interventions were evaluated. These included improvement of communications and decision making; for example, physicians were made responsible for giving patients their discharge instructions. Before, patients received the instructions from the nurses, who got the information from the physicians. The studies were carried out by an interdepartmental hospital committee, on which all relevant disciplines from the different worlds of management were involved.

- Risser et al. (1999) designed work teams in the ED to improve team communication and coordination, and reduce error. Experiences from aviation were used to create small work teams, teach basic teamwork skills, and develop teamwork habits. "The teamwork system (...) encourages team members to actively coordinate and support each other in the course of clinical task execution by using the structure of work teams. Teams and teamwork behaviours do not replace clinical skills. Teamwork actions ensure that clinical activities are properly integrated and executed to deliver effective emergency care" (Risser et al., 1999, p.375). Members of the team monitored the actions of others to be able to quickly correct errors. They also received training in problem solving strategies.

- Hoffenberg et al. (2001) shared meaningful process differences between 291 EDs in a large hospital system. Patient length of stay was reduced as a result. A so-called best demonstrated practices team was established to identify process changes and share these with all of the participating hospitals. The members of the team included physicians, nurses, and clerical personnel actively participating in the provision of emergency care. An outside consultant facilitated the process and organised the team. Process changes concerned the entire value stream, including the collaboration with diagnostic departments and nursing wards. A limitation of the study is that measures of compliance with proposed interventions were not performed.

- Spaite et al. (2002) report the application of a process-improvement team approach to evaluate and redesign patient flow in a university-based ED. The approach rested on a major commitment by senior hospital administrators, an emphasis on emergency physician leadership, and a proper application of organisational resources through multidisciplinary improvement teams. A senior physician was appointed as full time administrative director of the ED, who had responsibility and authority for process, personnel, and budgets. Multidisciplinary process improvement teams were formed that included at least one 
senior hospital administrator, as well as appropriate physician, nursing, and ancillary personnel. Each team was guided and supported by a trained facilitator. Changes were made throughout the ED and in the collaboration with diagnostic departments and the nursing wards. Patient flow and patient satisfaction were improved —-though with significant investments in staff and equipment.

- Cardin et al. (2003) evaluated a multifaceted intervention that decreased the mean length of stay for patients discharged from the ED from 14 to 6 hours, without resulting in increased return visits to the ED or hospital readmission. The intervention included making physician coordinators responsible for speeding up decision-making about patient discharge and admission. Several communication policies were formulated and implemented. Staffing levels were also increased.

- Hospitals in Seattle and St. Louis used lean thinking to implement teamwork for better quality of care (Simmons, 2003). Process improvement workshops were held, some of which included patients as members. A policy was implemented to stop the line: anyone who saw a defect or potential defect notified the patient safety department, which ensured a root-cause analysis was done within hours, instead of months. Lean thinking was also made the foundation of hospital strategy. Senior executives were trained in and committed to lean production. A partnership was formed between hospital management and the physicians to radically change behaviour. Teamwork was focused on organising in terms of service lines, "tearing down professional chimneys". Metrics and measuring tools were also aligned around service-line performance.

- Walley (2003) reports on using lessons from manufacturing - which include lean thinking - to design ED flows. Researchers identified patient flows that could be used to design treatment processes around the needs of the patient. Some queues were built into existing treatment processes, which could be removed by better process design. The researchers also found that capacity imbalance, not shortage, caused some unnecessary waiting in the ED.

\subsection{Appropriate strategies for industrial engineers to help organise lean healthcare delivery}

In the last section of this chapter, we describe how industrial engineers can engineer production systems in healthcare contexts. Unable to find specific industrial engineering strategies for helping healthcare managers and workers organise lean healthcare delivery, we describe two general strategies. We choose the most appropriate for the research problem in this thesis. 
Table 2.3: Perspectives in two general industrial engineering strategies compared

\begin{tabular}{|c|c|c|}
\hline \multirow[b]{2}{*}{ Perspective on } & \multicolumn{2}{|c|}{ Industrial engineering strategy } \\
\hline & Systems engineering & Soft systems methodology \\
\hline World & $\begin{array}{l}\text { Contains systems to engineer } \\
\text { (hard systems approach) }\end{array}$ & $\begin{array}{l}\text { Contains complexity and } \\
\text { confusion (soft systems } \\
\text { approach) }\end{array}$ \\
\hline Organisation & $\begin{array}{l}\text { Open system of mechanically } \\
\text { operating parts aimed at } \\
\text { achieving goals }\end{array}$ & $\begin{array}{l}\text { Social structure, continuously } \\
\text { recreated and changed in human } \\
\text { interaction }\end{array}$ \\
\hline Role of manager & $\begin{array}{l}\text { Solve problems and make } \\
\text { decisions in pursuit of goals }\end{array}$ & $\begin{array}{l}\text { Initiate and facilitate } \\
\text { collaborative learning process }\end{array}$ \\
\hline $\begin{array}{l}\text { Role of industrial } \\
\text { engineer }\end{array}$ & $\begin{array}{l}\text { Analyse problem and recommend } \\
\text { optimal design to manager }\end{array}$ & $\begin{array}{l}\text { Facilitate and participate in } \\
\text { learning process by introducing } \\
\text { knowledge }\end{array}$ \\
\hline Engineering target & $\begin{array}{l}\text { Transformation process } \\
\text { architecture and formal } \\
\text { organisational arrangements }\end{array}$ & $\begin{array}{l}\text { Actions and conceptions of } \\
\text { participants in social structure }\end{array}$ \\
\hline
\end{tabular}

\subsubsection{Specific strategies}

We found no studies in the literature reporting on strategies for industrial engineers to help healthcare managers and workers organise lean healthcare delivery. This was a new subject, and only a few studies had been done. To our knowledge, none of these included industrial engineers studying healthcare delivery improvement. Hospitals have only recently started to allow in other disciplines to get involved in the healthcare delivery.

\subsubsection{Systems engineering and soft systems methodology}

More generally speaking, a distinction can be made between two industrial engineering strategies in the literature: systems engineering and soft systems methodology. The strategy depends on the perspective of the industrial engineer on the world-more specifically on the organisation, the role of managers, their own role, and the target of the engineering effort. Table 2.3 contrasts both strategies.

The traditional strategy for all engineering sciences is systems engineering (Checkland and Scholes, 1990), also named hard systems approach or systems analysis (Winston, 1994; Hopp and Spearman, 2000). In this strategy, an observer perceives the real world to contain interacting systems (Checkland and Scholes, 1990); these are complex objects that can be engineered to achieve their objectives (Checkland and Poulter, 
2006). Following the hard systems approach, an industrial engineer conceptualises an organisation as an open system devoted to achieving corporate objectives in an environment to which it must adapt (Checkland, 2000); the organisation consists of interrelated and interchangeable parts that operate like a machine to produce some output (Morgan, 1986; Jaffee, 2001). It is the task of managers to solve problems and take decisions in pursuit of the declared goals (ibid). A problem is basically a difference between the present state and a desired state of the transformation process, and the objective is overcoming this difference. An industrial engineer helps managers by designing several alternatives to reach the objective. To do this, the engineer makes a model of the system and defines relevant constraints and aspects of the system that may affect the objective (Winston, 1994; Hopp and Spearman, 2000). The engineering target includes the architecture of the transformation process and the formal structure of organisational arrangements. Creative alternatives are generated next. Some kind of quantification - through data collection, cost calculations, mathematical formulas or computer simulation models-is often performed to compare the alternatives in terms of the objective. The engineer presents chooses the alternative that best meets the objective and seeks approval from the manager. Then implementation can begin.

Checkland and Scholes (1990) and Hicks (1991) argue that systems engineering is not suitable in ill-defined, wicked problem situations, where someone has a feeling that something needs to be improved while the exact objective is unknown, or where there is no agreement on what the goal exactly is, or no power to subject everything to one goal or need. In these situation, soft systems methodology (SSM) is more appropriate. In this strategy, an observer perceives the real world to contain complexity and confusion, and to be characterised by clashes of different perspectives or worldviews (Checkland and Poulter, 2006). The world is continually being recreated by people thinking, talking, and taking action (Silverman, 1970; Morgan, 1983; 1986; Senge, 1990; Weick, 1995; Checkland and Poulter, 2006). An organisation is conceptualised essentially as a social structure, in which the participants have many different and possibly conflicting goals. The social structure is at the same time the medium for their actions and the recreated or changed outcome of it (Giddens, 1984; Bhaskar, 1998). Continuous negotiation takes place. The actual behaviour of peopletheir actions taken with intent-is more important than formal structures (French and Bell Jr, 1990; Visscher and Fisscher, 1999). This strategy paints a far less clear picture than the other.

In SSM, an industrial engineer works together with managers to facilitate an organised process of inquiry into a real-world situation they consider problematical (Checkland and Scholes, 1990). The managers operate as initiators of this learning process in their organisations, and facilitate the participation of relevant employees. The industrial engineer participates by introducing relevant knowledge. In the collaborative learning process, several models of purposeful activity are named to compare with the real-life situation. In each model, purposeful activity is defined as a transformation process according to a single declared worldview (Checkland and Poulter, 2006). This allows the different participants with different backgrounds to discuss 
problem situations with each other in a similar, organised way (Kramer and de Smit, 1982; Checkland and Scholes, 1990; Kerkhoff, 2006). The comparison between model and reality structures a debate towards choices of purposeful action (Checkland, 1985). Such a choice entails finding versions of the problem situation addressed which all participants can nevertheless live with (Checkland and Poulter, 2006). At this point, the participants have learned their way from finding out about a situation considered problematical to addressing it by taking desirable and feasible improvement actions (Checkland, 1985). The conceptions held by participants in the social structure about what they are doing while producing goods and services (the operating activities), thus, become the target of the engineering effort (Susman and Evered, 1978, p.594).

\subsubsection{An appropriate choice for our research problem}

We already concluded that transformation processes in a hospital cannot be engineered in the same way as production at Toyota, given their differences (see section 2.4.3). We now specify this conclusion by adding that systems engineering is an inappropriate strategy for industrial engineers to help improve existing healthcare delivery processes. A soft systems strategy is more appropriate; its collaborative nature allows all of the stakeholder groups to accept process improvement as a goal to contribute to, next to delivery of patient care itself (Berwick, 1989). The principles of lean thinking serve the purpose of providing a single declared worldview: creating value for customers in a continuous flow with no waste. This allows the participants to find and target that part of the patient flow most promising for improvement. We further explain our specific industrial engineering strategy in chapter 5 .

\section{References}

Barker J (1993). Tightening the iron cage: control in self-managing teams. Administrative Science Quarterly. 38:408-37.

Berwick D (1989). Continuous improvement as an ideal in health care. New England Journal of Medicine. 320:53-6.

Berwick D (1994). Eleven worthy aims for clinical leadership of health care reform. Journal of the American Medical Association. 272:797-801.

Bhaskar R (1998). The possibility of naturalism. A philosophical critique of the contemporary human sciences. Routledge, London, 3rd edn.

Boer H, Krabbendam J (1996). Processen in organisaties. Twente University Press, Enschede.

Brown-Humes C (1994). Production line treatment for patients. Financial Times. 7 January.

Cardin S, Afilalo M, Lang E, Collet J, Colacone A, Tselios C, Dankoff J, Guttman A (2003). Intervention to decrease emergency department crowding: does it have an effect on return visits and hospital readmissions? Annals of Emergency Medicine. 41:173-85.

Checkland P (1985). Achieving 'desirable and feasible' change: an application of soft systems methodology. Journal of the Operational Research Society. 36:821-31. 
Checkland P (2000). Soft systems methodology: a thirty year retrospective. Systems Research and Behavioral Science. 17:S11-58.

Checkland P, Poulter J (2006). Learning for action. John Wiley \& Sons, Chichester.

Checkland P, Scholes J (1990). Soft systems methodology in action. John Wiley \& Sons, Chichester.

Child J (1972). Organizational structure, environment and performance: the role of strategic choice. Sociology. 6:1-22.

Cyert R, March J (1963). A behavioral theory of the firm. Prentice Hall, Englewood Cliffs.

Daft R (2000). Management. The Dryden Press, Fort Worth.

Dessler G (1986). Organization theory: integrating structure and behavior. Prentice-Hall International, London, 2nd edn.

Ezzamel M, Willmott H (1998). Accounting for teamwork: a critical study of group-based systems of organizational control. Administrative Science Quarterly. 43:358-96.

Fehse K (2002). The role of organizational politics in the implementation of information systems. Three cases in a hospital context. PhD thesis, University of Twente, Enschede.

French W, Bell Jr C (1990). Organization development: behavioral science interventions for organization improvement. Prentice-Hall International, Englewood Cliffs, 4th edn.

Giddens A (1984). The constitution of society: outline of the theory of structuration. University of California Press, Berkeley.

Glouberman S, Mintzberg H (2001a). Managing the care of health and the cure of disease. Part I: differentiation. Health Care Management Review. 26:56-69.

Glouberman S, Mintzberg H (2001b). Managing the care of health and the cure of disease. Part II: integration. Health Care Management Review. 26:70-84.

Graham L (1995). On the line at Subaru-Isuzu: the Japanese model and the American worker. ILR Press, Ithaca.

Ham C (2003). Improving the performance of health services: the role of clinical leadership. The Lancet. 361:1978-80.

Hayes R, Pisano G, Upton D, Wheelwright S (2005). Operations, strategy, and technology: pursuing the competitive edge. Wiley, Hoboken.

van den Heuvel J (2006). The Effectiveness of ISO 9001 and Six Sigma in Healthcare. PhD thesis, Erasmus University Rotterdam, Rotterdam.

Hicks M (1991). Problem solving in business and management: hard, soft and creative approaches. Chapman \& Hall, London.

Hickson D, Pugh D, Pheysey D (1969). Operations technology and organization structure: an empirical reappraisal. Administrative Science Quarterly. 19:22-44.

Hoffenberg S, Hill M, Houry D (2001). Does sharing process differences reduce patient length of stay in the emergency department? Annals of Emergency Medicine. 38:533-40.

Hopp W, Spearman M (2000). Factory physics. McGraw-Hill, Singapore, 2nd edn.

Imai M (1997). Gemba kaizen. McGraw-Hill, New York.

Jaffee D (2001). Organization theory: tension and change. Mc Graw-Hill Higher Education, Singapore.

Jermier J (1998). Introduction: critical perspectives on organizational control. Administrative Science Quarterly. 43:235-56.

Kerkhoff A (2006). Interactief ontwerpen van beleid in de openbare gezondheidszorg. Budel, 
Damon.

Kramer N, de Smit J (1982). Systeemdenken. Stenfert Kroese, Leiden, 3rd edn.

Kyriacou D, Ricketts V, Dyne P, McCollough M, Talan D (1999). A 5-year time study analysis of emergency department patient care efficiency. Annals of Emergency Medicine. 34:326-35.

Lewchuk W, Robertson D (1996). Working conditions under lean production: a worker-based benchmarking study. In Stewart P (ed.) Beyond Japanese management: the end of modern times?, Frank Cass, Portland.

Lincoln J, Kalleberg A (1985). Work organization and workforce commitment: a study of plants and employees in the U.S. and Japan. American Sociological Review. 50:738-60.

Miller E, Rice A (1967). Systems of organization: the control of task and sentient boundaries. Tavistock Publications, London.

Mintzberg H (1980). Structure in 5's: a synthesis of the research on organization design. Management Science. 26:322-41.

Mintzberg H (1997). Toward healthier hospitals. Health Care Management Review. 22:9-18.

Morgan G (ed.) (1983). Beyond method. Strategies for social research. Sage Publications, Beverly Hills.

Morgan G (1986). Images of organization. Sage Publications, Beverly Hills.

NHS Institute for Innovation and Improvement (2005). Improvement leaders' guide: Improving flow. http://www.institute.nhs.uk/quality_and_service_improvement_tools/quality_and_ service_improvement_tools/patient_flow.html.

Nolan T (2000). System changes to improve patient safety. British Medical Journal. 320:771-3.

Nonaka I, Takeuchi H (1995). The knowledge creating company. Oxford University Press, New York.

Ohno T (1988). Toyota production system: beyond large-scale production. Productivity Press, Cambridge.

Parsons T (1960). Structure and process in modern society. The Free Press, New York.

Peppard J, Rowland P (1994). The essence of business process reengineering. Prentice Hall, New York.

Perrow C (1967). A framework for the comparative analysis of organizations. American Sociological Review. 26:854-65.

Porter M, Teisberg E (2004). Redefining competition in healthcare. Harvard Business Review. 82:64-76.

Risser D, Rice M, Salisbury M, Simon R, Jay G, Berns S (1999). The potential for improved teamwork to reduce medical errors in the emergency department. Annals of Emergency Medicine. 34:373-83.

Rother M, Shook J (1999). Learning to see: value stream mapping to add value and eliminate muda. Lean Enterprise Institute, Brookline.

Scott W (1998). Organizations: rational, natural, and open systems. Prentice Hall, Upper Saddle River, NJ, 4th edn.

Senge P (1990). The fifth discipline: the art and practice of the learning organization. Doubleday, New York.

Shingo S (1989). A study of the Toyota production system from an industrial engineering viewpoint. Productivity Press, Cambridge. 
Silverman D (1970). The theory of organisations: a sociological framework. Heinemann Educational, London.

Simmons J, (ed) (2003). Turning teamwork into quality care. Quality Letter for Healthcare Leaders. 15:2-11.

de Sitter L (2000). Synergetisch produceren. Van Gorcum, Assen, 3rd edn.

Slack N, Chambers J, Johnston S (2004). Operations management. Prentice Hall, Harlow, 4th edn.

Slack N, Chambers S, Harland C, Harrison A, Johnston R (1998). Operations management. Pearson Education, Harlow, 2nd edn.

Spaite D, Bartholomeaux F, Guisto J, Lindberg E, Hull B, Eyherabide A, Lanyon S, Criss E, Valenzuela T, Conroy C (2002). Rapid process redesign in a university-based emergency department: decreasing waiting time intervals and improving patient satisfaction. Annals of Emergency Medicine. 39:168-77.

Susman G, Evered R (1978). An assessment of the scientific merits of action research. Administrative Science Quarterly. 23:582-603.

Swank C (2003). The lean service machine. Harvard Business Review. 81:123-9.

Thompson J (1967). Organizations in action: social science bases of administrative theory. McGrawHill, New York.

Veen P (1980). Kenmerken van organisaties. In Drenth P, Thierry H, Willems P, de Wolff C (eds.) Handboek arbeids- en organisatiepsychologie, chap. 4.1, pp. 1-37, Van Loghum Slaterus, Deventer.

Visscher K, Fisscher O (1999). Bedrijfskundig ontwerpen: theoretische inzichten. In van Heffen O, Maassen P, Rip A (eds.) Sociale wetenschappen van ontwerppraktijk naar ontwerpmethodologie., pp. 179-91, Twente University Press, Enschede.

Walley P (2003). Designing the accident and emergency system: lessons from manufacturing. Emergency Medicine Journal. 20:126-30.

Weggeman M (2007). Provocatief adviseren. Organisaties mooier maken. Scriptum, Schiedam.

Weick K (1995). Sensemaking in organizations. Sage Publications, Thousand Oaks.

Winston W (1994). Operations research: applications and algorithms. Duxbury Press, Belmont.

Womack J, Jones D (1996a). Beyond Toyota: how to root out waste and pursue perfection. Harvard Business Review. 74:140-58.

Womack J, Jones D (1996b). Lean thinking. Simon \& Schuster, London.

Womack J, Jones D (2003). Lean thinking. Simon \& Schuster, London, 2nd edn.

Womack J, Jones D, Roos D (1990). The machine that changed the world. Rawson Associates, New York.

Womack J, Jones D, Roos D (2007). The machine that changed the world. Free Press, New York, 2nd edn. 


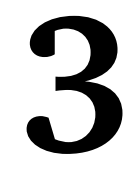

\section{Research context}

This chapter describes the context of the research: the emergency department (ED) of the Academic Medical Centre (AMC) in Amsterdam. We first describe an ED in general terms (section 3.1). Then we proceed to the ED in the AMC, describing the department layout, main patient flows, and available resources (3.2). We pay specific attention to the organisational arrangements for emergency care delivery in the AMC-both within the ED and in the collaboration with partners in the value stream (3.3). Next we describe several trends in the domains of the various healthcare professionals contributing to the emergency care delivery (3.4). The chapter ends with a list of the research projects carried out in the department (3.5).

\subsection{An emergency department in general}

An emergency department (ED) is a department within a hospital for patients who need to be seen within the day. It is open 24 hours per day, 7 days a week. Patients arrive in conditions varying from life-threatening situations to less than urgent. They are brought in by ambulance, or go to the department themselves. Some patients visited their general practitioner (GP) first, who then referred them to be seen in the ED of a nearby hospital. The prime decision that has to be made in the ED is: does the patient need further hospital care or can the patient safely be discharged home after treatment? In the first case, an operation or admission to an intensive care unit or nursing ward may be needed; in the second case, the patient may require a follow-up appointment in the outpatient department or with the GP. To help make this decision, the ED has fast access to diagnostics such as x-ray, laboratory, CT and ECG. These services are often provided by other hospital departments. The ED is, thus, at the heart of a value stream of collaborators contributing to the care delivery, both within and outside of the hospital.

The main patient flows to and from the ED are: ambulance arrival or walk-in arrival (own transportation) on the input side, and admission or discharge on the 


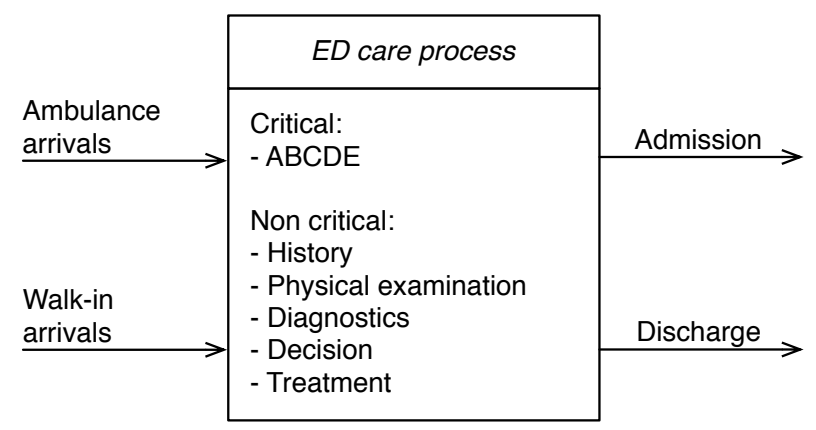

Figure 3.1: Main patient flows in an emergency department (ED); ABCDE $=$ airway, breathing, circulation, disability, environment

output side. The patient care delivery in the ED—-the throughput side-includes the following main steps. A history of the patient is taken to find out about the symptoms; the physician performs a physical examination and requests additional diagnostic examinations if necessary, such as x-rays or laboratory work; the physician decides about treatment of the patient; the physician or nurse administers treatment, such as plaster work, suturing, bandages, a drip, pain medication, advice, etc. For patients in life-threatening conditions, the main steps are slightly different. The patient care delivery follows a specific order, related to airway, breathing, circulation, disability, and environment. This is done to "treat first what kills first" for acute trauma care, cardiac care, neurological care, etc. See figure 3.1.

\subsection{The ED in the Academic Medical Centre}

We now describe the ED in which the $\mathrm{PhD}$ research was carried out. Please note that this description is based on the situation during the research from 2004 to 2008.

\subsubsection{Numbers of patients and main patient flows}

The ED is part of the Academic Medical Centre (AMC) of the University of Amsterdam. It is designated as level-1 trauma centre, which means that it can handle the most complex cases. The 1000-bed hospital, located in Amsterdam Southeast, opened its doors in 1981. The ED receives about 32.000 patients yearly. The number of patients arriving during the day follows a distinct pattern, see figure 3.2. Night times are generally quiet; after $8 \mathrm{hrs}$ in the morning there is a sharp increase, leading to a peak around $18 \mathrm{hrs}$ and decreasing again from $21 \mathrm{hrs}$ on. A sinus-shaped trendline can be drawn for the average rate of patients arriving per hour during the day.

The emergency patients can be divided into three major patient flows: about 3 percent arrive in critical conditions, about 20 percent are referred by their GP and 


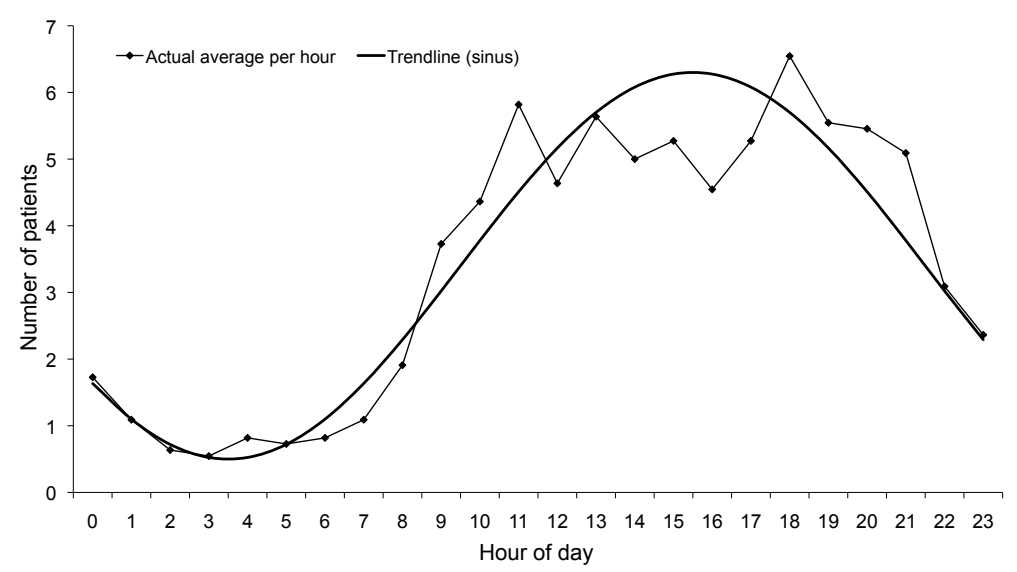

Figure 3.2: Patient arrivals at the AMC emergency department during the day $(n=899)$

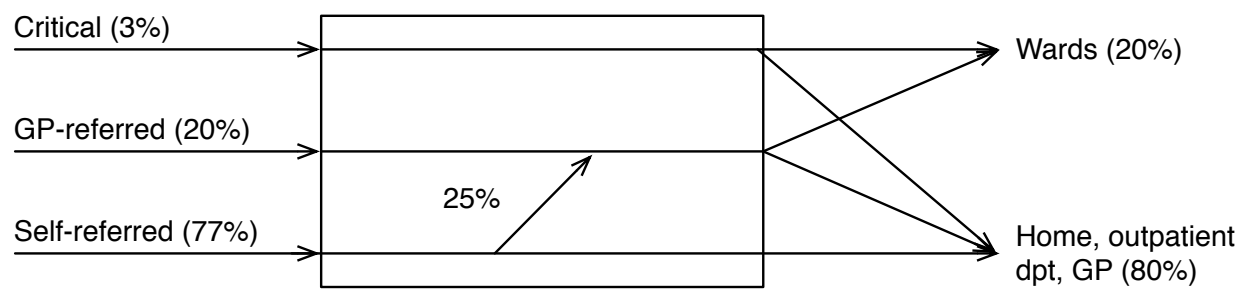

Figure 3.3: Main patient flows in the AMC emergency department; dpt = department; GP = general practitioner

the remaining 77 percent are self-referred. All of these groups of patients may arrive either by ambulance or using their own means of transportation. Most of the critical patients arrive by ambulance; they are seen in specially equipped trauma rooms. There are regular treatment rooms available for the other patients. About 20 percent of all patients are admitted to the hospital; about 80 percent are discharged. After initial care, about one in four self-referred patients is transferred within the ED. These patients require further specialist care and may also be admitted. Their treatment is continued by other physicians and nurses in the department. See figure 3.3.

\subsubsection{Department layout}

Figure 3.4 displays the layout of the ED. The red areas are treatment rooms-the three trauma rooms can be seen in the top right corner and the shock room is just above the right yellow dot. Blue areas are waiting areas for patients; green areas are working 
spaces for staff. The yellow dots indicate where patients enter the department. The left is for walk-in patients, the right for patients arriving by ambulance. Critical patients can directly proceed to the trauma rooms. The black lines display the main walking lines across the department.

Striking about the layout is its stretched design. There seem to be actually two departments in one. In the original design from the 1970s, the emergency department was considered as a kind of outpatient department-not as a unique department with unique needs requiring a unique design. The trauma rooms area was added later, in 2005. Especially in the left area of the ED there is no central overview over the treatment rooms. The lines of sight do not connect. Staff regularly search for each other; patients may feel left alone and search to find the exit. There is no waiting area for patients arriving by ambulance-they go directly into a treatment room. When the department is full, patients wait in the narrow hallways.

\subsubsection{Available resources}

The available resources for the three main patient flows are as follows. See figure 3.5. For the critical patients, there are three very modern trauma rooms available. Two have access to a CT-scanner. The staffing consists of a trauma team, with members from the ED and other hospital departments: one leading trauma surgeon, two surgeons, one radiologist, two radiographers, one anaesthesiologist, one anaesthesiology assistant, and two emergency nurses. Next to the three trauma rooms, there is one shock room for resuscitations and acute neurological problems. There is also a special acute neurological team, of similar organisation as the trauma team. The critical care has the highest priority in the department. It interferes with the care delivery for other patients in the ED.

For GP-referred patients, there are 10 treatment rooms available and up to four emergency nurses. Treatment is carried out by up to 10 residents; one or two per specialty. These are physicians who are training to become specialists-they work in the ED as part of their specialist education. They report to their supervisors from different medical specialties. These specialists work for their own departments, outside of the ED. The main specialties include surgery, internal medicine, neurology, paediatrics, ear nose throat, etc. The patients' condition determines the specialty to which he or she is referred. Sometimes more than one specialty is needed. For the self-referrals, there are four treatment rooms available, one staff physician (a general physician with additional experience in acute symptoms for the different specialties) and one emergency nurse. The GP-referred patients are generally more ill than the self-referred patients. This is why they require relatively more medical staff and treatment rooms.

There is one coordinating emergency nurse in the ED. This nurse keeps an overview, promotes patient flow, and serves as the first point of contact for physicians, nurses, other staff, and for patients and their families. The coordinating nurse will also assist the other nurses when the ED is very busy. As of 2007, there is also one triage 


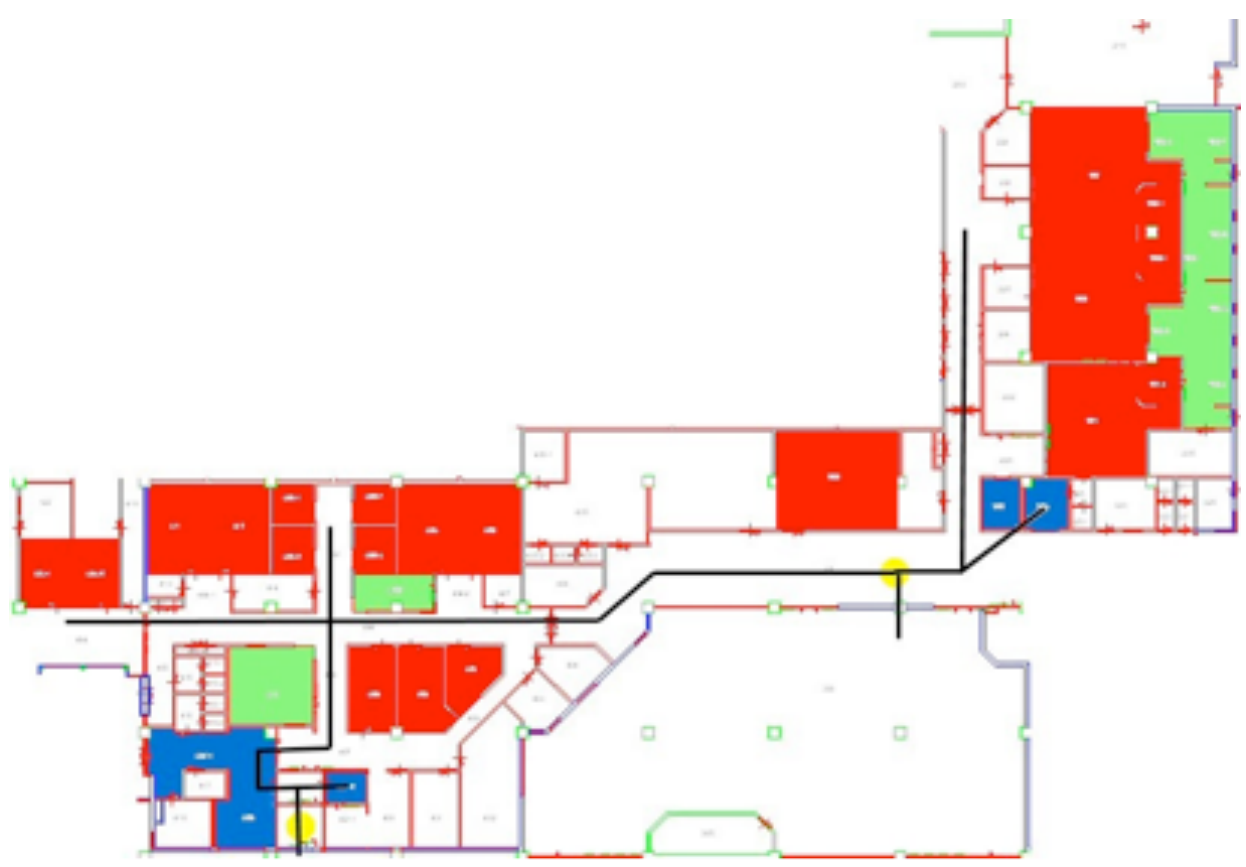

Figure 3.4: Layout of the AMC emergency department

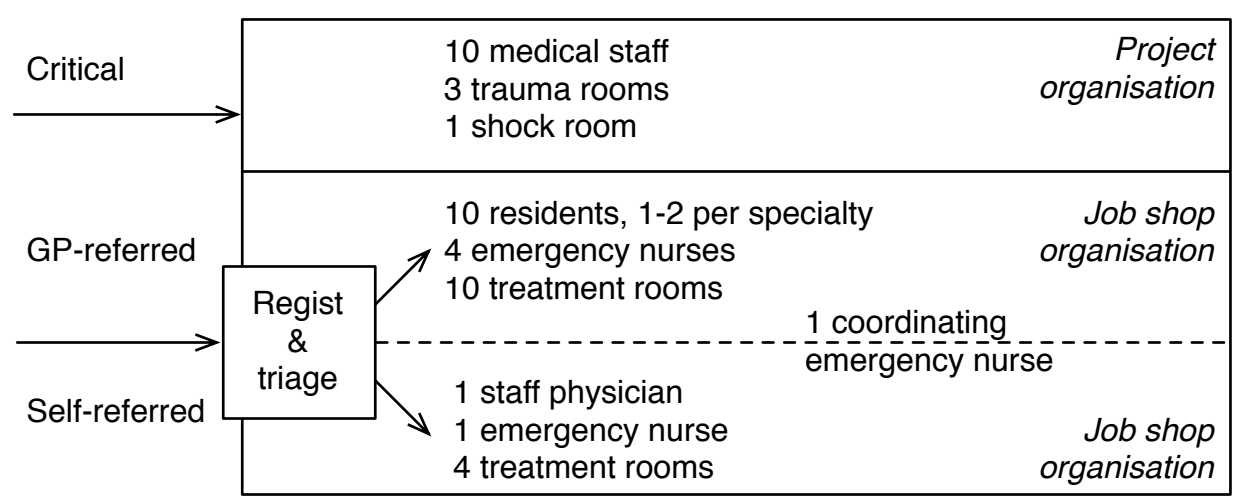

Figure 3.5: Available resources for the main patient flows in the AMC emergency department; GP = general practitioner; regist = registration 
nurse in the ED. This emergency nurse determines the urgency of arriving patients. Using the Manchester triage system, the nurse determines the maximum time the patient can wait to be seen by a physician; the nurse also directly administers pain medication if required. There are five different urgency categories with waiting times varying from 0 to 240 minutes. The staff physicians and the emergency nurses work only for the ED.

\subsection{Organisational arrangements for emergency care delivery in the AMC}

Many different healthcare professionals collaborate to deliver emergency care. Within the ED, there are two distinct arrangements in which value for patients is created in an entirely different way. The care delivery in the ED also depends on partners in the value stream, who may exert opportunistic behaviour (Lamming, 1996; Sahay, 2003; Hoffmann et al., 2011).

\subsubsection{Task division and coordination in the ED}

The first arrangement, concerning the care delivery for the critical patients, can be characterised as a project organisation (Slack et al., 2007). All caregivers are present in the trauma room with the patient, carrying out their activities largely simultaneously and coordinating around the patient in the trauma room. The members of this team disband when treatment is complete. The project organisation takes priority over all other activities when necessary - three times per day on average. The urgency and the goal are clear. Members of the team have been trained to assume their appropriate roles. There is a strict $\mathrm{ABCDE}$ action sequence following standard protocols. The trauma surgeon provides medical leadership continuously throughout the patients' course of treatment. The treatment of a complex trauma patient requires less than one hour; it is less than 30 minutes for a patient with acute neurological problems. There is hardly any waiting between the activities; value is created in a continuous flow for these patients (representing 3 percent of all ED visits).

The second arrangement, concerning the care delivery for the GP- and selfreferred patients, can be characterised as a job shop organisation (Pinedo and Chao, 1999). One caregiver carries out one activity at a time for the patient, one after the other. The specific activities required depend on the symptoms of the patient. If the caregivers cannot continue with one patient, they continue with another. When finished, they return to the previous patient, or search for their colleague. The caregivers coordinate their activities not in the treatment room but in a work room or the hallways. As a result, the patients wait in between the visits from the different caregivers. There is no dedicated medical leadership throughout the patients' course of treatment; progress depends on the individual qualities of the caregivers, their improvisational capabilities and teamwork. The average total time spent in the ED is 
about three hours for GP-referred patients and 90 minutes for self-referrals. Waiting time is a significant amount of the total for these patients (representing 97 percent of all ED visits).

\subsubsection{Dependencies in the value stream}

The activities in the ED depend on the collaboration with partners in the value stream. We describe several dependencies that occur regularly and have a substantial impact on patient flow. Our illustration is not inclusive. See the dashed boxes in figure 3.6. On the left side of the figure: in case the hospital's outpatient departments are closed for holidays or are near closing time, many of the patients are sent to the ED for treatment and hospital admission. The department gets considerably more busy. On the top middle side: medical staff from outside the ED are needed to treat critical patients in the trauma rooms, as well as two emergency nurses and a surgical resident from the ED. This means that the care delivery of GP-referred emergency patients is delayed. Other ED patients may also experience waiting time, because radiology staff is also not available to make x-rays. On the bottom middle side: the residents treating GP-referred patients depend on their superiors to consult their treatment plans with. The supervisors are at work outside of the ED, in the outpatient departments or operating rooms, and need to be immediately available for the resident to continue. The residents often have responsibilities in other departments next to their work in the ED, such as the nursing wards during the night. They also leave the ED to go to a joint meeting for their specialty, where all patients are discussed to hand over between the shifts. This meeting takes up to 45 minutes. These complexities all cause delays for GP-referred patients. The staff physicians remain in the ED at all times, in contrast to the residents, but cannot take over the care delivery. On the right side: the centralised radiology and laboratory facilities are used by patients from all different hospital departments. Although activities for the ED are often prioritised, interference may still occur during peak hours. The same applies to the nursing wards. If they are full, patients who need admission cannot leave the ED, which in turn affects patients who are waiting to be seen.

\subsubsection{How complex arrangements create waiting}

We now explore the care delivery in more detail to give an impression of how waiting occurs. Let us consider the typical treatment process for a self-referred walk-in patient. The patient enters the department and registers at the receptionist's desk. The triage nurse invites the patient into the triage room. The nurse takes a short history and checks vital signs such as blood pressure and saturation. The urgency is determined and pain medication is administered if needed. After triage, the patient is sent to the waiting area (urgent patients proceed directly to a treatment room). After waiting, another nurse invites the patient into a treatment room, checks the vital signs and may take a short history. Then the nurse leaves and the patient waits to be seen by the staff 


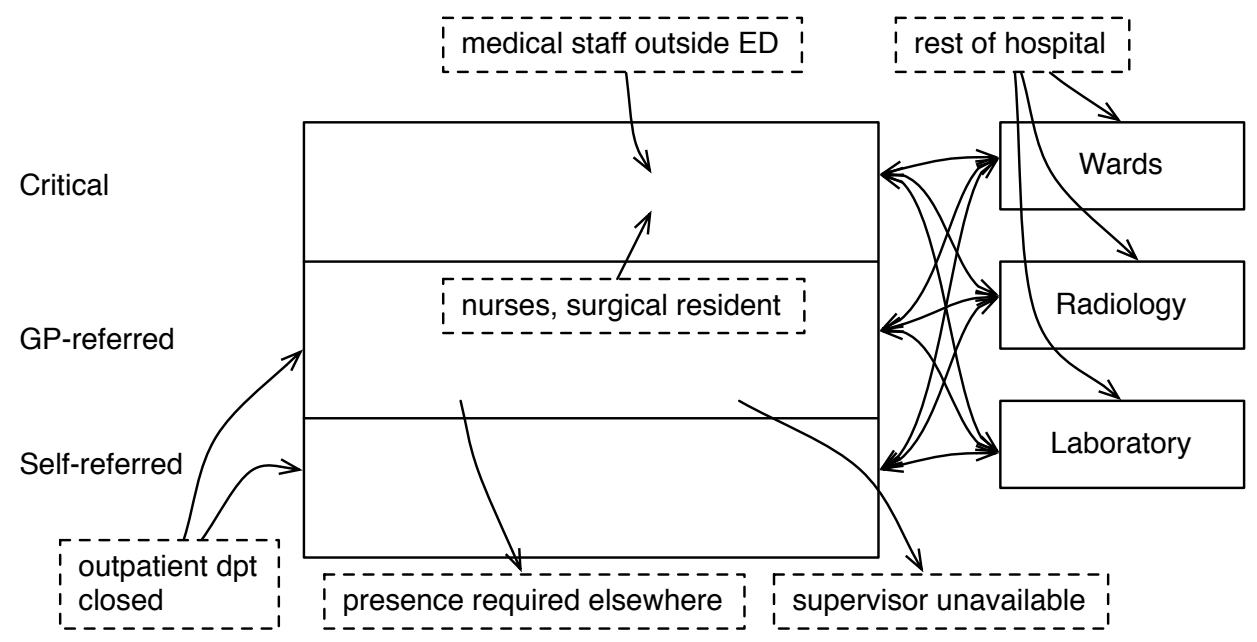

Figure 3.6: Complexities in the value stream of the AMC emergency department; dpt = department; GP = general practitioner

physician. The physician takes a history, performs a physical examination and decides about additional diagnostics. If diagnostics are needed, it is often the nurse who starts up the examinations on physician's orders. The patient leaves the ED to go to acute radiology, or blood is sent to the laboratory. After the processing time, the results are analysed by the physician, who then decides on the course of treatment. The decision includes questions such as: what medication does the patient need, does the patient need hospital admission, or additional examinations and specialist consultations? (If the staff physician decides to transfer the patient to a resident, then the resident has to discuss the intended course of treatment with their supervisors.) Next, the physician or nurse administers a kind of treatment. The nurse then finalises the remaining work: print out a letter for the GP and say goodbye to the patient or arrange the admission. See figure 3.7 .

The figure clearly shows the typical job shop organisation. The task division includes strictly separated activities that are carried out by the nurse, then the physician, and then the nurse again, and so on. The sequence of activities involves recirculation when extra diagnostics are needed or additional specialists are called in. Many of the individual activities depend on something: an available supervisor for the resident to discuss the course of treatment, or an available ward bed for the patient to leave the ED. The complexity in the sequence of activities makes it difficult to create value in a continuous flow. It is even more complex when we consider that most of the time, several different sequences are occurring simultaneously for different patients in the ED.

A general rule of thumb for the nurses to promote flow in the ED is ensuring 


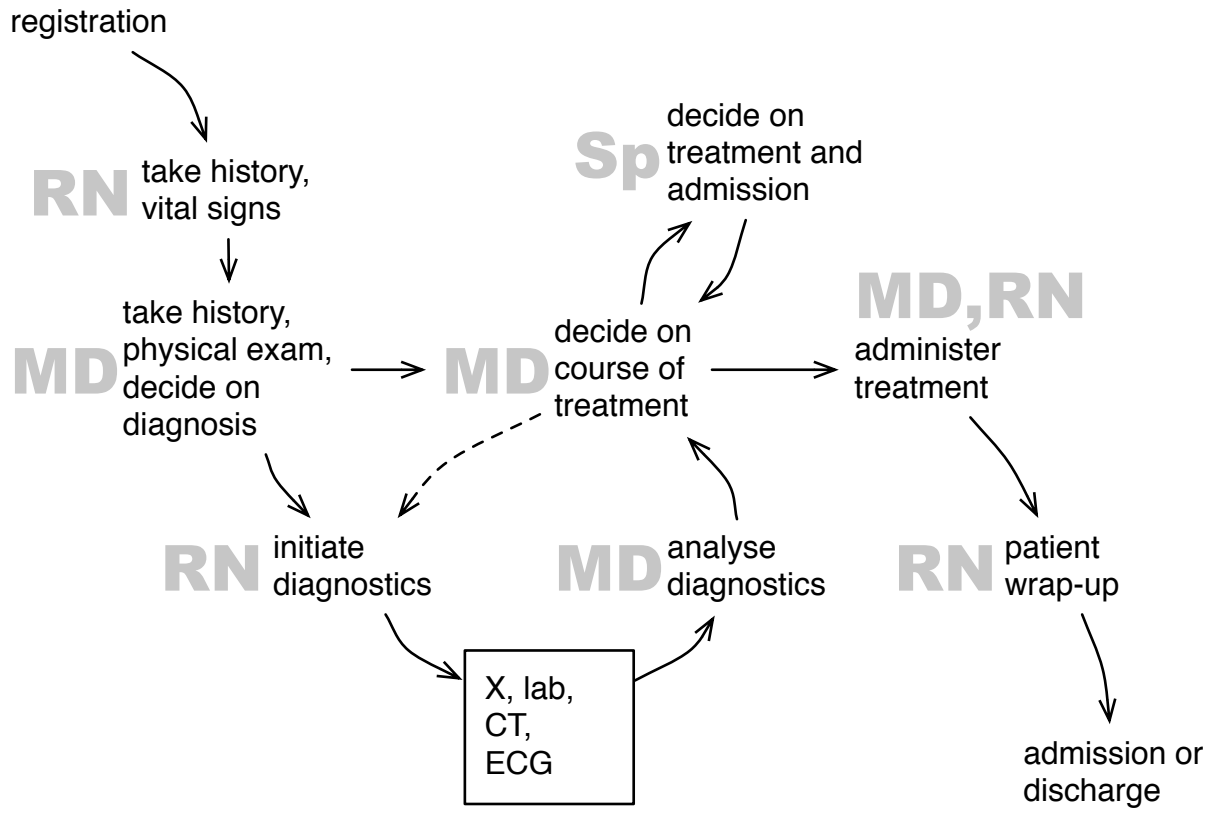

Figure 3.7: Organisation of care delivery for GP-referred and self-referred patients in the AMC emergency department; lab = laboratory examinations; $\mathrm{MD}=$ resident (medical doctor); $\mathrm{RN}=$ emergency nurse (registered nurse); $\mathrm{Sp}=$ supervisor; $\mathrm{X}=\mathrm{x}$-rays 
that the physicians are always busy. The physician is often the deciding factor in the progress of the patients' care delivery-the so-called bottleneck, which should never be without work (Goldratt and Cox, 1984). The nurses, therefore, keep the treatment rooms filled with patients. However, if the nurses allow too many patients into the treatment rooms, the physicians cannot keep up. Patients end up waiting in the treatment rooms. As the total number of treatment rooms is limited, it follows that progress for other patients is quickly blocked. It is, therefore, important for the nurses not to fill up rooms because they are empty, but to restrict the number of patients allowed in to the maximum number that the physician can handle (so-called CONWIP, see Hopp and Spearman, 2000, p. 349).

Problematic in the ED context is that almost anything can keep the physician from continuing work: a nurse who is busy with another patient, a ward bed that is unavailable, a delay in test results, a supervisor who is unavailable, a problem with the IT system. What is more, these disturbances may change from minute to minute. Also problematic is that variability-in the number of arriving patients and the processing times of individual activities - by itself creates waiting within the total sequence of activities (Slack et al., 1998; Hopp and Spearman, 2000; de Sitter, 2000). It requires special skills for the emergency nurses to coordinate the activities of the physicians when there are many patients in the ED.

\subsection{Trends in professional domains involved in emergency care delivery}

The ED is a place where many different medical professionals meet. The boundaries of the different professional domains are in constant development. In the AMC there are three general professional domains, related to the care delivery for critical, GP-referred and self-referred patients. The emergency nurses provide care for patients in all three domains, from the most critical to the most elementary self-referred patient. The situation is different for the physicians. GP-referred patients are seen by residents within their medical specialty; about 10 specialties are involved in emergency care. The surgical residents also see the most critical patients. Self-referred patients are seen by staff physicians, who refer several of them to the residents. Over recent years, the staff physicians have been catching up with the nurses, expanding their professional domain to all of the other patient groups in the ED. They intend to become medical specialists in their own right-emergency physicians, as their colleagues in the United States and Australia already are. In the future, they will assume the medical leadership role over the entire ED; this role is currently performed by a trauma surgeon, as in many Dutch EDs. Naturally this means that the emergency physicians have residents of their own specialty. The training of residents of other specialties in the ED is likely to fall within the responsibility of the emergency medicine specialty, and not their own. The close collaboration between the emergency physicians and the other specialists, however, is likely to remain. This applies especially to the trauma surgeons in the trauma rooms, 
and to all other specialists in case of hospital admission or acute operations.

There is also a trend related to the GPs. About half of all ED patient visits in the Netherlands are estimated to have been handled by GPs just as well. Many patients choose to go to the hospital because they think they need to, or because of the perception that the GPs are not always available. The charge for treatment in the ED is much higher than for the same treatment by a GP. The Dutch government intends to create one rate for this type of patient care. Insurers are also keen to reduce costs. There are two consequences. Many GPs are moving closer to the hospitals. Their group practices are being integrated into many EDs, treating a major part of the self-referred patients during opening hours. The EDs are also reorganising to do more GP-related work, either by actually employing GPs in the department or by employing nurse practitioners. This will allow the emergency physicians to concentrate on the complex, undifferentiated patients they are trained for (van Geloven et al., 2003).

\subsection{Research projects in the AMC ED}

Figure 3.8 displays the research projects that have been carried out during the course of the PhD research. The figure shows on which parts of the patient flow the projects concentrated, as well as their order. A number of these projects or parts of them were carried out by MSc and BSc students (te Poele, 2006; Schnellen, 2006; van Schuppen, 2006; Pezij, 2007; Roskam, 2007). In essence, all patient flows in the ED including the diagnostic flows (see also van Tuijn et al., 2010) were completely covered in this way. The only exception is the care delivery for the critical patients-several other research projects studied this (Fung Kon Jin et al., 2008; Saltzherr and Goslings, 2009; Beenen et al., 2010; Fung Kon Jin et al., 2010; Saltzherr et al., 2010).

The research projects:

1. Pilot project. In this project, a new scheduling system was tested that allowed general practitioners to schedule arrival times for patients they referred to the ED. The project goal was to match the variable number of patients better to the available resources in the ED. See the next chapter.

2. Radiology project. In this project, the patient flow was analysed for ED patients who needed x-rays. The project goal was to improve patient flow between the ED and the radiology department and to reduce waiting times. See chapter 5.

3. Planning board project. In this project, a central planning board was developed and implemented. The project goal was to increase the overview of patient flow and the feeling of control over the department for ED staff. See chapter 5.

4. Computer simulation project. In this project, a computer simulation model was designed of the care delivery process for self-referred ED patients (the analysis also included the acute laboratory flow, not reported in this thesis). The model enabled us to predict the effects of interventions on the patient flow. The project 


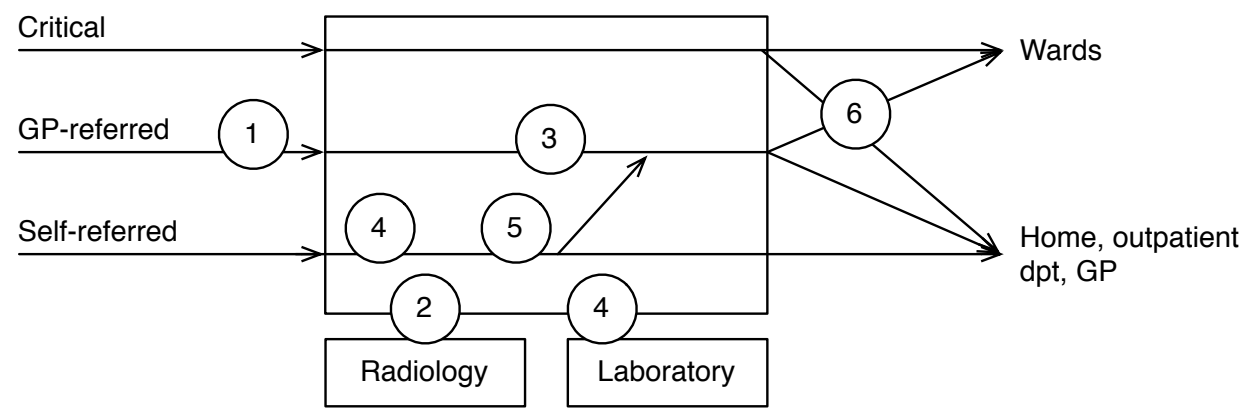

Figure 3.8: Research projects carried out in the AMC emergency department, located within the main patient flows; GP = general practitioner; outpat dpt $=$ outpatient department

goal was to design a simulation model as a tool to facilitate action taking in the AR process. See chapter 6.

5. Advanced triage project. In this project, an advanced triage protocol was developed and tested for self-referred ED patients. In advanced triage, emergency nurses initiate additional diagnostic examinations independently, directly from the triage. The project goal was to reduce patient waiting times while maintaining the quality of medical care. The computer simulation model mentioned before was used in this project. See chapters 6 and 7.

6. Nursing wards project. In this project, the patient flow was analysed for ED patients who were admitted to one of the nursing wards of the internal medicine specialty. The project goal was to inform hospital management about implementing a special observation unit to improve patient flow. See chapter 8 .

\section{References}

Beenen L, Adams R, Koster R, Otto T (2010). Computed tomography scanning during a traumatic resuscitation. American Journal of Emergency Medicine. [Epub].

Fung Kon Jin P, Dijkgraaf M, Alons C, van Kuijk C, Beenen L, Koole G, Goslings J (2010). Improving CT scan capabilities with a new trauma workflow concept: simulation of hospital logistics using different CT scanner scenarios. European Journal of Radiology. [Epub].

Fung Kon Jin P, Goslings J, Ponsen K, van Kuijk C, Hoogerwerf N, Luitse J (2008). Assessment of a new trauma workflow concept implementing a sliding CT scanner in the trauma room: the effect on workup times. Journal of Trauma. 64:1320-6.

van Geloven A, Luitse J, Simons M, Volker B, Obertop H, Verbeek M (2003). Emergency medicine in the Netherlands, the necessity for changing the system: results from two questionnaires. European Journal of Emergency Medicine. 10:318-22. 
Goldratt E, Cox J (1984). The goal: a process of ongoing improvement. North River Press, Great Barrington.

Hoffmann P, Schiele H, Song M, Krabbendam J (2011). Enhancing supply risk management performance: a transaction cost and social exchange theory perspective. In Proceedings of the International Purchasing and Supply Education and Research Association Conference.

Hopp W, Spearman M (2000). Factory physics. McGraw-Hill, Singapore, 2nd edn.

Lamming R (1996). Squaring lean supply with supply chain management. International Journal of Operations \& Production Management. 16:183-96.

Pezij J (2007). Testing scenarios in a simulation model of the emergency department. Unpublished BSc thesis, University of Twente, Enschede.

Pinedo M, Chao X (1999). Operations scheduling with applications in manufacturing and services. McGraw-Hill, Singapore.

te Poele R (2006). Impact of laboratory turnaround time on the patient length of stay of an emergency department. Unpublished BSc thesis, University of Twente, Enschede.

Roskam S (2007). Emergency internal medicine: an analysis of the patient flow from the emergency department to the internal medicine's wards and the potential of an observation unit in the AMC. Unpublished MSc thesis, University of Twente, Enschede.

Sahay B (2003). Understanding trust in supply chain relationships. Industrial Management \& Data Systems. 103:553-63.

Saltzherr T, Goslings J (2009). Total body CT scan as the primary diagnostic modality in multi-trauma patients. Nederlands Tijdschrift voor Geneeskunde. 153:A982.

Saltzherr T, Visser A, Ponsen K, Luitse J, Goslings J (2010). Complications in multitrauma patients in a dutch level 1 trauma center. Journal of Trauma. 69:1143-6.

Schnellen M (2006). Developing a model to compare two emergency departments in the Netherlands and the United States. Unpublished BSc thesis, University of Twente, Enschede.

van Schuppen J (2006). A simulation tool for the emergency department. Unpublished MSc thesis, University of Twente, Enschede.

de Sitter L (2000). Synergetisch produceren. Van Gorcum, Assen, 3rd edn.

Slack N, Chambers S, Harland C, Harrison A, Johnston R (1998). Operations management. Pearson Education, Harlow, 2nd edn.

Slack N, Chambers S, Johnston R (2007). Operations management. Pearson Education, Harlow, 5th edn.

van Tuijn C, Luitse J, van der Valk M, van Wissen S, Prins M, Rosmulder R, Geerlings S (2010). Reduction of the door-to-needle time for administration of antibiotics in patients with a severe infection: a tailored intervention project. Netherlands Journal of Medicine. 68:123-7. 



\section{4}

\section{Planning emergency patients: an attempt to change the nature of the emergency department}

R.W. Rosmulder, J.J. Krabbendam and J.S.K. Luitse

European Journal of Emergency Medicine 2006, 13:377-379

This paper was presented at the 4th International Conference on the Management of Healthcare \& Medical Technology, Aalborg, Denmark, 25-27 August 2005 


\begin{abstract}
Throughout the day, arrivals of patients at the emergency department (ED) are unannounced, unpredictable and fully determined by chance. Healthcare professionals in the ED naturally react as quickly as possible when patients arrive. We wondered whether they could somehow act in advance.

We introduced a planning system that enabled the ED to regulate arrival times of emergency patients referred by the general practitioner (GP). The system established direct contact between GP and ED at the press of a button. As a result, the ED was able to schedule a fraction of its unpredictable patient demand.

Implementation of the system at large was unsuccessful however. Changing the nature of the ED turned out to be far more difficult than expected. In our opinion, successfully planning emergency patients requires that the ED has full control over the referral process, and that scheduled patients are treated in a separate, undisturbed care process.
\end{abstract}




\subsection{Can we defy chance?}

Typically, patients may enter the emergency department (ED) at any moment. Throughout any day, the arrivals are unannounced, unpredictable and fully determined by chance. Healthcare professionals in the ED naturally react as quickly as possible when patients arrive. We wonder: could they somehow act in advance?

Suppose it would be possible, that ED staff knows which patients are coming and even determine when. The ED may create a much more steady flow of patients (NHS Institute for Innovation and Improvement, 2005) into the department by reducing the variation in their arrivals (Institute for Healthcare Improvement, 2005a). Patient demand is better matched to available resources (Institute for Healthcare Improvement, 2005b; NHS Institute for Innovation and Improvement, 2005), allowing the ED to treat patients faster with the same number of staff and treatment rooms. In addition, the ED may anticipate demand by dedicating its resources with certainty and even preparing for the arrival of the patients.

Placing our idea into context, we are discussing planning or scheduling of emergency patients. The subject of scheduling has its background in the operations management of manufacturing companies (Pinedo and Chao, 1999; Hopp and Spearman, 2000). Among other industrial concepts (Walley, 2003), it has frequently been applied in healthcare environments as well. There are reports on ED nurse staffing (Helmer et al., 1988), scheduling emergency physicians (Carter and Lapierre, 2001) and scheduling elective care (Dexter and Traub, 2002). However, we are not aware of any published research on planning emergency patients.

We put our thoughts into action by attempting to introduce a basic scheduling system for emergency patients who are referred by the general practitioner (GP). As we will demonstrate, a simple idea turns out to be surprisingly difficult to realise.

\subsection{The scheduling idea}

The scheduling attempt took place at the ED of an urban-based university hospital in the Netherlands. The hospital has one thousand beds and is designated as level onetrauma centre. The ED treats about 33.000 patients yearly: 3 percent in life-threatened conditions, 77 percent self-referrals and 20 percent referred by GPs. For these groups of patients, 3 trauma rooms, 4 and 10 cubicles are available respectively.

The group of GP-referred patients satisfies two conditions needed for patient scheduling. First, their arrival is known in advance since the GP needs to contact the hospital to refer the patients. Second, their arrival may be postponed within the day; generally, GP-referred patients require treatment within the same day but not immediately.

Though relatively small in number, GP-referred patients make up an important group in the ED. They are sicker than the self-referred group, require more extensive 
Old situation

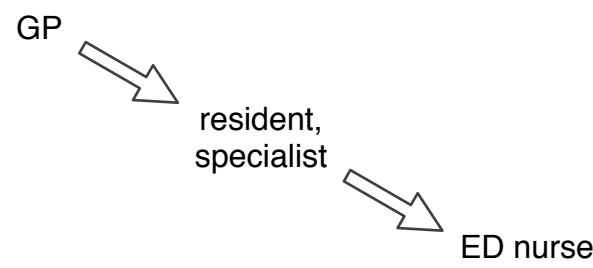

(a) No direct contact between GP and ED

New situation

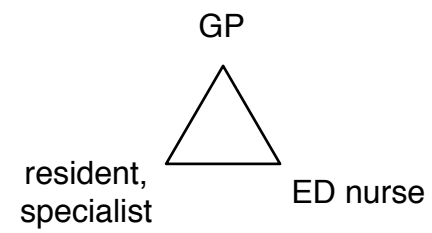

(b) Three-way contact enables arranging arrival times at ED

Figure 4.1: Old and new referral process for GP-referred patients; ED = emergency department, GP = general practitioner

treatment and are admitted more often. In addition, more capacity is available for their treatment. Scheduling these patients may well benefit the entire ED.

The introduction of the scheduling system required a redesign of the existing referral process (see figure 4.1). In the old situation, the GP first contacted the relevant speciality to decide about referring a patient. When this conversation was over, the attending resident or specialist then informed the ED that the patient was due. As a result, the ED knew that patients were coming but not when. In addition, the ED could not control the arrival times of the patients.

We changed this situation by establishing direct contact between the GP and the ED. In the new design, attending residents and specialists use the conference function of the hospital telephone. At the press of a button, the resident or specialist adds a nurse from the ED to the conversation with the GP. Together, they decide about a time at which the patient is expected. In this appointment, they take account of the condition of the patient, the expected travelling time and the current activity at the ED. 


\subsection{Making the idea work}

We realise that the ED is a complex environment of ad hoc action and improvisation. We therefore made extensive preparations to implement the scheduling idea.

To limit the great number of people involved, we carried out a pilot with the specialities of surgery and medicine. We discussed all stages of the project with relevant contact persons who helped us reach each discipline in the best way possible. We gave presentations about the scheduling attempt to ED nurses, residents and specialists. They received pocket cards explaining the use of the conference function. The hospital informed the GPs by letter. At the ED, a planning board was installed to keep track of scheduled patients.

The key group in the project were the residents and specialists. The ED has no direct control over them since they are employed by their speciality. We meant to ensure their cooperation by pointing out the expected benefits for the emergency patients (Ham, 2003), by explaining the research rationale, by personally reminding them of the intervention and by providing instructions during the pilot period.

During our two-week pilot period in January 2004, only 24 patients out of a possible 164 were actually planned. Implementation was unsuccessful.

\subsection{Reasons for the limited success}

Relevant healthcare professionals have different views on emergency care. Generally, ED staff and general practitioners were willing to cooperate in the planning experiment. The group of specialists on the other hand expressed negative feelings toward the idea of scheduling and thus postponing emergency patients.

The referral process is complex and historically ill-structured. Patients are sent from many specialist departments at the hospital, largely outside the control of the ED. In this regard, it is certainly not helpful that specialists may accept referrals from GPs without personally seeing these patients at the ED.

Other patients interrupted the treatment process of planned patients. Residents treat several groups of patients at the ED. Some of them continued to arrive at completely unpredictable moments.

\subsection{Conclusion: can we defy chance?}

Simply by using existing technology, the ED managed to schedule a fraction of its variable patient demand. Yet, changing the nature of the ED was far more difficult than expected.

In our opinion, planning emergency patients firstly requires that the ED has full control over the referral process, and secondly, that scheduled patients are treated in a separate, undisturbed care process. In other words, successful implementation of our 
simple idea would turn both the professionals' way of working and the organisation of care upside down.

\section{References}

Carter M, Lapierre S (2001). Scheduling emergency room physicians. Health Care Management Science. 4:347-60.

Dexter F, Traub R (2002). How to schedule elective surgical cases into specific operating rooms to maximize the efficiency of use of operating room time. Anesthesia \& Analgesia. 94:933-42.

Ham C (2003). Improving the performance of health services: the role of clinical leadership. The Lancet. 361:1978-80.

Helmer F, Freitas C, Onaha B (1988). Determining the required nurse staffing of an emergency department. Journal of Emergency Nursing. 14:352-8.

Hopp W, Spearman M (2000). Factory physics. McGraw-Hill, Singapore, 2nd edn.

Institute for Healthcare Improvement (2005a). Decrease and smooth variation. http://www.ihi. org/knowledge/pages/changes/decreaseandsmoothvariation.aspx.

Institute for Healthcare Improvement (2005b). Match capacity and demand. http://www.ihi. org/knowledge/pages/changes/matchcapacityanddemand.aspx.

NHS Institute for Innovation and Improvement (2005). Improvement leaders' guide: Improving flow. http://www.institute.nhs.uk/quality_and_service_improvement_tools/quality_and_ service_improvement_tools/patient_flow.html.

Pinedo M, Chao X (1999). Operations scheduling with applications in manufacturing and services. McGraw-Hill, Singapore.

Walley P (2003). Designing the accident and emergency system: lessons from manufacturing. Emergency Medicine Journal. 20:126-30. 


\section{Action research and soft systems methodology for studying problems in emergency care delivery}

R.W. Rosmulder, J.J. Krabbendam, A.H.M. Kerkhoff and J.S.K. Luitse International Journal of Healthcare Technology and Management 2009, 10:289-302

This paper was presented at the 6th International Conference on the Management of Healthcare \& Medical Technology, Pisa, Italy, 3-5 October 2007 


\begin{abstract}
This article describes the use of action research (AR) and soft systems methodology (SSM) for studying and taking action in complex and unstructured problem situations. Drawing from AR and SSM principles, it proposes a research methodology to study and improve problematic flows of patients in emergency departments using operations management concepts. Three examples illustrate the methodology: analysis and improvement actions in acute radiology service, the design and introduction of a central status board, and tests of an advanced triage system. This article concludes that an action mode of research is worthy of being pursued further, in emergency departments and beyond.
\end{abstract}




\subsection{Introduction}

Patients in emergency departments all over the world today experience problems in the delivery of the service, such as long waiting times, poor information provision and a generally unpleasant stay. Many research efforts are taken to study and improve these problems (Saunders, 1987; Kyriacou et al., 1999; de Vries et al., 1999; Alvarez and Centeno, 2000; Derlet and Richards, 2000; Hoffenberg et al., 2001; Spaite et al., 2002; Asplin et al., 2003; Cardin et al., 2003; Puente et al., 2003; Pickard et al., 2004; Kelly et al., 2007). In the Netherlands, a four-year PhD research in operations management $(\mathrm{OM})$ is under way, focusing its efforts on all patient flow aspects of a large university hospital's emergency department. OM is a field that studies all activities required to create and deliver a product or service, from procurement through conversion to distribution (Hopp and Spearman, 2000; Hayes et al., 2005). Several OM concepts that have originated in industry, such as total quality management, just-in-time production scheduling, business process reengineering, lean thinking, and benchmarking are considered as main contributors to successful improvements in the industrial sector over recent decades. The $\mathrm{PhD}$ research employs these $\mathrm{OM}$ concepts to study the problematic flow of patients through the department and corresponding chain of care, attempting to explore the benefits of industrial concepts to healthcare. Central to the approach in the research is the actual taking of action in the problem situation, thus really putting the concepts to the test. From these research aims arises an important question: what research methodology is appropriate?

This paper presents a methodology for studying problems in emergency care delivery, which is based on principles from action research (AR) and soft systems methodology (SSM). Later on, three examples from the research setting serve as illustration. This paper starts by establishing the need for the proposed methodology based on a concrete experience.

\subsection{Lessons from an attempt to schedule emergency patients}

Arrivals of patients at emergency departments are highly variable and unpredictable. Yet, the arrivals of one group of patients may potentially be scheduled. This concerns patients who, in countries with networks of general practitioners (GPs), have first seen their GP and then been referred to an emergency department (ED). A project, carried out at the start of the $\mathrm{PhD}$ research, attempted to regulate the inflow of GP-referred patients, expecting to better match capacity and demand at the ED. A simple technical intervention established direct contact between GP and ED, so that arrival times could be arranged. The project was extensively prepared through project team meetings, presentations for all relevant professional groups, instruction cards and hospital-level consultations with regional GPs. The result of the project was unsuccessful; far too few 
patients were actually scheduled. The main cause was that scheduling patients was not considered an improvement by all parties involved, as their commitment to the referral process differed. In addition, it turned out that the original idea entailed much more than a simple technical intervention. For details, see Rosmulder et al. (2006).

Now was this project a failure and a waste of time? A lot of work did result in very little. Yet, when taking a different perspective, there is much more to say. Several important lessons have been learned from actually testing this OM idea:

- A lesson about OM theory was that the idea itself turned out fine. It has been possible to schedule arrivals of previously unscheduled emergency patients. Also, some of the senior nurses at the department still feel for the idea, years later.

- A lesson about the ED was that the complexity of the situation could be appreciated more fully. More was needed than the technical intervention alone; it took extensive effort to change the status quo, which was rooted in historical patterns stemming from old ways of cooperation. In addition, taking measurements to study the effect of the intervention was far from straightforward at the study setting, especially during busy moments.

- A lesson about healthcare was that it differs considerably from the world where OM concepts have originated from. The implementation process involved making explicit the expected benefits to patients, convincing healthcare professionals of these benefits (Ham, 2003), and dealing with different professional groups that were involved in different ways. It seems that political skill and a drive to ensure proper sharing of problems are crucial in this world.

These lessons suggest that research in these situations requires an approach where learning from trying an idea is as important as actual improvement results. Before further exploring this research approach, the next section puts the lessons within a wider theoretical context.

\subsection{Theoretical perspectives}

The value of OM concepts to EDs is in their concern with problematic flow. OM has developed from work in manufacturing companies, where the design and control of production flows has steadily been improved over the years. Several characteristics describe the backgrounds of OM:

- A systems focus: an organisation may be viewed as a system, a whole consisting of interrelated parts, with an input, transformation, and output (e.g. Kast and Rosenzweig, 1972). The system exists within an environment. An organisation uses input and output components to protect the transformation from disturbances by the environment (Thompson, 1967; Scott, 1998); for example, by keeping both supplies of parts and of finished products. 
- A process focus: a number of subsequent activities take place to transform inputs into outputs. Typical phases include: taking customer orders, product design, process design, production, delivery, and receiving customer feedback. Within a process, a distinction is made between the product flow and the information flow (Slack et al., 2004). Information on customer demands flows upwards to an organisation, which then starts the process of production to delivery, downwards to the customer. An information flow is also used by management to control the product flow.

- A focus on management control: manufacturing organisations have traditionally divided work into its smallest components, which were then assigned to workers and machines, while managers controlled the whole. Different ways of organising work have developed since, which include job rotation, semi-independent work groups and virtual teams (Venkatraman and Henderson, 1998; Pasmore, 2001).

- A focus on performance measurement and improvement: process performance is measured, sometimes using advanced statistical process control techniques. Results may then be used for continuous and radical improvement programmes. In addition, results may be used to standardise working methods and design processes in optimal ways, which have evolved around process stages, such as the mass production paradigm, or around families of products, such as the lean production paradigm (Hayes et al., 2005).

When taking an OM perspective on an ED, a number of similarities and differences occur:

- An ED can be seen as a system with an input, throughput and output, involving a related set of activities in the chain of care, which involve registration, nurse anamnesis, physician anamnesis and physical examination, diagnostic tests by radiology or laboratory, treatment and discharge or admission to a nursing ward.

- Arrivals of patients largely dictate the pace of work at the department, as they are unpredictable and unstoppable, and often require a rapid response. The influence of the environment is thus considerable within an ED. In addition, only upon arrival is it known what combination of activities is required exactly (Thompson, 1967). The direction of patient flow and information flow are the same.

- During their stay at an ED, patients see many different professionals, who are each responsible for their own contribution to patients' care and manage this independently, for they are professionals. As a result, patients need to wait frequently in between visits by different healthcare professionals. A major exception happens in situations of highest urgency, when a trauma team gathers to provide uninterrupted care, dropping all other tasks they were working on.

- Performance measurement at an ED happens through complaints from patients, or reports on excessive lengths of stay, or through inspections, but is often not an integrated part of the care delivery process. In addition, cooperation between 
professionals or departments is often not subject to study; historical patterns may persevere. Standards of performance are mostly determined by professional disciplines outside of the organisation (Thompson, 1967; Mintzberg, 1980).

- Performance improvement is complicated, as different professional disciplines are involved at different levels (Glouberman and Mintzberg, 2001). This implies that goals for improvement may not always be shared. When no agreement exists on goals, then means for improvement are unclear as well.

\subsection{Three implications, calling for an action mode of research}

The discussion up to now has shown what research may involve that studies problematic patient flows in an emergency department, with an explicit concern to learn from testing OM concepts. The attempt to schedule emergency patients has indicated the need for a research methodology that incorporates learning. Putting this experience in a theoretical context has resulted in several similarities and differences between healthcare and the background of OM concepts. This discussion presents three implications for a research methodology:

1. A methodology is required that facilitates research goals that incorporate both study and action.

2. The promise of using OM concepts to study problematic patient flows in an ED meets with difficulties, as the backgrounds are different. A translation of the concepts is required, which especially incorporates the complexity of human interaction in a professional environment.

3. Researchers cannot escape from direct collaboration with professionals; they need to take effort that problems and improvement goals are shared. The translation of OM concepts also implicates cooperation with healthcare professionals.

Together, these implications clearly point to an action research (AR) methodology. In addition, soft systems methodology, which may be called a developed form of AR, is very well suited. A description follows of both methodologies, their differences and similarities.

\subsection{Action research and soft systems methodology}

Action research has been defined as the application of the scientific method of fact finding and experimentation to practical problems requiring action solutions and involving the collaboration and cooperation of scientists and practitioners (French and Bell Jr, 1990). AR works through iterative cycles of collecting data about an ongoing system relative to some objective of that system, feeding these data back into 
the system, taking action by altering selected system variables based both on data and on hypotheses, and evaluating the action by collecting more data (French and Bell Jr, 1990). An assumption underlying AR is that one gets the best knowledge about a system by trying to change it (Schein, 1987); another is that people are more likely to provide valid information about their own intentions and reasons for action when they share control of the process of generating, interpreting, testing and using information (Argyris and Schön, 1996). This implies that researchers in action research settings can not be neutral, independent observers; as they work together with members of the system to take action and study it, they act as participant-observers or agents of change (Coughlan and Coghlan, 2002). Susman and Evered (1978) have contrasted the philosophical viewpoints of AR with the principles underlying positivist science, concluding that AR requires a scientific paradigm of its own. Theory generation in AR proceeds incrementally, it develops from a synthesis of that which emerges from the data and that which emerges from the use in practice of the body of theory that informed the intervention and research intent (Eden and Huxham, 1996). This corresponds nicely with the research aims of studying problematic patient flows within an ED, which uses in practice a body of OM theory to inform and test several interventions. For research in operations management, AR has been acknowledged as a valid methodology (Coughlan and Coghlan, 2002) that overcomes deficiencies in traditional research methods (Westbrook, 1994). For example, in contrast to traditional methods, AR does produce results that are of practical value to managers in organisations, and it is better suited for unstructured real-world problems (Westbrook, 1994).

Soft systems methodology (SSM) has been defined as an organised use of systems ideas in a methodology for learning one's way to purposeful action in human situations regarded as problematical (Checkland and Scholes, 1990). The learning takes place through a cyclical process of using systems concepts to reflect upon and debate perceptions of the real world, taking action in the real world, and again reflecting on the events using systems concepts (von Bulow, 1989). This process consists of seven well-crystallised steps. SSM is a hermeneutical activity: it accepts that whenever we describe purposeful human activity, we include an interpretation, a taken-as-given point of view; there are no right or wrongs, only multiple possible interpretations (Checkland, 1985). Eventually, these interpretations are used in a debate that aims to arrive at changes that could be introduced in the problem situation. The parallels with action research may have become clear by now. In fact, SSM is a developed form of AR, a methodological framework for it; by declaring in advance an intellectual framework that the research will follow, explicit research lessons may be extracted from it (Checkland, 1985; Checkland and Holwell, 1998). This is a useful extension to $\mathrm{AR}$, as the question how lessons are generated is generally left implicit in AR literature (Eden and Huxham (1996) do state that AR demands an explicit concern with theory). The word soft in SSM implies a contrast to hard; in hard systems thinking, solutions are engineered to problems, in other words, what to do has been defined, and how to do it remains to be solved. For example, designing a bridge to cross a valley 
Table 5.1: Action research and soft systems methodology, key similarities and differences in focus

\begin{tabular}{|c|c|}
\hline Action research & Soft systems methodology \\
\hline \multicolumn{2}{|l|}{ Similarities } \\
\hline \multicolumn{2}{|c|}{ A method of both research and improvement } \\
\hline \multicolumn{2}{|c|}{ Cooperative and interactive } \\
\hline \multicolumn{2}{|c|}{ Concerned with learning, reflection on action } \\
\hline \multicolumn{2}{|c|}{ Cyclical process of research } \\
\hline \multicolumn{2}{|c|}{ Produces knowledge that is useful to practitioners } \\
\hline \multicolumn{2}{|c|}{ A research paradigm next to positivist science } \\
\hline \multicolumn{2}{|l|}{ Differences } \\
\hline $\begin{array}{l}\text { Incremental theory development } \\
\text { from using in practice a body of } \\
\text { theory }\end{array}$ & $\begin{array}{l}\text { Explicit declaration of intellectual } \\
\text { framework in advance }\end{array}$ \\
\hline Analysis and feedback of data & A hermeneutical debate \\
\hline Unstructured problems & Soft problem situations \\
\hline
\end{tabular}

of certain width and depth. In soft systems thinking, both what and how are unclear, only problem situations exist that someone, often a manager, desires to have addressed. SSM then has been proposed by its developers as a way out: a system of enquiry (the seven steps), which is a broad approach to examining problem situations in a way that leads to decisions on actions on the level of both what and how (Checkland and Scholes, 1990). This again is a useful addition, as problematic flows in emergency departments may well be classified as soft problems. The use of systems concepts in SSM is promising for applications of OM theory, as this theory itself has a systems focus. This focus in OM is traditionally rooted in hard systems thinking, so a soft extension of OM theory may be very useful for applications in healthcare.

Table 5.1 summarises the principles that underlie both AR and SSM, and contrasts where the methodologies differ in focus.

\subsection{Toward a methodology for studying and improving problematic ED patient flow}

Action research and its variant soft systems methodology are suitable research methodologies to study problematic emergency patient flows and learn from testing OM 
concepts. The methodologies support goals of both study and action, and support translation of OM concepts by involving professionals at the ED in the research. By framing problematic patient flows as soft problems, the complexity of human interaction in the ED may be incorporated. A debate with members of the department to name relevant perceptions of problem situations may ensure that goals and actions for improvement are shared. By explicitly stating that 1 ) a set of established OM concepts is used in 2) an action research methodology to address 3) problem situations in patient flows, lessons may be learned about these three items. (Checkland and Holwell (1998) provide a more extensive discussion on this topic.)

The above mainly theoretical methodological considerations have resulted in the following practical approach to research at the study setting, a university hospital's ED in the Netherlands:

- An action research team has been formed, consisting of representatives from all relevant disciplines in the ED, including the medical and nursing director of the ED, an ED physician and nurse, a consultant surgery and internal medicine, a senior radiology technician, a secretary with 40 years of working experience at the hospital, and a $\mathrm{PhD}$ researcher in operations management. This team has carried out a number of action research projects, in which the healthcare professionals have contributed their local knowledge and experience at the site, and the researcher his theoretical backgrounds and approach to analysis of problem situations. The researcher's role has been that of actor and observer, facilitating thinking about problem situations, directing analysis and feedback of data into the team, bringing OM concepts into the debate, and reflecting on the experience for wider implications. Decisions about which problem situations to address have been taken by the researcher and the ED managers. The team convened every two to three weeks over a period of two years.

- More researchers have participated in the AR projects; the $\mathrm{PhD}$ researcher has supervised (together with more senior others) several students who carried out projects for their MSc or BSc theses.

- The researcher's entry into the action research situation has followed upon completion of his MSc thesis at the study setting. This entry has been very smooth, as contact had already been established, granting the researcher comprehensive access to the social situation at the ED. Nevertheless, extensive action has been taken at the start to discuss the goals of the research and the research approach with members of the study setting.

- Over the course of the AR projects, the relationship between researcher and professionals at the ED has developed, which enabled more fundamental actions to be taken. At the start of the collaboration, the researcher has done most of the work, guiding the analysis and feeding back data, while the professionals have added their insights in the debates about actions; later on, the professionals have done most of the work, taking action in a problem situation by testing a 
different way of working that the professionals and researcher have developed together, while the researcher has been present to monitor these events.

- Crucial to deciding on the scope of an AR project has been the notion of taking well-delineated actions in the real-life situation that could be controlled as much as possible, which is Popper's piecemeal engineering approach to science (e.g. Irzik, 1985). Action thus proceeds in small steps that can be continually improved upon. Such an incremental approach, called muddling through by Lindblom (1959), has also been used between projects; experiences from one project have been allowed to determine the course of a next one. Thus, although with a general, directive OM theory in mind, the research has proceeded in small steps, examining various parts of the ED as a whole.

The next section describes three action research projects to illustrate the research approach at the study setting.

\subsection{The methodology illustrated}

The first project carried out by the action research team concerned an analysis of radiology services at the emergency department. For similar research work, see Derlet and Richards (2000); Anderson and Karlberg (2001); Ondategui-Parra et al. (2004). The team members considered this project a good way to start the collaboration, for it was well-defined and not overly involving, and expected to easily achieve results. The problem situation was as follows. When patients need x-rays, they leave their treatment rooms at the ED to go to acute radiology. Here, they wait to enter a radiology room, often without knowing how long it will take and why they are waiting. When the x-rays have been made, patients are sent or brought back to the ED, frequently in the middle of the hallway because radiology technicians do not know what room the patients were in. Next to these problems in patient flow, problems existed in the information flow. Nurses at the ED order x-rays by filling out request forms and calling to radiology. These calls are not always answered, and the nurses also feel that they should not make calls during office hours, when the radiology technicians are expected to be present at acute radiology. The radiology technicians, in turn, head back to their much more comfortable central station when there are no patients at acute radiology. They are unable to answer calls when in the elevator. To the radiology technicians, it was problematic to find patients waiting at acute radiology with items that needed to be removed before taking the x-rays, such as jewellery; they felt that this should have already been done at the ED. In short, the common goal of providing care to patients was not perfectly shared between ED and radiology.

The AR team has analysed the full complexity of the situation in process mapping sessions (Welch et al., 2007; see also NHS Institute for Innovation and Improvement, 2007), and the researcher has observed the flow of patients between the departments. It turned out that patients were actually sent to two different sites for acute radiology. 
Next, patients have been given forms to measure the duration of each step in the process $(n=501)$. This revealed the following: patients spend on average 8 minutes getting to and back from radiology, they spend 9 minutes in the radiology waiting area, 8 minutes inside the radiology suite, and 21 minutes waiting to be told the results of the x-rays when they have returned at the ED. Of the total 47 minutes, patients wait the longest after they have returned at the ED; this may be explained by the fact that when patients leave for x-rays, physicians naturally start treating other patients, creating this delay. Interestingly, the nurses felt that the radiology technicians' response was far quicker than normal during these measurements, while the radiology technicians felt that the nurses sometimes called them too late in order for them to achieve slow response times! Next, the nurse and radiology technician in the AR team have joined each other during their shifts to see what their working situations involved. This resulted in increased appreciation for each others' way of working and problems encountered. Finally, the AR team has been able to implement a number of changes: patients now go to only one site for acute radiology; the waiting area has been made more pleasant and includes an information sign; a hostess regularly checks on waiting patients; symbols have been placed on a status board to indicate what rooms patients were in; and a telephone signal is being considered so nurses do not have to wait for radiology technicians to answer their telephone requests when patients require standard $\mathrm{x}$-ray procedures. After these changes, the measurement by patients of the duration of steps in the total process has been repeated $(n=301)$, indicating no differences however. The AR team found that results were far from easily achieved in this project. The team also concluded that more structural changes were needed, which could only be realised by much more integrating the acute radiology into the emergency department.

Learning the lesson that implementation is difficult when other departments are involved, the AR team decided to keep the scope of the second project within the ED. This project concerned the problem situation of central overview over the department. At the study setting, keeping central overview is hampered by a scattered department layout and the fact that emergency patients' medical records are kept on paper. At the start of the project, a small status board was present on which nurses could keep track of the patients' name, room number and designated nurse. The AR team decided to design a new status board, aiming to increase the nurses' and physicians' overview over the department, and their feeling of control over their activities. This expectation is consistent with an earlier study that reported improved efficiency of work and communication in the ED in the presence of an electronic whiteboard (France et al., 2005). After careful analysis of patient flows and information flows, and several meetings to discuss the analysis and decide on what to include on the board and how to organise it, the AR team designed a much larger and more inclusive status board. This board included patients' room number, name, time of arrival, chief complaint, triage code, designated nurse and physician, and information about patients' logistics, whether admission was required or an x-ray, CT or ultrasound, laboratory service, ECG, or a specialists' consultation. In addition, the board included details on GP-referred 
patients who were expected at the ED. To install the board, several things had to be moved around at the central nurse and physician station. To assess whether the new status board brought the expected improvements, the AR team sent out questionnaires to nurses and physicians, before and after the introduction of the new board. The questionnaire contained a number of items that respondents were asked to score on a 10 point scale, with 10 being highest. The results were positive: the nurses reported improved overview over the department, scoring on average 5.4 before and 7.7 after, and a feeling of improved control over their activities, scoring 6.9 before and 7.5 after $(p<0.05)$. The physicians reported improved scores as well, but these were not statistically significant. Of course, everyone at the study setting agrees that the status board should long have been replaced by an electronic version; but these innovations are often part of hospital-wide investments which are slow to diffuse to individual departments. Considering this, the ED managers expressed that the process analysis and design decisions made in this project have been worthwhile preparations.

Based on the results of the second project, a third, more involving project was started to investigate the effects of an advanced triage system (Cheung et al., 2002). A different AR team was formed, but the way of working was similar. Incorporating concepts of lean thinking (Womack and Jones, 1996), this project studied the idea of initiating diagnostic tests directly after patient triage, which promises an optimal use of patients' waiting time to see a physician, who will have test results available upon initial assessment. These ideas are part of a growing body of research that describes new ways of professional cooperation in the ED, including teamwork and nurse-initiated treatment (Risser et al., 1999; Chan et al., 2005; Patel and Vinson, 2005). At the study setting, the idea of advanced triage was radically different than the way nurses and physicians are used to cooperate; it has therefore evoked much discussion about the assumptions underlying their professional cooperation. The AR team has developed the new way of working, which the nurse and physician participants have tested in a number of shifts, allowing it to be further refined. A discrete-event simulation model, developed at the study setting, has been used in this AR project as a tool to gather evidence about the effects of the idea beforehand and to create a stimulus for change. Then, during 10 shifts, the nurses and physician have worked in the newly designed way for one large patient group. The results $(n=198)$ show a decrease in length of stay compared to a baseline measurement $(n=506)$ : 83 minutes compared to 97 ( $p<0.05$ ). These are promising results achieved by one nurse-physician team, of which many patients may benefit as triage is central to all emergency care processes. However, this new way of working is still far from being the standard operating procedure at the emergency department. The ED managers at the study setting are currently considering a follow-up for this project. 


\subsection{Conclusion and implications}

This article has proposed a methodology for research that studies theoretical concepts by testing them in real-life problem situations. Drawing on the research methodologies of action research and its developed form soft systems methodology, the article has described an approach to study and improve problematic flows of patients in emergency departments using operations management concepts. This focus on learning from experimenting in daily practice brings along some limitations. As the research is necessarily responsive to the particular research setting (Dick, 1993), it is highly local and context-bound. In addition, experimenting in daily operations is not as specific as would be when in a laboratory; action taken in the research always changes many things at same time, and the situation itself may also change independently of the research effort. Thus, the action mode of research is as far removed from achieving generalisability as possible when compared to other methods, such as surveys, interviews and laboratory experiments (McGrath, 1982). This is a fact that action researchers need to take explicitly into account when drawing conclusions about their work.

There are several ways to improve generalisability and also validity of action research efforts. The first is repetition of action research cycles at the research setting. Doing more projects may lead to observing similar phenomena, which then strengthens the results found. A second way is involving more than one group of participants and working with multiple researchers (Coughlan and Coghlan, 2002). More people implies more standpoints and thus reduced subjectivity. A third way is repetition of cycles across settings. Especially in the pursuit of developing theory as applicable technique, these repetitions may take on a life-cycle form: cooperation in initial settings may focus on exploration and narrowing down of scope, cooperation in further settings may start theory development, while research in final settings may test the emerging theories and express them as applicable technique (Westbrook, 1994). Finally, it is important to realise that action research and SSM are part of a research paradigm of its own (Susman and Evered, 1978). Susman and Evered regard this action research paradigm as existing next to the traditional positivist research paradigm; they consider neither to be better, but point out that researchers may select an appropriate paradigm based on the phenomena they wish to study and the conditions under which they are to be studied (ibid., p. 600). Whereas the positivist science model aims for broad, universal knowledge across populations, which is free of context, the action research paradigm considers cases or action research cycles to be sufficient sources of knowledge (ibid.). Checkland and Holwell (1998) help illustrate this realisation by recognising that particular results achieved in any action research cycle are always part of a larger context of learning: the participants involved always learn valuable lessons about the area of interest studied, and the framework of ideas used in the research always has larger implications. To illustrate, recall the emergency department examples in this article: though the research work in each of them appears highly specific, the 
implications are relevant across different settings because all emergency departments in the world perform radiology services, all emergency departments require some sort of central overview and most if not all use triage as initial function upon patient entry. The action research paradigm invites us to see beyond specific and different local details and look at greater implications to similar elements.

When looking beyond the specifics of problems in emergency care delivery, it appears that the research methodology outlined in this paper allows for use in many situations. Its foundations, action research and SSM, are especially suited for unstructured problem situations where creative, new solutions are required. The outlined methodology would seem a waste of energy and time in situations where solutions are already available, for it is highly demanding of both participants and researchers. Other methodologies are much better suited then. The action mode of research is worthy of being pursued further, in emergency departments and beyond.

\section{References}

Alvarez A, Centeno M (2000). Simulation-based decision support for emergency rooms systems. International Journal of Healthcare Technology and Management. 2:523-38.

Anderson G, Karlberg I (2001). Lack of integration, and seasonal variations in demand explained performance problems and waiting times for patients at emergency departments: a 3 years evaluation of the shift of responsibility between primary and secondary care by closure of two acute hospitals. Health Policy. 55:187-207.

Argyris C, Schön D (1996). Organizational learning II. Addison-Wesley, Reading.

Asplin B, Magid D, Rhodes K, Solberg L, Lurie N, Camargo C (2003). A conceptual model of emergency department crowding. Annals of Emergency Medicine. 42:173-80.

von Bulow I (1989). The bounding of a problem situation and the concept of a system's boundary in soft systems methodology. Journal of Applied Systems Analysis. 16:35-41.

Cardin S, Afilalo M, Lang E, Collet J, Colacone A, Tselios C, Dankoff J, Guttman A (2003). Intervention to decrease emergency department crowding: does it have an effect on return visits and hospital readmissions? Annals of Emergency Medicine. 41:173-85.

Chan T, Killeen J, Kelly D, Guss D (2005). Impact of rapid entry and accelerated care at triage on reducing emergency department patient wait times, lengths of stay, and rate of left without being seen. Annals of Emergency Medicine. 46:491-7.

Checkland P (1985). Achieving 'desirable and feasible' change: an application of soft systems methodology. Journal of the Operational Research Society. 36:821-31.

Checkland P, Holwell S (1998). Action research: its nature and validity. Systemic Practice and Action Research. 11:9-21.

Checkland P, Scholes J (1990). Soft systems methodology in action. John Wiley \& Sons, Chichester.

Cheung W, Heeney L, Pound J (2002). An advance triage system. Accident and Emergency Nursing. 10:10-6.

Coughlan P, Coghlan D (2002). Action research for operations management. International Journal of Operations \& Production Management. 22:220-40. 
Derlet R, Richards J (2000). Overcrowding in the nation's emergency departments: complex causes and disturbing effects. Annals of Emergency Medicine. 35:63-8.

Dick B (1993). You want to do an action research thesis? http://www.scu.edu.au/schools/gcm/ ar/art/arthesis.html.

Eden C, Huxham C (1996). Action research for management research. British Journal of Management. 7:75-86.

France D, Levin S, Hemphill S, Chena K, Rickard D, Makowski R, Jones I, Aronsky D (2005). Emergency physicians' behaviors and workload in the presence of an electronic whiteboard. International Journal of Medical Informatics. 74:827-37.

French W, Bell Jr C (1990). Organization development: behavioral science interventions for organization improvement. Prentice-Hall International, Englewood Cliffs, 4th edn.

Glouberman S, Mintzberg H (2001). Managing the care of health and the cure of disease. Part I: differentiation. Health Care Management Review. 26:56-69.

Ham C (2003). Improving the performance of health services: the role of clinical leadership. The Lancet. 361:1978-80.

Hayes R, Pisano G, Upton D, Wheelwright S (2005). Operations, strategy, and technology: pursuing the competitive edge. Wiley, Hoboken.

Hoffenberg S, Hill M, Houry D (2001). Does sharing process differences reduce patient length of stay in the emergency department? Annals of Emergency Medicine. 38:533-40.

Hopp W, Spearman M (2000). Factory physics. McGraw-Hill, Singapore, 2nd edn.

Irzik G (1985). Popper's piecemeal engineering: what is good for science is not always good for society. The British Journal for the Philosophy of Science. 36:1-10.

Kast F, Rosenzweig E (1972). General systems theory: Applications for organization and management. The Academy of Management Journal. 15:447-65.

Kelly A, Bryant M, Cox L, Jolley D (2007). Improving emergency department efficiency by patient streaming to outcomes-based teams. Australian Health Review. 31:16-21.

Kyriacou D, Ricketts V, Dyne P, McCollough M, Talan D (1999). A 5-year time study analysis of emergency department patient care efficiency. Annals of Emergency Medicine. 34:326-35.

Lindblom C (1959). The science of 'muddling through'. Public Administration Review. 19:79-88.

McGrath J (1982). Dilemmatics. the choice of research problems and dilemmas. In McGrath J, Martin J, Kulka R (eds.) Judgment calls in research, pp. 69-102, Sage, London.

Mintzberg H (1980). Structure in 5's: a synthesis of the research on organization design. Management Science. 26:322-41.

NHS Institute for Innovation and Improvement (2007). Improvement leader's guide to process mapping, analysis and redesign. http://www.institute.nhs.uk/index.php?option=com content\&task=view\&id=134\&Itemid $=35$.

Ondategui-Parra S, Gill I, Bhagwat J, Intrieri L, Gogate A, Zou K, Nathanson E, Seltzer S, Ros $P$ (2004). Clinical operations management in radiology. Journal of the American College of Radiology. 1:632-40.

Pasmore W (2001). Action research in the workplace: the socio-technical perspective. In Reason P, Bradbury H (eds.) Handbook of action research, pp. 38-47, Sage, London.

Patel P, Vinson R (2005). Team assignment system: expediting emergency department care. Annals of Emergency Medicine. 46:499-506. 
Pickard D, Bulbeck K, Woolmore A (2004). The complex causes of delays in a\&e. Accident and Emergency Nursing. 12:85-93.

Puente J, Gomez A, Parreno J, de la Fuente D (2003). Applying a fuzzy logic methodology to waiting list management at a hospital emergency unit: a case study. International Journal of Healthcare Technology and Management. 5:432-42.

Risser D, Rice M, Salisbury M, Simon R, Jay G, Berns S (1999). The potential for improved teamwork to reduce medical errors in the emergency department. Annals of Emergency Medicine. 34:373-83.

Rosmulder R, Krabbendam J, Luitse J (2006). Planning emergency patients: an attempt to change the nature of the emergency department. European Journal of Emergency Medicine. 13:377-9.

Saunders C (1987). Time study of patient movement through the emergency department: sources of delay in relation to patient acuity. Annals of Emergency Medicine. 16:1244-8.

Schein E (1987). The clinical perspective in field work. Sage Publishers, Newbury Park, CA.

Scott W (1998). Organizations: rational, natural, and open systems. Prentice Hall, Upper Saddle River, NJ, 4th edn.

Slack N, Chambers J, Johnston S (2004). Operations management. Prentice Hall, Harlow, 4th edn.

Spaite D, Bartholomeaux F, Guisto J, Lindberg E, Hull B, Eyherabide A, Lanyon S, Criss E, Valenzuela T, Conroy C (2002). Rapid process redesign in a university-based emergency department: decreasing waiting time intervals and improving patient satisfaction. Annals of Emergency Medicine. 39:168-77.

Susman G, Evered R (1978). An assessment of the scientific merits of action research. Administrative Science Quarterly. 23:582-603.

Thompson J (1967). Organizations in action: social science bases of administrative theory. McGrawHill, New York.

Venkatraman N, Henderson J (1998). Real strategies for virtual organizing. Sloan Management Review. 40:33-48.

de Vries G, Bertrand J, Vissers J (1999). Design requirements for health care production systems. Production Planning \& Control. 10:559-69.

Welch S, Jones S, Allen T (2007). Mapping the 24-hour emergency department cycle to improve patient flow. The Joint Commission Journal on Quality and Patient Safety. 33:247-55.

Westbrook R (1994). Action research: a new paradigm for research in production and operations management. International Journal of Operations \& Production Management. 15:6-20.

Womack J, Jones D (1996). Lean thinking. Simon \& Schuster, London. 


\section{6}

\section{Computer simulation within action research: a promising combination for improving healthcare delivery?}

R.W. Rosmulder, J.J. Krabbendam, A.H.M. Kerkhoff, C.M. Houser and J.S.K. Luitse

Systemic Practice and Action Research 2011, 1:1-16

This paper was presented in part at the 5th International Conference on the Management of Healthcare \& Medical Technology, Chicago, USA, 17-18 August 2006 


\begin{abstract}
Action research (AR) is increasingly being used to study the improvement of healthcare delivery. Ensuring that all the stakeholders in the AR are willing to take action, however, can be difficult. Especially in healthcare contexts, action plans may challenge the autonomy of the healthcare professionals and the positions of the different stakeholder groups. Does the use of computer simulation techniques within the AR promote action taking by all the stakeholders?

We performed an AR experiment with computer simulation in a university hospital's emergency department in the Netherlands. A simulation model was designed that replicated the actual healthcare delivery process in the study setting. Together with representatives from the medical and nursing staff and department management, we used the model to discuss improvement actions. The team designed an improvement scenario that fundamentally rearranged the task division between the physicians and the nurses. The promising projections in the simulation model motivated the team to try the scenario in reality. The implementation was successful, although it generated much concerns and discussion. The new task division successfully improved patient length of stay (LOS) in the ED. The results achieved by the single team turned out to have lasting effects on the other stakeholders in the ED. Our AR experiment with computer simulation promoted action taking by all the stakeholders. Computer simulation within $\mathrm{AR}$ is a promising combination for improving healthcare delivery.
\end{abstract}




\subsection{Introduction}

Action research (AR) is increasingly being used in healthcare settings. It is regarded as a promising way to study and improve the organisation and delivery of healthcare services (Nichols et al., 1997; Bridges and Meyer, 2000; Meyer, 2000; Fulop et al., 2001; Huxham, 2003; Hall, 2006; Walsh et al., 2008). In AR, practitioners and researchers collaborate to address problem situations and simultaneously produce new knowledge and better insights (Susman and Evered, 1978; Checkland, 1985; French and Bell Jr, 1990; Gill and Johnson, 1991; Westbrook, 1994; Eden and Huxham, 1996; Coughlan and Coghlan, 2002). The research takes place in an ongoing process of action planning, action taking and evaluating, leading to further action planning and so on. In this process, the researchers provide theoretical backgrounds and problem analysis approaches, while the practitioners contribute their knowledge and experience of what works in their setting.

In our own research program in healthcare technology management, we have encountered several difficulties practising AR (Rosmulder et al., 2006; 2009). These all seem to concentrate on the action taking phase. In more than one AR project, it turned out that one group of stakeholders was unwilling to try the suggested changes-despite extensive efforts to involve all of them in the change process. As the contribution of all the groups was essential to make the change happen, the AR project ended at the action taking phase. A promising improvement idea then failed to be tried and learned from. The literature provides several explanations why changing the delivery of healthcare is so hard to achieve. First, the organisation of healthcare delivery is outside the physicians' main scope of interest. Their job is to concentrate on medical interventions and individual patients (Glouberman and Mintzberg, 2001a). Second, the division of tasks in healthcare is strictly separated between different groups of professionals. The physicians manage the cure, the nurses manage the care and the administrators manage the control in the hospital (Mintzberg, 1997; Glouberman and Mintzberg, 2001b). Proposing changes to the healthcare delivery implies challenging the established positions of the stakeholder groups (Mitchell et al., 1997) and the autonomy of the individual healthcare professionals (Fitzgerald and Teal, 2003). Third, AR combines research and action in an ongoing process of action planning, action taking and evaluating (Eden and Huxham, 1996). This kind of continuous experimentation runs counter to the common approach in medicine of first doing research and then implementing changes with a solid evidence base only (Walshe and Rundall, 2001). Considered together, all three explanations provide the different stakeholder groups with a reason to withdraw their cooperation at any time: "we are not interested, we feel that our professional position and autonomy is threatened, and we are rightly worried that our patients may be at risk".

Searching for a way to promote action taking by all the stakeholders, we decided to use computer simulation techniques. In a computer simulation model, users replicate the dynamic behaviour of a system on the computer. The computer can then project 
the effects of different improvement scenarios without changing the actual system. Currently available computer simulation software is user-friendly and robust, making it easy to apply for change-oriented purposes. We planned to use computer simulation within the AR in two steps. First, to design a computer model together with the stakeholders in the AR. The model should replicate the actual healthcare delivery process in their work setting. Second, to explore improvement scenarios with the stakeholders and project the effects in the model. We anticipated the following outcomes:

1. The use of the simulation model invites all of the stakeholders to think in terms of organising healthcare delivery. It forces them to jointly think about and discuss the current way of working. This promotes shared understanding of the problem situation (Rouwette et al., 2002; Kerkhoff, 2006) and involvement in the change process (Richardson and Andersen, 1995; Lane et al., 2003; den Hengst and de Vreede, 2004; Scholl, 2004).

2. The ability of the simulation model to project the effects of changes before implementation creates a kind of evidence base that better fits the medical mindset (Shojania and Grimshaw, 2005; Neuhauser and Diaz, 2007; Leykum et al., 2009). Promising projections motivate the stakeholders to take action in the real-life situation.

To our knowledge, the idea of using computer simulation to facilitate AR is relatively new and little reported in the literature. We have found no studies that describe the outcomes of research projects in which simulation models were used for change. This article describes an AR experiment in which computer simulation was used to improve healthcare delivery. An improvement scenario was explored that presented a fundamental change to the task division between medical and nursing professionals. Our research question was: does the use of computer simulation promote action taking by all the stakeholders involved in the AR?

\subsection{Methods}

\subsubsection{Study setting and research situation}

This study was carried out in the emergency department (ED) of a 1,000-bed university hospital in the Netherlands. The ED is designated as level-one trauma centre and receives about 32,000 patients per year. Because of increasing patient visits, long waiting times for patients and problematic availability of ward beds, improving ED patient flow is currently a main hospital policy objective. Unsatisfied with the improvisational nature of problem solving in the hospital (see Spear, 2005), the medical director of the ED expressed a desire for scientific analysis and theory about organising care processes. Collaboration in a doctoral research project was established with an industrial engineering department of a technical university. From the standpoint of 
the university, this presented a unique opportunity to investigate the benefits of the new approaches to operations in healthcare. Based on unsuccessful implementation of process improvement in an exploratory study (Rosmulder et al., 2006), it was decided to proceed in an AR mode (Rosmulder et al., 2009). A traditional, mechanistic-oriented AR approach was chosen (Coghlan, 2003), in which researchers and members of the study setting worked together to address problematic patient flow in the ED. The traditional approach was suitable because the prime focus of the research was to address problem situations experienced by the organisation, as a social system (Checkland and Scholes, 1990; French and Bell Jr, 1990). The focus was not on the personal and professional development of the individual stakeholders involved in the AR, as is custom in more modern, organistic-oriented approaches (Coghlan, 2003).

\subsubsection{The subject of the simulation model}

The researchers used a transformation-process perspective as the theoretical basis for modelling patient care, see figure 6.1. A transformation process changes inputs like raw materials, customers, and information into outputs: products and services. Such a process consists of interrelated operating activities that are needed to complete the transformation (Miller and Rice, 1967), and transforming resources that perform or enable the operating activities (Slack et al., 2004). These include people, machines, and facilities. It has been demonstrated that smarter configurations of transforming resources and operating activities can improve the performance of transformation processes in terms of speed, cost, quality, and efficiency in various industries (Hayes et al., 2005). Improvements were achieved, for example, by removing all operating activities that did not add value for customers, and modifying the remaining activities to proceed without interruption (the concept of lean manufacturing, see Womack and Jones 1996). When we now consider an ED, the transformation process involves turning patients arriving in acute situations into patients recovering from treatment or admitted to the hospital. Medical and nursing staff use treatment rooms, equipment and materials to perform physical examinations, X-rays, and various kinds of treatment. Patient symptoms designate the exact combination of operating activities that is needed (Thompson, 1967); the healthcare professionals decide how, when, and in which order these activities are performed. Several applications of the lean manufacturing concept in emergency care delivery processes have demonstrated promising results (Simmons, 2003; King et al. 2006; Dickson et al. 2009a; Dickson et al. 2009b).

\subsubsection{Strategy to design and use the simulation model}

The researchers realised that the design of the simulation model would play a crucial role in the AR experiment. To promote their willingness for action taking, all the stakeholders in the AR should accept the model and have confidence in its structure and outcomes (Richardson and Andersen, 1995; Lane et al., 2003; Scholl, 2004). It was therefore essential that the design of the simulation model and the development 


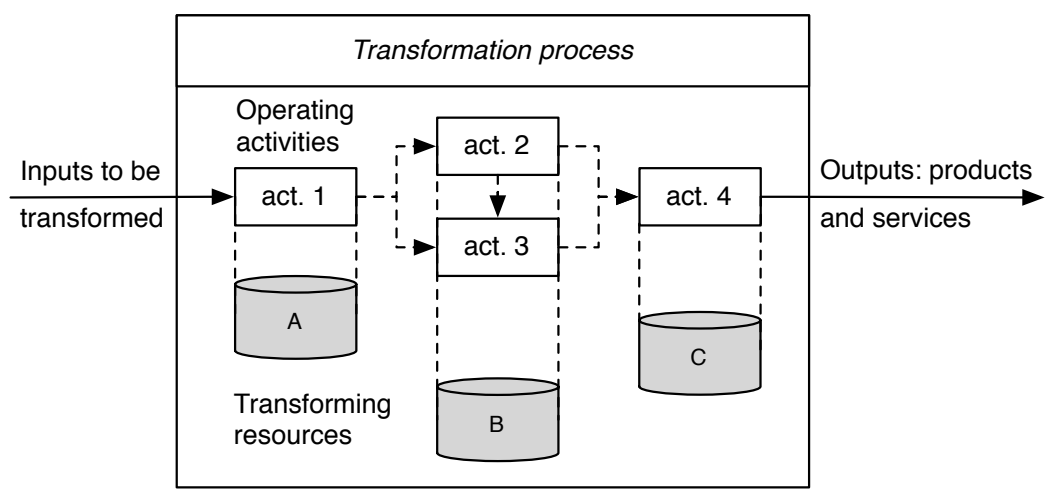

Figure 6.1: A model of a transformation process

of the improvement scenarios was carried out in close cooperation with the members of the study setting. The researchers planned the following course of action:

1. Convince the key stakeholder to use computer simulation. The medical director of the ED is a key stakeholder for research access and initiation of change. Convince this person to use computer simulation for improvement based on the transformation-process perspective. Together, define the primary outcome measure of the simulation model.

2. Make a conceptual model of the care delivery process. Collaborate with the key stakeholder to analyse the current care delivery process in the ED. Describe the configuration of operating activities and transforming resources in a conceptual model. Share this with other stakeholders, i.e. members from the medical and nursing staff, for approval and modification.

3. Build the computer model. Make a computer simulation model based on the conceptual model. This requires data or assumptions about the duration and variability of operating activities, the number and availability of transforming resources, the arrival rates of patients and the combinations of activities they require. Acquire these data from the work setting and share the assumptions for approval and modification. Verify if the simulation model operates as intended and assess the accuracy of model output. Present the final model to the key stakeholder and the members from the medical and nursing staff for evaluation of its dynamic behaviour. Establish that they understand the general modelling assumptions and accept the model as a valid representation of the actual working situation.

4. Explore improvement scenarios. Invite representatives from the medical and nursing staff to join the collaboration with the key stakeholder. Together, explore promising alternatives to the current configuration of operating activities and 
transforming resources. Project the effects of the process improvement scenarios in the simulation model.

5. Apply a promising scenario. If all of the stakeholders consider an improvement scenario desirable and feasible to implement (Checkland, 1985), take the necessary actions to realise it. Monitor possible unintended effects with regard to patient safety.

\subsubsection{Evaluation of the outcomes}

This study involved an experiment to investigate if the use of computer simulation promoted action taking by all the stakeholders involved in AR in a healthcare setting. The ideal outcome of the experiment would be that the stakeholders did indeed take action to realise the improvement scenario, or indicate a willingness to support it in other ways. And if action was in fact taken, that the outcomes of the healthcare delivery process would improve as projected by the model. This required a measurement of the model's primary outcome measure before and after the experiment.

\subsection{Execution of the experiment}

\subsubsection{Preparations; defining the primary outcome measure}

The researchers met with the medical director to discuss the idea of using computer simulation for process improvement. This idea appealed to him, because of the ability to project the effects of changes beforehand. The researchers explained their perspective, or worldview (Checkland and Scholes, 1990), on the subject of the simulation model. He agreed to use the transformation-process perspective because it captured the essence of the care delivery. A team was formed to design the simulation model, which included the medical director of the ED, the doctoral student/action researcher, a professor in operations management, a professor in operations research, and a MSc student responsible for model programming. The design team decided to program the model with so-called discrete-event simulation software. Discrete-event simulations of care delivery processes in EDs are quite common (Saunders et al., 1989; Huddy et al., 1999; Connelly and Bair, 2004; Hung et al., 2007). The researchers used the EMPlant (Tecnomatrix) software package, which is one of the scientific and educational standards for simulating production processes. The medical director of the ED considered long waiting times for patients as the most urgent problem to be addressed. The design team therefore defined patient length of stay (LOS) as the primary outcome measure. Patient LOS is the total time patients spend in the ED, which consists of time during which operating activities are performed and waiting time. It is one of the key outcome measures for patient satisfaction and process efficiency in the medical literature. 


\subsubsection{Making the conceptual model}

The action researcher and the MSc student set out to make a conceptual model of the care delivery process. They joined the medical and nursing staff to observe their activities and understand the way of working. They also accompanied patients during their stay in the ED. There are several patient populations with different processing in Dutch EDs. After discussing the initial findings, the design team decided not to include all patient populations in the conceptual model of the ED. The model's scope was defined around the largest patient group in the ED, the self-referred patients. This group made up 60 percent of the total patient population. The configuration of transforming resources assigned to self-referred patients was simple: there was always one staff physician, one emergency nurse, and up to five treatment cubicles available $24 \mathrm{~h}$ per day. The physician and nurse were not responsible for treating other emergency patients, and the cubicles were assigned for their use exclusively. The thus limited scope made the design of the simulation model less complex, and it also facilitated the experiment by restricting the number of stakeholders involved. The student made a flowchart of the healthcare delivery process for the self-referred patients, see figure 6.2. The flowchart was placed in the refreshment room of the ED, with an invitation to everyone to comment. The final version was completed after several modifications.

\subsubsection{Designing the computer model}

The design team used the flowchart to define eight different patient flows that would form the basis of the simulation model, see figure 6.3. The flows resulted from combining three characteristics relating to patients' use of transforming resources. First, arrival: self-referred patients who walk into the ED take a seat in the waiting area; patients arriving by ambulance are immediately assigned to a treatment cubicle. Second, need for diagnostics: if patients require diagnostics such as X-rays or laboratory examinations, processing and transport time are consumed. Third, departure: most self-referred patients are discharged and leave the ED, but some require additional treatment and/or admission. These patients are transferred to residents in the ED, which involves waiting time and a relocation.

The design team defined a basic sequence of operating activities for each of the patient flows. A task list was programmed that triggered the correct sequence in response to the arrival of a patient. It assigned transforming resources to activities in real time, allowing for immediate changes in priority. Two sources ( $n=666$ and $n=323$ ) from the study setting were used to simulate the arrival rates of patients. Exponential distributions (Law and Kelton, 2000) were created that captured the natural variability in the patient arrival rate throughout the day. The durations of the operating activities were modelled primarily with gamma distributions (Winston, 1994). The student performed several time study observations to gather the required data ( $n>20$ for each activity). The medical and nursing staff were asked to estimate 


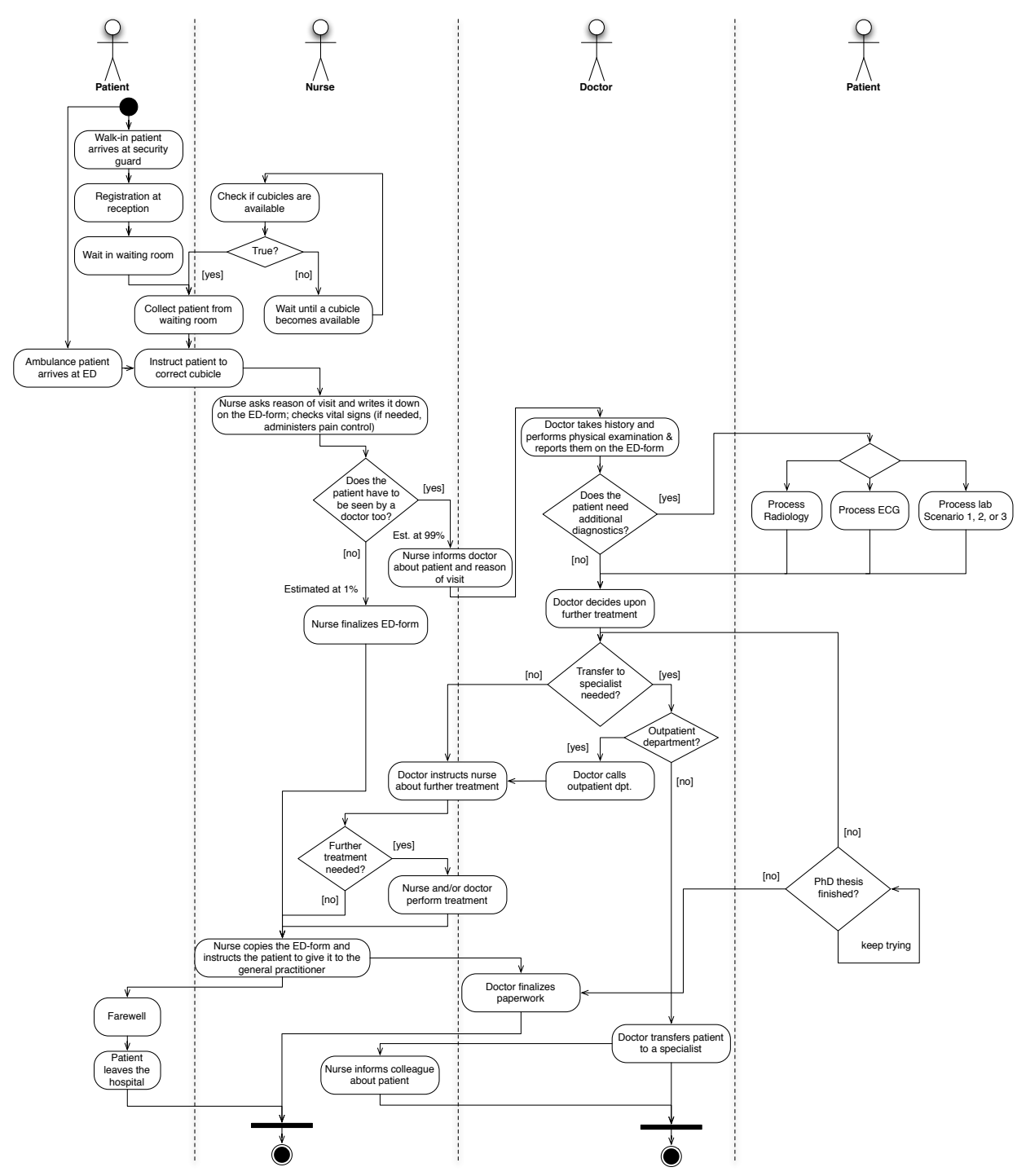

Figure 6.2: Care delivery flowchart for self-referred patients in the ED 


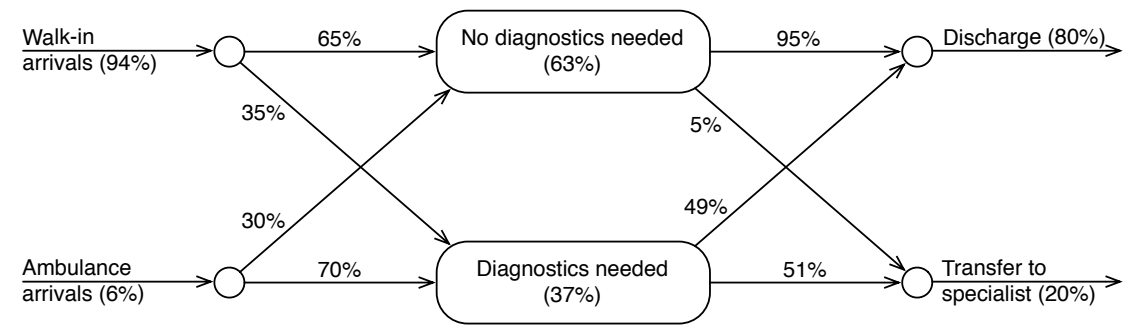

Figure 6.3: Flows of self-referred patients through the emergency department, based on resource use

the shortest, longest, and most occurring durations for activities that proved too complex and time-consuming to observe. Existing sources could be used for radiology and laboratory turnaround times ( $n=91$ and $n=285$ ).

Elements of the modelled working order were checked by the medical and nursing staff to ensure a close resemblance to daily practice. All program modules were documented as flowcharts with explanatory comments explaining the logic. To verify that the programmed code operated as intended, the student performed sensitivity analyses (Sargent, 1992). The robustness of the programming was stresstested under varying numbers of operating resources and different patient arrival rates. In addition, distributions for operating times and arrival rates were replaced with mean values. Inconsistencies that occurred during the analyses were corrected. To assess the accuracy of the model, over 40,000 patient visits were simulated using the so-called replication-deletion method (Law and Kelton, 2000). The average patient LOS from these data was compared with the most recent source of data available in the ED $(n=506)$, see table 6.1. The model overestimated the overall average patient LOS with 26 min (35 percent). Average LOS for walk-in patients was overestimated while it was underestimated for ambulance arrivals. Unfortunately, comparison was hampered because of inconsistencies between the data sources, so that several estimates were needed.

The design team presented the final working model to the members of the study setting. In an animation, the ED nurses and physicians could see their simulated counterparts moving across the model's visual interface. The exact department layout was used, see figure 6.4. The medical and nursing staff were asked to evaluate the animated representation for accuracy, completeness and specificity to setting. They had not previously evaluated the model's dynamic behaviour. The medical and nursing staff judged that the displayed movements and working order accurately represented the actual working situation. They responded enthusiastically to the presentation and brought up several improvement suggestions. There were no arguments about the design of the model. The design team concluded that the model's performance was acceptable, even though output accuracy could be improved. The work of this team was now finished. 
Table 6.1: Actual and modelled mean lengths of stay (min) compared

\begin{tabular}{lrcc}
\hline Flows (in order of largest size) & $\begin{array}{r}\text { Modelled } \\
\text { LOS }\end{array}$ & $\begin{array}{r}\text { Actual } \\
\text { LOS }\end{array}$ & Difference \\
\hline 1. Walk-in, no diagnostics, discharge & 80 & 56 & 24 \\
2. Walk-in, diagnostics, transfer & 135 & $99 *$ & 36 \\
3. Walk-in, diagnostics, discharge & 145 & 105 & 40 \\
4. Walk-in, no diagnostics, transfer & 74 & $26 *$ & 48 \\
5. Ambulance, diagnostics, transfer & 92 & $101 *$ & -9 \\
6. Ambulance, diagnostics, discharge & 102 & 118 & -16 \\
7. Ambulance, no diagnostics, discharge & 36 & 6 & -32 \\
8. Ambulance, no diagnostics, transfer & 28 & $50 *$ & -22 \\
Overall & 100 & $74(*)$ & $26(*)$ \\
\hline
\end{tabular}

* indicates estimate

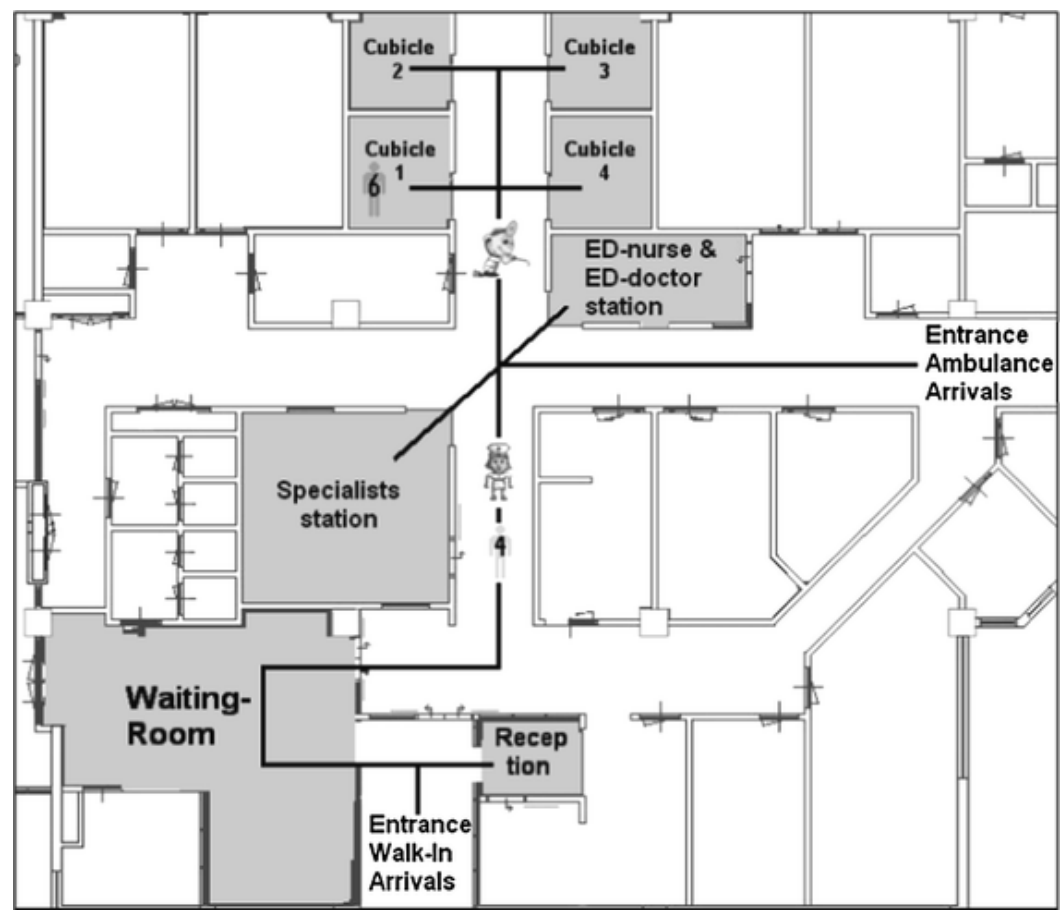

Figure 6.4: Simulation model screenshot. NB: It displays a nurse in the hallway, taking a patient of flow 4 into a treatment room. The black lines indicate paths along which nurses, physicians and patients move 


\subsubsection{Exploring improvement scenarios}

At this point in the AR experiment, a team of researchers and the medical director of the ED had designed a simulation model that was enthusiastically received and accepted by all stakeholder groups as valid. It was now time to start using the model for action taking. The action researcher formed a new team with department management and representatives from the medical and nursing staff who were enthusiastic about collaborating in the research process. This "action team" included a staff physician, two emergency nurses, the medical director and the head nurse of the ED, the doctoral student/action researcher and also a BSc student who programmed the improvement scenarios in the simulation model. First, and most naturally, the action team talked about general improvement scenarios that involved adding transforming resources such as extra physicians and nurses, and reducing diagnostic turnaround times. The effects were calculated in the model, projecting reductions in patient LOS. The team especially appreciated having this predictive functionality of the simulation model at hand. However, implementation of these scenarios was deemed unfeasible by department management for economic reasons. The team then studied the model's animation of the care delivery process for self-referred patients. The model showed repeating waiting lines for patients during their stay in the ED. Discussing about ways to remove some of these waiting lines, the team observed that the physician and the nurse carried out their activities in an individual and successive fashion. This needlessly interrupted the patients' care delivery process. The staff physician and the emergency nurses realised that they could carry out their activities more in parallel; they could change their existing task division to improve the patients' care delivery. The team had learned to see that process improvements were possible without adding resources. This direction was certainly deemed desirable.

The team redesigned the professional task division for the self-referred patient group (in terms of "The Subject of the Simulation Model" section: they altered the configuration of transforming resources and operating activities). In the new situation, the triage nurse, who assesses the urgency of emergency patients upon arrival, would also initiate diagnostics such as laboratory examinations and X-rays. In the usual situation, diagnostics were only initiated by staff physicians. This occurred much later in the care delivery process: only after the patient was triaged, then waited for an available treatment room, and finally was seen by the physician. By bringing operating activities forward, the new task division promised to better utilise patient waiting time and thus reduce patient LOS. The effects of the improvement scenario were projected in the simulation model; with some effort, the BSc student altered the programming so that X-rays and laboratory examinations were initiated in the model directly after the triage. The scenario projected a promising 24-min reduction (24 percent) of average patient LOS, see table 6.2. The results were even more promising for patients who required diagnostics. Motivated by this outcome, the action team proceeded to see if the scenario was feasible in practice. 
Table 6.2: Modelled average patient length of stay (min) compared, model baseline to scenario; LOS = length of stay

\begin{tabular}{lr}
\hline Group & Modelled LOS \\
\hline Baseline, overall & 100 \\
Scenario, overall & 76 \\
Difference & -24 \\
Baseline, no diagnostics & 78 \\
Scenario, no diagnostics & 58 \\
Difference & -20 \\
Baseline, diagnostics & 135 \\
Scenario, diagnostics & 102 \\
Difference & -33 \\
\hline
\end{tabular}

\subsubsection{Implementing the scenario}

The action team prepared a pilot for the improvement scenario. A protocol was made that the triage nurse could use to initiate diagnostic examinations for the most common patient conditions. It was also agreed that the staff physician would provide quick assistance to the nurse in case of doubt. The emergency nurses and the staff physician then successfully piloted the new task division over two shifts. In their experience, the improvement scenario was feasible and beneficial for patient LOS. As a response, however, other staff physicians and members of the radiology department expressed concerns. They had seen or heard that the triage nurse had carried out an activity that was normally performed by the medical staff. This fundamentally changed the generally accepted professional task division in the ED, which had remained virtually unaltered since the hospital's opening in 1981. In their opinion, the initiation of diagnostics by triage nurses threatened the quality of patient care: it could possibly produce unnecessary diagnostic examinations and inadequate imaging requests.

The action team decided to integrate the concerns and perform a real experiment with more representatives from the medical and nursing staff. They asked two of the staff physicians who had expressed concerns and several previously uninvolved emergency nurses to participate. Ten experimental shifts (day and evening) with the new task division were scheduled. Outcome data would be collected on patient LOS and the quality of care. After two of these shifts were completed, a large difference occurred in the collaboration by the physicians. The newly joined doctors continued to bring up concerns and were generally unwilling to try the new way of working. The experiment was halted and the medical staff was gathered to discuss the concerns together with the medical director of the ED and the action researcher. In the meeting, it turned out that only the staff physician on the action team really wished to adopt the improvement scenario. His colleagues refused further participation, expressing a heartfelt "initiating diagnostics belongs to our responsibilities, the nurses cannot 
Table 6.3: Actual average patient length of stay ( $\mathrm{min}$ ) before and during the experiment; LOS = length of stay

\begin{tabular}{lrrr}
\hline Group & Actual LOS & $p$ & $n$ \\
\hline Pre intervention, overall & 97 & & 506 \\
Post intervention, overall & 83 & & 198 \\
Difference & -14 & 0.05 & \\
Pre intervention, no diagnostics & 64 & & 309 \\
Post intervention, no diagnostics & 52 & & 105 \\
Difference & -12 & 0.03 & \\
Pre intervention, diagnostics & 148 & & 197 \\
Post intervention, diagnostics & 121 & & 93 \\
Difference & -27 & 0.02 & \\
\hline
\end{tabular}

properly do it". Despite efforts of the action team to further involve the physicians in the experiment and stress the potential benefits to patient care, their standpoint remained.

The action team realised that the AR experiment could not proceed in its original form: not all of the stakeholders were willing to take action directly. The team decided to continue in a more indirect way: the one staff physician and the nurses would complete the experiment. If they could achieve the projected reduction of patient LOS while maintaining the quality of care, then these results could help promote the willingness of the other stakeholders. Ten new experimental shifts were scheduled and then implemented without problems. A total of 198 self-referred patients were included in the experiment. Table 6.3 shows the average patient LOS during the experiment and before the experiment (based on the source used to assess the accuracy of the simulation output). The action team realised a 14-min overall reduction (14 percent) of average patient LOS. The reduction was $27 \mathrm{~min}$ for self-referred patients who required diagnostics. This confirmed the trend projected by the simulation model, although the improvement was less than predicted. The outcome data confirmed that the quality of care was maintained. In the experience of the staff physician and the nurses on the action team, the care delivery process was faster and more efficient. They also perceived the new task division as more intensive and interactive compared to the usual situation. For more details on the methods of measurement, see Rosmulder et al. (2010).

\subsection{Results}

In this study, an AR experiment with computer simulation was performed to improve healthcare delivery for self-referred patients in a university hospital's emergency department. A team of researchers and the medical director of the emergency department 
designed a computer simulation model using locally available data and several straightforward observations and assumptions. All important modelling decisions were shared with the medical and nursing staff in the study setting. The model was accepted by all stakeholder groups as a valid representation of the actual work situation. A second team, consisting of the action researcher, the ED medical director and head nurse, a staff physician and two emergency nurses, used the simulation model to explore several improvement scenarios. Without any problems, this action team designed a scenario that fundamentally rearranged the task division between the physician and nurses. Based on the promising reduction of patient LOS projected by the simulation model, the scenario was brought into practice. This generated a lot of discussion and concerns, especially from other staff physicians in the ED. Convinced of the positive effects of the new task division, the action team proceeded to implement the improvement scenario over a number of experimental shifts. The outcome data of the successful implementation demonstrate that patient LOS was reduced and the quality of care was maintained. The simulated projections were confirmed to a large extent. The action team concluded that the improvement scenario could improve the delivery of patient care for more than 20,000 self-referred patients each year.

Up to the phase of scenario implementation in the AR experiment, the collaboration between the researchers and practitioners had been relatively free of engagement. This changed abruptly when the action team piloted the new task division. What had started as projections in a distant computer model now became directly visible on the work floor. In their enthusiasm to take action, the action team had underestimated how fundamentally different the new task division was for their colleagues-who had not shared in the exploration of improvement scenarios. This elicited discussions among the physicians, nurses and managers about the values behind the process of delivering healthcare in the ED. Especially the other staff physicians were challenged in their professional position and autonomy. They remained unwilling to further participate in the experiment. This clearly demonstrates how easily proposed changes to the healthcare delivery can be halted in the AR.

With time, the results achieved by the single action team turned out to have lasting effects on the other stakeholders in the ED. When the results of the experiment were presented to the medical and nursing staff, the emergency nurses responded enthusiastically. Several of them became inspired to take spontaneous action and tried the new protocol in the triage on their own initiative. They indicated that it made the nursing task more interesting. The nursing staff in general supported the improvement scenario. The results of the experiment made a number of staff physicians change their standpoint about the new task division. This process took several years: at the time of the experiment, their standpoint was that all diagnostic examinations could be initiated only after a physician had seen the patient; later, they indicated that the nurses could initiate some diagnostics at the triage to speed up the care delivery. The majority of the medical staff became supportive of the new task division, which was also a result of personnel changes. As a follow-up from the experiment, the physicians and nurses implemented regular staff meetings to discuss their professional 
collaboration. The medical director and head nurse of the ED gained sufficient insights from the experiment to put department-wide implementation high on the improvement agenda. They had learned that the new task division reduced waiting time for patients, improved teamwork and efficiency for the professionals, and maintained the quality of care. We conclude that in this single AR experiment with computer simulation, the willingness for action taking by all the stakeholders was promoted-albeit in different forms.

\subsection{Discussion}

To action researchers (with or without an industrial engineering background), the use of computer models is a way to involve practitioners in the research process. Our study demonstrated that if the researchers program the model and share the most important modelling decisions, then the healthcare professionals and managers will confide in the outcomes and projections of the simulation model. It was not complicated to design a simulation model for change-oriented purposes. The use of existing sources of data and several straightforward observations and assumptions was sufficient. The decision to limit the scope of the simulation model proved useful for keeping the model design simple and the change process manageable. We found it important to separate the responsibilities for programming the model and supervising the change process. The modeller's primary concern is the valid representation of reality, the action researcher's primary concern is the creative group process of using the model to improve practice. The two roles of facilitator and modeller are distinct and need to be embodied by different individuals (Vennix et al., 1992).

The members of the study setting who participated in the action team indicated several reasons why the experiment succeeded. The model provided one communication channel for the different groups to talk about the organisation of their activities to deliver patient care. This contrasted to the traditional way of discussing healthcare delivery from a medical, nursing or management perspective only. The exploration of improvement scenarios with the action researcher gave the team members a focus of what could be improved. The simulated projections provided an evidence base of what would and would not work under the local conditions in the study setting, which in turn motivated the staff physician and emergency nurses to take action. This shared process of consensus-building toward feasible action proved essential in the experiment, and is something that nicely fits with the Dutch cultural characteristics. A final reason for the successful implementation was the fact that the new task division could be safely and easily tried within the established general way of working. This model line approach (Spear, 2005) was a useful way of organising the improvement of healthcare delivery within the department.

A question that rises is whether the measured improvement of patient LOS did not actually result from the experimental situation itself (Hawthorne effect) or from the deliberate selection of participants who were already enthusiastic. There are three 
counter-arguments that can be brought up. First, the creation of an experimental situation alone does not promote willingness of the different stakeholders to engage in action taking. With our efforts to involve all stakeholders, we managed to achieve change with one team only-those who were involved in exploring improvement scenarios. Second, the outcome data demonstrate that the intervention to initiate diagnostic examinations earlier on explains most of the improvement in patient LOS. The most compelling argument however is the following. The improvement scenario that we developed in this study is not original: the intervention of initiating diagnostics at triage is known as "advanced triage" (Cheung et al., 2002; Seguin, 2004; Wiler et al., 2010). Several countries including the United States have already successfully adapted this way of working (Hoffenberg et al., 2001; Wiler et al., 2010). In the process of developing it, the members of the study setting learned that the improvement scenario already existed in the international context. If the managers or the researchers had directly proposed to implement this scenario from the beginning, the healthcare professionals would most likely not have cooperated. The advanced triage challenged their assumed positions too much. The use of the computer in the change process made joint discussions about the professional task division possible, which was needed to allow implementation of the scenario.

To our knowledge, this study was the first application of computer simulation that explicitly aimed to change everyday healthcare practice. Simulation studies have concentrated primarily on the accuracy of the model output and on policy recommendations based on simulated projections (e.g. Saunders et al., 1989; Connelly and Bair, 2004; Hung et al., 2007; VanBerkel and Blake, 2007). It remains unknown whether recommendations were in fact implemented to improve the real-life situation, and whether the results were successful (Scholl, 2004). A recent literature review reports that computer simulation models are hardly used in healthcare to support management decision making (van Sambeek et al., 2010). Other relevant work studied collaborative model design without the change component (Lane et al., 2003), or was performed outside of the healthcare sector (Vennix et al., 1996; den Hengst and de Vreede, 2004).

Our promising investigation merits further research on the use of computer simulation models to facilitate AR in emotionally-charged and risk-filled contexts such as healthcare. The experiment in this study can be repeated on a larger scale, with a random selection of participants into experimental and control groups. It is also worthwhile to involve more (teams of) stakeholders from the beginning in the exploration of improvement scenarios. Our decision to do this with only a single action team could have reduced the cooperation with others later on. In general, healthcare studies with computer simulation techniques should be more aimed at improving practice. The use of simulation software that is especially oriented toward healthcare settings is probably a good choice for this. We used a package that was a standard for simulating transformation processes in industry. In addition to healthcare-friendly software, learning to use flowcharting techniques can also help healthcare professionals and managers to better describe and understand the delivery of care. More research 
is finally needed on the socio-psychological processes taking place when groups of professionals redefine their ways to divide and coordinate tasks, and especially on how these can be influenced.

\section{Acknowledgments}

We thank Jacqueline van Schuppen, Matthieu van der Heijden, Renée te Poele, and Janwillem Pezij for contributing to the research. We also wish to thank Paul Coughlan and David Coghlan for providing helpful comments on earlier versions of the manuscript.

\section{References}

Bridges J, Meyer J (2000). Older people in accident and emergency: the use of action research to explore the interface between services in an acute hospital. Educational Action Research. 82:277-89.

Checkland P (1985). Achieving 'desirable and feasible' change: an application of soft systems methodology. Journal of the Operational Research Society. 36:821-31.

Checkland P, Scholes J (1990). Soft systems methodology in action. John Wiley \& Sons, Chichester.

Cheung W, Heeney L, Pound J (2002). An advance triage system. Accident and Emergency Nursing. 10:10-6.

Coghlan D (2003). Practitioner research for organizational knowledge: mechanistic- and organistic-oriented approaches to insider action research. Management Learning. 34:451-63.

Connelly L, Bair A (2004). Discrete event simulation of emergency department activity: a platform for system-level operations research. Academic Emergency Medicine. 11:1177-85.

Coughlan P, Coghlan D (2002). Action research for operations management. International Journal of Operations \& Production Management. 22:220-40.

Dickson E, Anguelov Z, Vetterick D, Eller A, Singh S (2009a). Use of lean in the emergency department: a case series of 4 hospitals. Annals of Emergency Medicine. 54:504-10.

Dickson E, Singh S, Cheung D, Wyatt C, Nugent A (2009b). Application of lean manufacturing techniques in the emergency department. Journal of Emergency Medicine. 37:177-82.

Eden C, Huxham C (1996). Action research for management research. British Journal of Management. 7:75-86.

Fitzgerald J, Teal G (2003). Health reform, professional identity and occupational sub-cultures: the changing inter-professional relations between doctors and nurses. Contemporary Nurse. 16:9-19.

French W, Bell Jr C (1990). Organization development: behavioral science interventions for organization improvement. Prentice-Hall International, Englewood Cliffs, 4th edn.

Fulop N, Allen P, Clarke A, Black N (eds.) (2001). Studying the organisation and delivery of health services: research methods. Routledge, London.

Gill J, Johnson P (1991). Research methods for managers. Chapman, London.

Glouberman S, Mintzberg H (2001a). Managing the care of health and the cure of disease. Part I: differentiation. Health Care Management Review. 26:56-69. 
Glouberman S, Mintzberg H (2001b). Managing the care of health and the cure of disease. Part II: integration. Health Care Management Review. 26:70-84.

Hall J (2006). Professionalizing action research - a meaningful strategy for modernizing services? Journal of Nursing Management. 14:195-200.

Hayes R, Pisano G, Upton D, Wheelwright S (2005). Operations, strategy, and technology: pursuing the competitive edge. Wiley, Hoboken.

den Hengst M, de Vreede G (2004). Collaborative business engineering: a decade of lessons from the field. Journal of Management Information Systems. 20:85-113.

Hoffenberg S, Hill M, Houry D (2001). Does sharing process differences reduce patient length of stay in the emergency department? Annals of Emergency Medicine. 38:533-40.

Huddy J, McKay J, Culp K (1999). Computer simulation: making better operational and architectural ED design decisions. Journal of Emergency Nursing. 25:307-10.

Hung G, Whitehouse S, O’Neill C, Gray A, Kissoon N (2007). Computer modeling of patient flow in a pediatric emergency department using discrete event simulation. Pediatric Emergency Care. 23:5-10.

Huxham C (2003). Action research as a methodology for theory development. Policy \& Politics. $31: 239-48$.

Kerkhoff A (2006). Interactief ontwerpen van beleid in de openbare gezondheidszorg. Budel, Damon.

King D, Ben-Tovim D, Bassham J (2006). Redesigning emergency department patient flows: application of lean thinking to health care. Emergency Medicine Australasia. 18:391-7.

Lane D, Monefeldt C, Husemann E (2003). Client involvement in simulation model building: hints and insights from a case study in a london hospital. Health Care Management Science. 6:105-16.

Law A, Kelton W (2000). Simulation modelling and analysis. McGraw-Hill International, Arizona, 3rd edn.

Leykum L, Pugh J, Lanham H, Harmon J, McDaniel Jr R (2009). Implementation research design: integrating participatory action research into randomized controlled trials. Implementation Science. 4:69.

Meyer J (2000). Using qualitative methods in health related action research. British Medical Journal. 320:178-81.

Miller E, Rice A (1967). Systems of organization: the control of task and sentient boundaries. Tavistock Publications, London.

Mintzberg H (1997). Toward healthier hospitals. Health Care Management Review. 22:9-18.

Mitchell R, Agle B, Wood D (1997). Toward a theory of stakeholder identification and salience: defining the principle of who and what really counts. Academy of Management Review. 22:85386.

Neuhauser D, Diaz M (2007). Quality improvement research: are randomised trials necessary? Quality \& Safety in Health Care. 16:77-80.

Nichols R, Meyer J, Batehup L, Waterman H (1997). Promoting action research in healthcare settings. Nursing Standard. 11:36-8.

Richardson G, Andersen D (1995). Teamwork in group model building. System Dynamics Review. 11:113-37. 
Rosmulder R, Krabbendam J, Kerkhoff A, Luitse J (2009). Action research and soft systems methodology for studying problems in emergency care delivery. International Journal of Healthcare Technology and Management. 10:289-302.

Rosmulder R, Krabbendam J, Kerkhoff A, Schinkel E, Beenen L, Luitse J (2010). 'Advanced triage' improves patient flow in the emergency department without affecting the quality of care. Nederlands Tijdschrift voor Geneeskunde. 154:A1109.

Rosmulder R, Krabbendam J, Luitse J (2006). Planning emergency patients: an attempt to change the nature of the emergency department. European Journal of Emergency Medicine. 13:377-9.

Rouwette E, Vennix J, van Mullekom T (2002). Group model effectiveness: a review of assessment studies. System Dynamics Review. 18:5-45.

van Sambeek J, Cornelissen F, Bakker P, Krabbendam J (2010). Models as instruments for optimizing hospital processes: a systematic review. International Journal of Health Care Quality Assurance. 23:356-77.

Sargent R (1992). Validation and verification of simulation models. In Proceedings of the 1992 winter simulation conference, pp. 104-14.

Saunders C, Makes P, Leblanc L (1989). Modeling emergency department operations using advanced computer simulation systems. Annals of Emergency Medicine. 18:134-40.

Scholl H (2004). Action research and system dynamics: can they benefit from each other? In Proceedings of the 37th Hawaii International Conference on System Sciences, pp. 1-11.

Seguin D (2004). A nurse-initiated pain management advanced triage protocol for ED patients with an extremity injury at a level I trauma center. Journal of Emergency Nursing. 30:330-35.

Shojania K, Grimshaw J (2005). Evidence-based quality improvement: the state of the science. Health Affairs. 24:138-50.

Simmons J, (ed) (2003). Turning teamwork into quality care. Quality Letter for Healthcare Leaders. 15:2-11.

Slack N, Chambers J, Johnston S (2004). Operations management. Prentice Hall, Harlow, 4th edn.

Spear S (2005). Fixing health care from the inside, today. Harvard Business Review. 83:78-91.

Susman G, Evered R (1978). An assessment of the scientific merits of action research. Administrative Science Quarterly. 23:582-603.

Thompson J (1967). Organizations in action: social science bases of administrative theory. McGrawHill, New York.

VanBerkel P, Blake J (2007). A comprehensive simulation for wait time reduction and capacity planning applied in general surgery. Health Care Management Science. 10:373-85.

Vennix J, Akkermans H, Rouwette E (1996). Group model-building to facilitate organizational change: an exploratory study. System Dynamics Review. 12:39-58.

Vennix J, Andersen D, Richardson G, Rohrbaugh J (1992). Model-building for group decision support: issues and alternatives in knowledge elicitation. European Journal of Operational Research. 59:28-41.

Walsh M, Grant G, Coleman Z (2008). Action research - a necessary complement to traditional health science? Health Care Analysis. 16:127-44.

Walshe K, Rundall T (2001). Evidence-based management: from theory to practice in health care. Millbank Quarterly. 79:429-57. 
Westbrook R (1994). Action research: a new paradigm for research in production and operations management. International Journal of Operations \& Production Management. 15:6-20.

Wiler J, Gentle C, Halfpenny J, Heins A, Mehrotra A, Mikhail M, Fite D (2010). Optimizing emergency department front-end operations. Annals of Emergency Medicine. 55:142-60.

Winston W (1994). Operations research: applications and algorithms. Duxbury Press, Belmont.

Womack J, Jones D (1996). Lean thinking. Simon \& Schuster, London. 



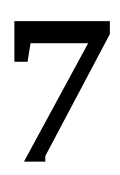

\section{'Advanced triage' improves patient flow in the emergency department without affecting the quality of care}

R.W. Rosmulder, J.J. Krabbendam, A.H.M. Kerkhoff, E.R. Schinkel, L.F. Beenen and

J.S.K. Luitse

Originally published in Dutch: Nederlands Tïdschrift voor Geneeskunde 2010, 154:A1109

This paper was presented at the 12th National Congress of the Dutch Society for Emergency Nurses, Ede, The Netherlands, 30 March 2010 


\begin{abstract}
Objective To investigate whether 'advanced triage' improved patient flow among self-referred patients in the emergency department of a level 1 trauma centre and, most importantly, whether the quality of medical care was maintained. In advanced triage, the triage nurse initiates additional diagnostic investigations independently.

Design Interventional study.

Methods After a baseline measurement had been carried out for eleven days $(n=506)$, the advanced triage protocol was tested during ten day or evening shifts $(n=198)$. The length of stay in the emergency department was measured. The attending emergency physician assessed the correctness and completeness of the additional diagnostics initiated by the triage nurse. Two traumatologists and two radiologists assessed the quality of $\mathrm{x}$-ray imaging requests independently of each other.

Results Average patient length of stay (LOS) was reduced by fourteen minutes (14 percent). The improvement was achieved primarily in patients who required additional diagnostic investigations. Their average LOS decreased by 27 minutes (18 percent). There was an 8 percent increase in the total number of diagnostic investigations requested. The triage nurse initiated the investigations correctly and fully in 93 percent of cases. The quality of $\mathrm{x}$-ray imaging requests remained the same as before the introduction of advanced triage.

Conclusion The implementation of advanced triage improved patient flow for self-referred patients in the emergency department without affecting the quality of medical care. Advanced triage was successful in the Dutch system, too.
\end{abstract}




\subsection{Introduction}

Emergency departments (ED) regularly face crowding problems due to increasing healthcare demands and resource shortages. As a result patients often have to wait for a long time, which increases the risk that acute symptoms are treated later than necessary. Many EDs apply triage to prevent this. Directly upon patient arrival, the triage nurse determines the patients' clinical priority and the associated maximum waiting period. If necessary patients receive paracetamol or diclofenac for pain relief. After this initial help patients have to wait for an available doctor.

In the United States and some European countries triage nurses have more responsibilities. After classifying patient urgency, they also initiate additional diagnostic evaluations, using so-called advanced triage protocols (McKay, 1999). These protocols contain standard work orders for the most common complaints (Hoffenberg et al., 2001). Studies from Canada, Denmark, England and Hong Kong demonstrated that advanced triage enables efficient use of patient waiting time (Lee et al., 1996; Lindley-Jones and Finlayson, 2000; Cheung et al., 2002; Pedersen and Storm, 2009). This resulted in shorter patient length of stay (LOS). The quality of the treatment would also be fully maintained.

To our knowledge advanced triage has not been implemented in the Netherlands. Currently x-rays and laboratory examinations are only initiated at triage on prior request by a general practitioner or specialist. Evidently this is not the case with patients who refer themselves to an ED. We investigated if the patient flow of selfreferred patients improved after implementation of advanced triage. Furthermore we determined if this did not affect the quality of care.

\subsection{Patients and methods}

\subsubsection{Study setting and design}

The research took place in the ED of a level-1 trauma centre in Amsterdam. Approximately 32,000 patients visit the ward yearly. Over 70 percent are self-referred patients. This percentage is much higher than the national average of 54 percent (Dutch Council for Public Health and Health Care, 2003). The self-referred patients are treated by an Emergency physician and an ED nurse. 25 percent of the self-referred patients require hospital admission or further specialised treatment. The Emergency physician hands them over to the residents. The department uses the Manchester Triage System (MTS), which is much used in the Netherlands. It divides patients into 5 urgency levels, each with a corresponding maximum waiting period. Patient urgency is determined with flow charts based on 52 entry complaints.

The research was an intervention study with a baseline measurement and a second measurement. The study was conducted as a so-called action research project. With this type of research scientists and practitioners together try to gain new knowl- 


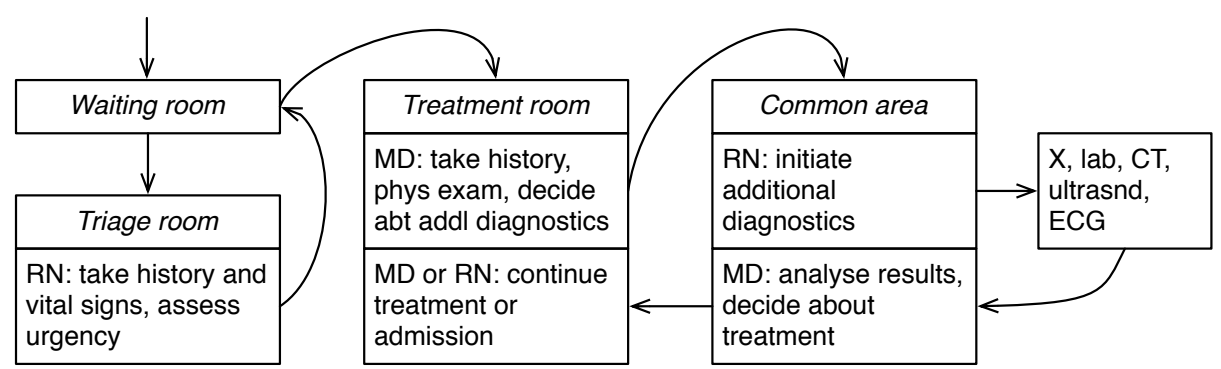

Figure 7.1: Protocol for ED care delivery process for self-referred patients according to the Manchester triage system, divided by activities of the staff physician (MD) and the triage nurse or emergency nurse (RN); abt = about; addl = additional; lab = laboratory examinations; phys = physical; ultrasnd $=$ ultrasound; $\mathrm{X}=\mathrm{x}$-rays

edge and better insights in practice (Coughlan and Coghlan, 2002; Westbrook, 1994; French and Bell Jr, 1990; Meyer, 2000).

The project team consisted of a $\mathrm{PhD}$ action researcher, 1 emergency physician, 2 ED nurses, the ED medical director and the head nurse. The action research was embedded in everyday practice. It had a cyclical structure in which phases of problem formulation, planning, taking action and evaluation followed each other constantly. The action research project was part of a PhD research in the field of emergency health care (Rosmulder et al., 2009). The study was exempted from review by the university hospital's medical-ethics committee.

\subsubsection{Emergency department care delivery process}

Typical situation Figure 7.1 shows the typical process of care delivery. A patient enters the ED, registers and takes a seat in the waiting room. The triage nurse takes a short anamnesis, performs a preliminary check-up, determines the urgency according to the MTS and if needed administers pain medication. The patient then waits in the waiting room until he or she is invited into a treatment cubicle. There the emergency physician takes an anamnesis and performs a physical examination. The doctor decides to request additional diagnostic evaluations if necessary. The doctor leaves the treatment cubicle and asks an ED nurse to complete the requests of the additional diagnostics. After the additional diagnostic research has been done, the doctor analyses the results and decides which course to follow.

The project team observed that the ED doctor and the ED nurse carried out their activities in an individual and successive fashion. This needlessly interrupted the patients care delivery. Using the industrial concept of 'lean thinking' a number of 
new basic guide lines were formulated for the method of working in the ED (Womack and Jones 1996; Simmons 2003; King et al. 2006; Parks et al. 2008). The lean thinking theory states that all activities that do not add value should be removed from a production process, and that the remaining activities should run smoothly. The basis guidelines for the process of an ED are: (a) The care delivery process for patients always has to go on. If something can be done, do it. (b) Carry out activities simultaneously so patients do not have to wait unnecessarily. (c) working simultaneously requires mutual adjustment. More frequent and faster consultations are necessary between the disciplines involved. (d) According to the literature the result of these guidelines is that gaps (waiting periods) are filled and the patient flow improves.

New situation Figure 7.2 shows the new process of care delivery. At the triage stage the nurse also decides on the necessity of additional diagnostic evaluations and initiates it immediately. When in doubt the triage nurse directly asks the ED doctor in consult in the triage room to make a decision together. The patient resumes his place in the waiting room after the diagnostic evaluations and (if urgency permits it) is only shown into the treatment cubicle when the evaluation results are available. After anamnesis and physical examination the ED doctor then has the additional diagnostic research directly at his disposal. If possible, the doctor makes a joint decision on further medical treatment with the nurse, in presence of the patient.

Advanced triage protocol Because of their schooling, Dutch ED nurses are competent and licensed to carry out triage independently. But an additional protocol was needed to also independently request diagnostic research. Such a protocol would make it possible for the ED nurses to carry out advanced triage under jurisdiction of the ED doctor. Because available protocols from other countries are based on different work methods and patient situations, our project team designed their own protocol in the action research. The collective development of this protocol also promoted its acceptance. While designing the protocol the project team had in mind patient groups and injuries which would apply for advanced triage. Consequently all entry complaints of the self-referred patients were subdivided into 4 categories. Per category it was ascertained which evaluations the triage nurse could request, see table 7.1.

The MTS dictates a maximum of 5 minutes triage time per patient. The project team foresaw that this time would be exceeded when many patients would arrive at the ED simultaneously. With 3 or more new waiting patients the triage nurse only indicated the necessary diagnostic research according to protocol. A colleague would then deal with the requested evaluations and, if needed, take blood samples.

\subsubsection{Data collection}

Prior to the collection of field data we developed a simulation model to get a virtual insight into the effects of advanced triage. This computer simulation predicted a 


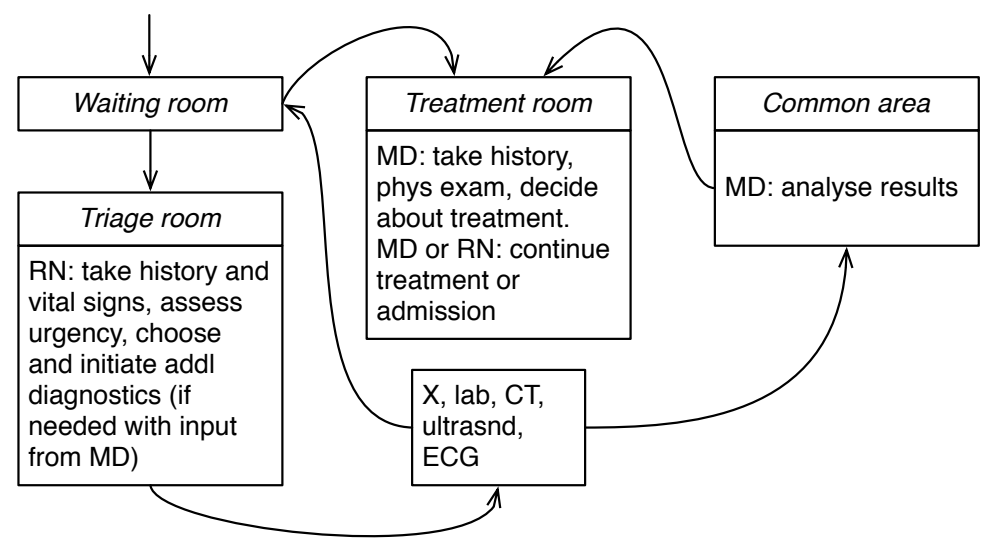

Figure 7.2: Protocol for ED care delivery process for self-referred patients according to the 'advanced triage' system, divided by activities of the staff physician (MD) and the triage nurse or emergency nurse $(\mathrm{RN})$; addl = additional; lab = laboratory examinations; phys $=$ physical; ultrasnd $=$ ultrasound; $\mathrm{X}=\mathrm{x}$-rays

Table 7.1: 'Advanced triage' protocol that the triage nurse used to initiate diagnostics after triage

\begin{tabular}{ll}
\hline $\begin{array}{l}\text { Entry complaints } \\
\text { self-referred patients }\end{array}$ & Decision \\
\hline Muscoskeletal & $\begin{array}{l}\text { In case of certainty about visible fractures, serious suspicion of } \\
\text { fractures, severe pain/haematoma obstructing examination of } \\
\text { affected joint: x-ray } \\
\text { In case of uncertainty: request consultation of ED physician in } \\
\text { triage room }\end{array}$ \\
& $\begin{array}{l}\text { Urinary tract infection: culture and/or urinalysis } \\
\text { Abdomen tender to palpation: lab, possibly consultation ED } \\
\text { physician }\end{array}$ \\
& $\begin{array}{l}\text { Non-tender to palpation: no lab } \\
\text { Cardial: ECG, lab, IV } \\
\text { Pulmonary complaint with cough, malaise, fever: x-thorax, lab, } \\
\text { arterial blood gas, blood culture } \\
\text { Pleuritic chest pain, no fever: } \mathrm{x} \text {-thorax, lab, blood gas } \\
\text { Not further specified }\end{array}$ \\
\hline
\end{tabular}


shortening of the average patient LOS by 24 minutes. Motivated by the success of the simulation the project group decided to try out the advanced triage protocol in two shifts on the ED (March 2007). When this try-out showed that the protocol also worked properly in practice, the actual experiment was started. In the experiment the members of the project group applied the new work methods during ten day or night shifts (between May-October 2007). The action researcher or a research assistant was present during all shifts to record times of the care delivery process. They also observed which diagnostic research was requested when, and if the emergency physician was present for consultation at the triage.

We determined the effect of the experiment on patient flow by comparing the LOS of patients from the experimental shifts with the results of a baseline measurement (October 2005). This measurement contained the LOS of all patients that visited the ER during a period of eleven consecutive days. We used this baseline measurement for comparison because it was the most accurate source of patient LOS in the department. In the period between the baseline measurement in 2005 and the second measurement in 2007 there were no changes in medical policy and treatment. The project group expected to include 60 percent less patients in the second measurement than in the baseline measurement, because the baseline measurement concerned whole days and the second measurement concerned only parts of days.

We ascertained the effect of the experiment on the quality of medical care in two ways. Firstly, the attending emergency physician assessed afterwards if the indication of the triage nurse for additional diagnostic evaluations was correct, and if the request was complete. This happened after the emergency physician himself had examined the patient involved. Patients who were already discussed between the doctor and the triage nurse were of course not included in the assessment. Secondly, two traumatologists and two radiologists assessed, independently from each other, the quality of the $\mathrm{x}$-ray imaging requests. For every $\mathrm{x}$-ray imaging request that was independently initiated by the triage nurse, two comparable requests in the regular work situation were found. This concerned requests made by the emergency physicians for the same research from the same period. All requests were then blinded and randomized. The project group established an assessment guideline, in accordance with earlier research, see table 7.2 (Triantopoulou et al., 2005; Stavem et al., 2004; Kahn Jr et al., 1997).

A short subjective evaluation by the project team concluded the data collection.

\subsection{Results}

Length of stay 506 Self-referred patients were included in the baseline measurement, 198 in the second measurement. The average LOS in the second measurement was 14 minutes (14 percent) shorter than in the baseline measurement, see table 7.3. This improvement was achieved especially through the patients that needed diagnostic evaluations. Their LOS decreased with 27 minutes (18 percent). The $75^{\text {th }}$ percentile in 
Table 7.2: Scoring system to assess the quality of $\mathrm{x}$-ray requests by triage nurses and staff physicians

\begin{tabular}{lll}
\hline Item & Assessment & Score \\
\hline Adequacy of & Optimal & 2 \\
clinical information & Acceptable & 1 \\
& Inadequate & 0 \\
Adequacy of & Optimal & 2 \\
clinical question & Acceptable & 1 \\
& Inadequate & 0 \\
Adequacy of & Optimal & 2 \\
requested studies & Correct study but also unnecessary studies & 1 \\
& Correct study but incomplete & 1 \\
& Suboptimal study & 1 \\
& Inadequate, not indicated & 0 \\
Legibility & Optimal & 2 \\
& Partial & 1 \\
& Not readable & 0 \\
\hline
\end{tabular}

the LOS of these patients was also considerably higher. For 81 percent of the patients in the second measurement the duration of triage was $<5$ minutes.

Quality of medical care Additional diagnostic evaluations were performed on 197 patients (39 percent) in the baseline measurement, and on 93 patients (47 percent) in the second measurement. The triage nurse requested evaluations for 55 patients in the second measurement. The emergency physician was present for consultation with 13 of these patients. In total the triage nurse initiated 29 x-rays imaging requests, twelve laboratory examinations, and four ECGs independently for 42 patients. The emergency physician judged that the indication of the triage nurse for additional evaluations was correct for 39 patients (93 percent). The requests were initiated fully for 39 patients also (93 percent). For one patient repeated x-ray imaging was needed because of an incomplete request. The traumatologists and radiologists judged that the quality of the x-ray imaging requests was maintained: the triage nurses' scores were on all fronts at the least equal to those of the emergency physicians in the normal work situation. See table 7.4. The kappa values of the independent assessments varied from 0.1-0.3.

Subjective evaluation by the project group During the experiment the members of the project group experienced that the self-referred patients in the experiment were helped faster and more efficiently. More frequent consultation made the work of the caregivers more intensive, but also more interesting. In contrast to the regular method of working people could now learn by seeing each other work. 
Table 7.3: Average patient ED length of stay during normal situation (baseline measurement) and after implementation of 'advanced triage' (second measurement)

\begin{tabular}{llll}
\hline & Average LOS & Stdev & IQR (25-75 pct) \\
\hline Total group & & & \\
Baseline measurement $(n=506)$ & 97 & 81 & $79(42-121)$ \\
Second measurement $(n=198)$ & 83 & 73 & $70(36-106)$ \\
Difference & -14 & & \\
& CI: $[-27,0]$ & & \\
& $p=0.05$ & & \\
No additional diagnostics & & 49 & $48(34-82)$ \\
Baseline measurement $(n=309)$ & 64 & 41 & $36(29-65)$ \\
Second measurement $(n=105)$ & 52 & & \\
Difference & -12 & & \\
& CI: $[-23,-1]$ & & \\
Additional diagnostics & $p=0.03$ & & \\
Baseline measurement $(n=197)$ & 148 & 94 & $126(79-205)$ \\
Second measurement $(n=93)$ & 121 & 85 & 85 (63-148) \\
Difference & -27 & & \\
& CI: $[-51,-4]$ & & \\
& $p=0.02$ & & \\
\hline
\end{tabular}

All $p$-values were calculated using a two-sided t-test; CI $=$ confidence interval, 95\%; $\mathrm{IQR}=$ interquartile range; LOS = length of stay; pct = percentile; stdev = standard deviation

Table 7.4: Average assessment by 2 radiologists and 2 traumatologists of the quality of $\mathrm{x}$-ray requests made by staff physicians or triage nurses, scored on a three-point scale $(0,1,2) *$

\begin{tabular}{llll}
\hline Item & $\begin{array}{l}\text { Staff physicians } \\
(n=58)\end{array}$ & $\begin{array}{l}\text { Triage nurses } \\
(n=29)\end{array}$ & $p$ \\
\hline Adequacy of clinical information & 1.20 & 1.40 & 0.09 \\
Adequacy of clinical question & 1.32 & 1.32 & 1 \\
Adequacy of requested studies & 1.41 & 1.52 & 0.2 \\
Legibility & 1.66 & 1.87 & 0.002 \\
\hline
\end{tabular}

* Table 7.2 illustrates the scoring system.

All $p$-values were calculated using a two-sided t-test; kappa values for the 4 independent assessments were between 0.1 and 0.3 


\subsection{Discussion}

Emergency department length of stay In this study we applied advanced triage to self-referred patients. Their average LOS decreased with 14 minutes. Although the number of additional diagnostic evaluations increased with 8 percent, the additional diagnostic requests made by the triage nurse were initiated fully and correctly in 93 percent of the time. There were no indications that the triage nurse requested unnecessary diagnostic evaluations. Furthermore, the quality of the x-ray imaging requests remained the same.

The results of our study correspond with those of studies from other countries. These already showed that patient LOS in the ED decreased, varying from nineteen to 47 minutes (Cheung et al., 2002; Pedersen and Storm, 2009; Lindley-Jones and Finlayson, 2000; Lee et al., 1996). In these studies the quality of medical care was also maintained, although this was established in various ways (Pedersen and Storm, 2009; Lindley-Jones and Finlayson, 2000; Lee et al., 1996).

Limitations of our research Firstly, the comparison of the second measurement to a baseline measurement established two years before was not ideal. Probably a bias in the data on LOS did not occur, because the medical policy and the treatment were unchanged in those two years. The baseline measurement did not include data about urine samples and ECGs, which may explain the increase in requested diagnostic evaluations in the second measurement. Another possible explanation is the nationwide trend to request more diagnostic evaluations in EDs in general.

Secondly, the emergency physician was not an independent assessor of the correctness and completeness of the diagnostic evaluations requested by the triage nurse. The emergency physician's judgement was based on a sincere appraisal of the required additional diagnostic evaluations after the physician examined the patient. This made assessment by other independent physicians impractical. The emergency physician made his assessment when the diagnosis of the patient was already known. We feel that this objective diagnosis prevented serious bias. The assessment of just one emergency physician does reduce the generalisability of the study (Wiler et al., 2010).

Finally, the mutual agreement between the assessors of the x-ray imaging was moderate (see table 7.4). Our results are comparable to those of others. Further investigation is needed to specify the assessment criteria in the future.

The future of advanced triage Advanced triage is one of the ways to organise the professional cooperation more jointly in EDs (Chan et al., 2005; Subash et al., 2004; Richardson et al., 2004). In the study setting, it radically changed the historically grown working culture. The new work method required more flexibility and mutual trust in the actions of the caregivers. That did not happen without elaborate discussions. The project team encountered many objections from staff members in and around the 
ED. Eventually it was possible to conduct the study by using the collaborative approach in the action research and the use of the simulation model.

The experiment with the self-referred patients made it possible to learn and improve the work in practice (Spear, 2005). As a result of the research the management of the ED intends to implement advanced triage. They are considering to integrate advanced triage with the Manchester triage system. Then there will be 260 (5 x 52) clinical pathways for which standard work orders can be made. Furthermore, the department management intends to include in the protocol other decisions that can be made by triage nurses, such as indicating hospital admission and ascertaining if further treatment should be conducted in the ED or by a general practitioner (group practice).

\subsection{Conclusion}

We conclude that advanced triage improves the patient flow for self-referred patients without loss of quality in the medical care. The favourable research results in other countries are also achievable in the Dutch situation. The more advanced application of triage proves to be a promising start of actual faster and better care in EDs.

\section{Acknowledgements}

Willeke Koster, Rob Köhlinger, Ferco Berger and Bart van Dijk contributed to the research. We thank Harm Appels for translating our work into the English.

\section{References}

Chan T, Killeen J, Kelly D, Guss D (2005). Impact of rapid entry and accelerated care at triage on reducing emergency department patient wait times, lengths of stay, and rate of left without being seen. Annals of Emergency Medicine. 46:491-7.

Cheung W, Heeney L, Pound J (2002). An advance triage system. Accident and Emergency Nursing. 10:10-6.

Coughlan P, Coghlan D (2002). Action research for operations management. International Journal of Operations \& Production Management. 22:220-40.

Dutch Council for Public Health and Health Care (2003). Acute Zorg. Publicatienr 03/14, Zoetermeer.

French W, Bell Jr C (1990). Organization development: behavioral science interventions for organization improvement. Prentice-Hall International, Englewood Cliffs, 4th edn.

Hoffenberg S, Hill M, Houry D (2001). Does sharing process differences reduce patient length of stay in the emergency department? Annals of Emergency Medicine. 38:533-40.

Kahn Jr C, Michalski T, Erickson S, Foley W, Krasnow A, Lofgren R, Quiroz F, Rand S (1997). Appropriateness of imaging procedure requests: do radiologists agree? American Journal of Roentgenology. 169:11-4. 
King D, Ben-Tovim D, Bassham J (2006). Redesigning emergency department patient flows: application of lean thinking to health care. Emergency Medicine Australasia. 18:391-7.

Lee K, Wong T, Chan R, Lau C, Fu Y, Fung K (1996). Accuracy and efficiency of x-ray requests initiated by triage nurses in an accident and emergency department. Accident and Emergency Nursing. 4:179-81.

Lindley-Jones M, Finlayson B (2000). Triage nurse requested x rays: are they worthwhile? Journal of Accident \& Emergency Medicine. 17:103-7.

McKay J (1999). The emergency department of the future: the challenge is in changing how we operate! Journal of Emergency Nursing. 25:480-8.

Meyer J (2000). Using qualitative methods in health related action research. British Medical Journal. 320:178-81.

Parks J, Klein J, Frankel H, Friese R, Shafi S (2008). Dissecting delays in trauma care using corporate lean six sigma methodology. The Journal of Trauma. 65:1098-105.

Pedersen G, Storm J (2009). Emergency department x-rays requested by physicians or nurses. Ugeskrift for Laeger. 171:1747-51.

Richardson J, Braitberg G, Yeoh M (2004). Multidisciplinary assessment at triage: a new way forward. Emergency Medicine Australasia. 16:41-6.

Rosmulder R, Krabbendam J, Kerkhoff A, Luitse J (2009). Action research and soft systems methodology for studying problems in emergency care delivery. International Journal of Healthcare Technology and Management. 10:289-302.

Simmons J, (ed) (2003). Turning teamwork into quality care. Quality Letter for Healthcare Leaders. 15:2-11.

Spear S (2005). Fixing health care from the inside, today. Harvard Business Review. 83:78-91.

Stavem K, Fossa T, Botnmark O, Andersen O, Erikssen J (2004). Inter-observer agreement in audit of quality of radiology requests and reports. Clinical Radiology. 59:1018-24.

Subash F, Dunn F, McNicholl B, Marlow J (2004). Team triage improves emergency department efficiency. Emergency Medicine Journal. 21:542-4.

Triantopoulou C, Tsalafoutas I, Maniatis P, Papavdis D, Raios G, Siafas I, Velonakis S, Koulentianos $E$ (2005). Analysis of radiological examination request forms in conjunction with justification of x-ray exposures. European Journal of Radiology. 53:306-11.

Westbrook R (1994). Action research: a new paradigm for research in production and operations management. International Journal of Operations \& Production Management. 15:6-20.

Wiler J, Gentle C, Halfpenny J, Heins A, Mehrotra A, Mikhail M, Fite D (2010). Optimizing emergency department front-end operations. Annals of Emergency Medicine. 55:142-60.

Womack J, Jones D (1996). Lean thinking. Simon \& Schuster, London. 


\section{The role of operations management in improving emergency department outflow}

R.W. Rosmulder and J.S.K. Luitse

International Journal of Healthcare Technology Management 2011. 12:293-306. 


\begin{abstract}
Worldwide, many hospitals experience problems in patient outflow from the emergency department into the clinical wards, and therefore, implement an observation unit. Literature and practical experiences, however, show that medical management in these units can be problematic. A university hospital in the Netherlands that considered implementation first analysed the problem situation using an operations management approach. For the internal medicine specialty, the steps in the patients' care delivery and the deployment of staff and resources around acute admissions were analysed. The analyses brought up many inefficiencies in the admission process and showed that nurse staffing levels in the wards did not match patient outflow from the emergency department. The results provided hospital management with more, and less extensive options to address the problem situation. These were implemented first, instead of an observation unit. We encourage healthcare managers who face similar decisions to incorporate operations management aspects into their decision-making processes.
\end{abstract}




\subsection{Introduction}

Many hospitals around the world experience problems in the acute patient flow, especially in the outflow from the emergency department into the clinical wards (Kyriacou et al., 1999; Derlet and Richards, 2000; Hoffenberg et al., 2001; Spaite et al., 2002; Asplin et al., 2003; Cardin et al., 2003). When emergency departments (EDs) regularly overflow with patients, it often happens that there are no more ward beds available to admit patients from the ED. The outflow into the wards is blocked, which worsens the situation in the ED (Bazarian et al., 1996). For the nursing wards, the unpredictable acute admissions disturb the work for the regularly scheduled admitted patients. The wards may also receive patients to reduce overflowing in the ED-patients who would normally not be admitted. These problems in acute patient flow produce frustration between the members of the different departments involved. They need to improvise frequently to arrange some kind of solution. For the patients, this implies experiencing excessive waiting and a possible admission to a ward of a completely different specialty or even to another hospital. The hospital is thus not providing optimal patient care and it may also lose revenue.

To address this situation, many hospitals have so-called observation units in place. An observation unit is a nursing ward located between the ED and the regular wards. It serves to hold acute patients who need hospital admission or extended observation (Brillman et al., 1995; Dick, 2004). An observation unit provides a buffer to accommodate overflowing in the ED. It also removes disturbances for the nursing wards and prevents unnecessary admissions (Graff et al., 2000). The literature shows that observation units generally improve patient care, but that there are serious drawbacks as well (Zun, 1990; Brillman et al., 1995; Gouin et al., 1997; Rydman et al., 1999; Daly et al., 2003; Mace et al., 2003; Scott et al., 2009). These are especially related to the conflicting medical responsibilities of stakeholders in the ED and the nursing wards.

An academic medical centre in the Netherlands experienced similar problems in ED outflow, and hospital management considered whether or not to implement an observation unit. As this solution is expensive and complex, it was decided to carry out research to better inform the decision. The problem situation was analysed using an operations management (OM) approach. The field of OM studies the activities that are required to create and deliver products and services, from procurement through conversion to distribution (Hopp and Spearman, 2000; Slack et al., 2004; Hayes et al., 2005). Specifically, the steps in the patients' care delivery process and the deployment of staff and resources around acute admissions were analysed. In addition, stakeholders in the ED and the wards were asked for their opinion about an observation unit as a solution. The results of the analyses provided hospital management with more, and less extensive options to address the problems in the acute patient flow. Instead of implementing an observation unit, it was decided to rethink the outflow from the ED into the nursing wards. This article describes our analysis, aiming to 
inform managers in other hospitals who face similar decisions, and to encourage them to incorporate $\mathrm{OM}$ aspects into their decision-making processes.

\subsection{Methods}

\subsubsection{Study setting and patient population}

The study took place in a 1,000-bed university hospital in the Netherlands, which is designated as level-one trauma centre. The emergency department receives about 32,000 patients per year. These fall into three main groups: patients in critical conditions, non-critical self-referred patients, and patients referred by general practitioners (GPs). This study concerned the last group, for patients referred to the specialty of internal medicine. This group comprises over 30 percent of all GP-referred emergency patients. Of these patients, 42 percent are admitted after treatment in the ED. Internal medicine has five nursing wards. Acute admissions from the ED are a substantial part (40 percent) of all hospital admissions for the specialty. We considered the group of internal medicine patients to be representative for the total research problem.

\subsubsection{Theoretical model of the research problem}

The flow of acute admissions from the ED is as follows, see figure 8.1. Most emergency patients for internal medicine arrive on referral by their GP. These patients are often already under treatment by the GP or a specialist. When they develop an acute situation in their illness, they consult their GP, who finds that they need hospital care within the day. In the Dutch system this means a referral to a hospital's outpatient department or, almost always, the ED. After treatment in the ED, the patients are admitted to one of five available nursing wards. The exact one depends on the patients' symptoms and the availability of beds. If there are no beds available, the patients are admitted to a ward of another specialty or to another hospital. In the nursing wards, the flow of acute patients joins with patients who were regularly scheduled for admission, for instance after surgery. After some time, the patients are discharged from the wards, back to their home situation or nursing home. 


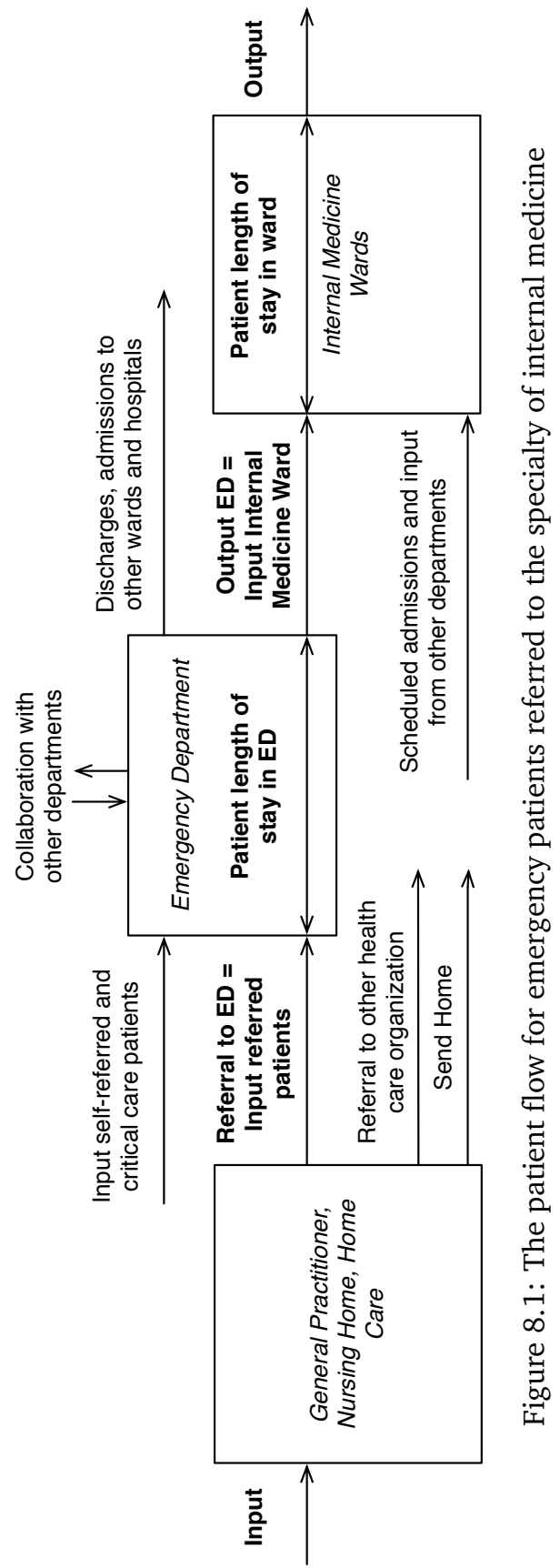


The main problems in the flow of acute admissions are as follows. For the wards, the unscheduled and seemingly unpredictable admissions from the ED disturb the care delivery for regularly scheduled patients. The ward can get crowded, which translates back into a problem for the ED: if there are no beds available in the wards, the emergency patients stay in the ED. This in turn interferes with the care delivery for other emergency patients. Figure 8.1 shows that the ED blocking problem ultimately depends on the discharge planning for patients in the wards. As a solution to these problems, many hospitals have an observation unit in place between the ED and the wards of the various specialties. Such a unit can generally serve three goals with three corresponding orientations (Brillman et al., 1995; Scott et al., 2009):

1. To observe patients after initial treatment in the ED. Emergency patients are placed in a comfortable environment to be observed for some time after treatment in the ED. It is then decided whether they should be admitted or discharged. Unnecessary admissions of patients are thus prevented, as they would normally be admitted to a ward for observation. This goal is predominantly patientoriented.

2. To finish decisions about diagnostics started in the ED. Emergency patients are placed in an observation unit after diagnostic examinations have been started in the ED. The decision about further treatment is made the next morning. This frees up treatment rooms in the ED but also extends the decision-making process. This goal is predominantly ED-oriented.

3. To hold patients destined for the nursing wards. Emergency patients who are normally admitted to a ward are placed in an observation unit first. This allows the wards to control the admission of unscheduled patients and to remove disturbances during night times. When beds become available in the wards, the patients are transferred. This goal is predominantly ward-oriented.

As an observation unit typically holds all the emergency patients needing admission, the medical responsibility for the patients can quickly get complicated. Who is responsible: an emergency physician, a surgeon, or an internal medicine specialist? Who ensures proper outflow from the observation unit into the wards of the various specialties? The surgeon knows the way around the surgical wards, but not necessarily around those of, say, neurology. There are competing interests and conflicting goals.

\subsubsection{Research approach}

This case study was part of a doctoral research project in healthcare technology management (Rosmulder et al., 2009). The research studies the application of industrial engineering concepts to improve patient flow in the ED. The application starts from an understanding that improving patient flow is not a technical engineering problem but essentially a social interaction problem between different groups of professionals. The research, therefore, uses an action research (AR) approach, in which practitioners and researchers collaborate to address problem situations and simultaneously produce 
better insights (Checkland and Scholes, 1990; Eden and Huxham, 1996; Coughlan and Coghlan, 2002). AR takes place in an ongoing process of action planning, action taking and evaluating, leading to further action planning and so on (Susman and Evered, 1978; French and Bell Jr, 1990). For this study, a joint analysis was made to investigate the flow of acute admissions and to build insights to inform decision-making about improvements. A team was formed that included the medical director of the $\mathrm{ED}$, an internal medicine specialist, a professor in operations management, an action researcher and a MSc student in health sciences. The researchers also collaborated closely with medical and nursing professionals in the ED and the internal medicine wards.

\subsubsection{Methods of measurement}

The analysis consisted of four parts, in which multiple sources and viewpoints were used (Eden and Huxham, 1996):

1. Analysis of emergency patient flow to the wards. What steps need to be performed to admit a patient from the ED to a ward? To answer this question, the MSc student first joined the professionals (nurses, residents, supervisors, admission coordinators) for several days to observe their work processes in the ED and the wards. This also served the purpose of him getting known by the staff and explaining the rationale for the research. Next, process mapping sessions (NHS Institute for Innovation and Improvement, 2007) were held with representatives of all disciplines involved in the patient care delivery process. Together with the student, they mapped the flow of acute admissions and explored the main problems. For practical reasons, the process mapping was split into one session in the ED and one session in the ward, as it was too complicated to involve all of the staff directly. The session in the ED focused on the moment when patients arrive in the ED until the moment when they leave the department; the session in the ward focused on the moment when the wards fist hear about a due admission until the moment when the patient from the ED has been safely admitted to a ward bed. The results of both sessions were also shared with staff members who were unable to attend.

2. Analysis of patient volume and meaningful time differences. How many patients are admitted to an internal medicine ward per day? How long do patients stay in the ED until they are admitted? When is the delay in the acute admissions flow the largest? Different sources were used to answer these questions: emergency patient records, data from a patient database in the ED, and data from the wards about the number of admissions. In addition, a time measurement study was carried out in the ED during six weeks. This measurement also recorded the location patients were admitted to.

3. Analysis of bed availability in the wards in relation to patient outflow from the ED. How many beds are available in the wards to admit patients from the ED during 
the day? To prevent blocking of beds, available bed capacity in the wards needs to be in line with the outflow pattern of patients from the ED. The bed planning and staffing schedules of nurses in the wards were analysed and compared to outflow data from the ED.

4. Interviews with management in the wards and the ED. The student interviewed several internal medicine supervisors, several heads of the wards and the medical director of the ED. They were asked for their opinion about an observation unit to solve the problems in acute patient flow. The interviews were semi-structured, focusing on the three orientations of implementing an observation unit: the patients, the ED, and the wards.

\subsection{Results}

\subsubsection{Emergency patient flow to the wards}

The basic steps in the care delivery process for patients referred to internal medicine in the ED is as follows. After arrival, the patient is seen by an ED nurse, who takes a short history and performs a preliminary evaluation. If possible, the nurse also initiates diagnostic examinations such as x-rays or laboratory tests, which have been requested when the GP referred the patient to the ED. Then the patient waits to see an internal medicine resident. The resident takes a history and performs a physical examination. The resident analyses the results of the diagnostics and decides about treatment or further diagnostics. The resident presents the plans to the internal medicine supervisor, who approves or modifies them. After treatment, the patients are admitted or go home.

The admission process starts when the resident consults the supervisor. Figure 8.2 shows the process map onwards from this point in detail. Squares in the figure represent activities carried out in presence of the patients; diamonds represent activities not carried out in presence of the patients; triangles indicate patient waiting time. Having discussed the diagnostics results with the supervisor and agreed on patient admission, the resident calls the admission coordinator to locate an appropriate bed in one of the wards. When the coordinator calls back with a bed found, the resident calls the nurse in the ward to announce the patient, and then the resident in the nursing department to hand over the patient. The resident in the ED then tells the ED nurse to which department the patient will go; the ED nurse arranges patient transportation. During the time it takes patient transport to arrive in the ED, the resident informs the patient about the admission and finishes the admission papers. The patient is brought to the ward, where a bed has been prepared. The ward nurse informs the resident in the ward on patient arrival. The nurse performs a preliminary evaluation, takes a history and starts the treatment policy as arranged by the resident.

The main problems brought up during the process mapping sessions were the following. For some patients, it is known already on arrival in the ED that they will not leave the hospital. The admission arrangements, however, are always made much 
later, when the resident consults the supervisor. The process map shows that the caregivers carry out many activities to get patients admitted, day in and day out again. During these activities, patients can wait for a long time while very little happens to them, occupying treatment rooms in the ED. In addition, the many dependencies in the admission process increase possibilities for delays or loss of information. In the wards, the nurses sometimes find that it is unclear what the treatment policy of the patients is and what already has been done in the ED. The complexity of the patient may also be higher than announced. After arrival in the wards, the nurses repeat many of the activities that have already been carried out for the patients in the ED. This takes about one hour per newly arrived patient, which they indicate as an intensive workload. 


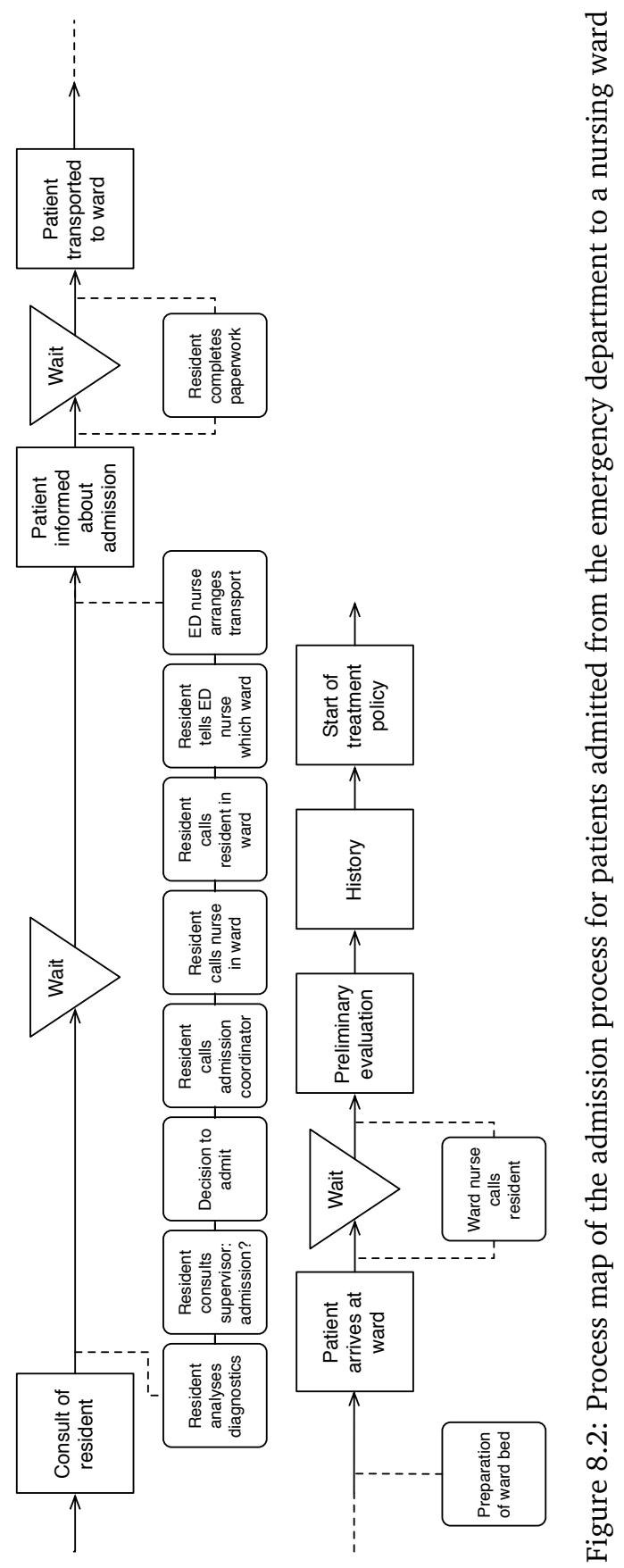


Table 8.1: Average daily numbers for internal medicine patients in the ED; $\mathrm{ED}=$ emergency department; stdev = standard deviation

\begin{tabular}{llll}
\hline Patient group & $\begin{array}{l}\text { Daily } \\
\text { average }\end{array}$ & Stdev & $\begin{array}{l}10-90 \% \\
\text { percentiles }\end{array}$ \\
\hline Internal medicine ED total $(n=625)$ & 6.9 & 2.8 & $4-11$ \\
discharged (51\%) & 3.5 & 2.0 & $1-6$ \\
admitted to ward (49\%) & 3.3 & 1.7 & $1-5$ \\
\hline
\end{tabular}

\subsubsection{Patient volume and meaningful time differences}

Table 8.1 shows the average daily numbers of internal medicine patients in the ED (ED patient database, $n=625$ ). About half of the patients are discharged or admitted. The 10- and $90 \%$ percentiles indicate that the internal medicine wards most likely receive between 1 and 5 patients from the ED per day. Of all internal medicine admissions from the ED, 78 percent go to the right ward, 14 percent go to a ward of another specialty, and 8 percent go to another hospital (time measurement study, $n=379$ ).

The length of stay (LOS) in the ED of patients admitted for internal medicine is on average 3.5 hours, which is between 15 and 30 minutes longer than patients who are discharged (patient records, $n=355$, and time measurement study, $n=379$ ). The delay of admission compared to discharge on a daily basis is thus not so large. Throughout the day, however, the LOS of patients admitted from the ED varies strongly, see figure 8.3. It is the longest between $4 \mathrm{pm}$ and $4 \mathrm{am}$, which is 70 minutes longer on average than between $4 \mathrm{am}$ and $4 \mathrm{pm}$. The data also suggest that patient LOS in the ED increases significantly if patients are admitted to a ward of another specialty or to another hospital.

\subsubsection{Bed availability in the wards in relation to patient outflow from the ED}

From the observations in the wards, it turned out that the number of available nurses on duty determines the number of ward beds available for admissions. The physical number of beds in each of the wards should be considered as a (mainly theoretical) maximum. The bed availability follows from established nurse to patient ratios for the daytime, evening and night. Of internal medicine's five nursing wards, there are three that primarily receive acute admissions and two that primarily receive scheduled admissions. When the number of available ward nurses was compared to the number of admitted patients for these two groups, an interesting difference emerged, see figure 8.4. The nurse staffing levels are always highest from 8 am to $4 \mathrm{pm}$, when there is the most nursing work to do. For the wards with primarily scheduled admissions, the nurse staffing level nicely fits the demand pattern. For the wards with primarily acute 


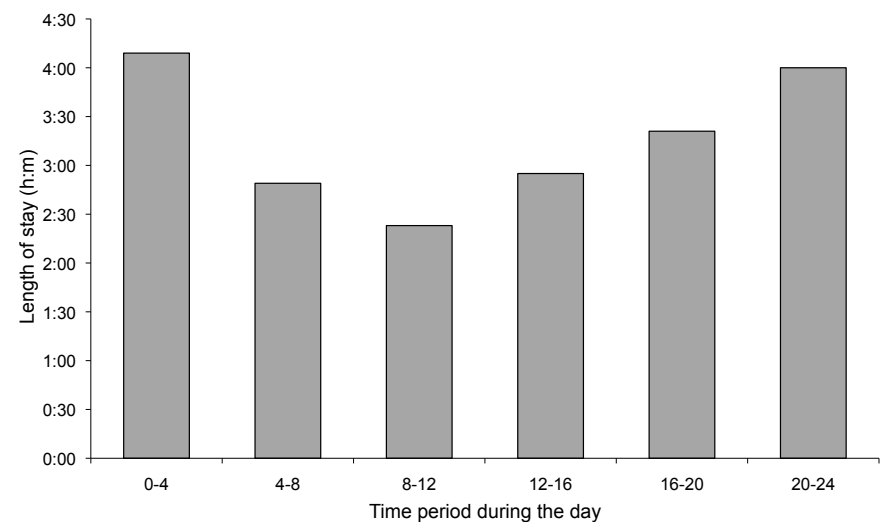

Figure 8.3: Length of stay during the day for emergency patients admitted to internal medicine $(n=321)$

admissions, however, the same staffing level does not fit the demand pattern. There is a mismatch between $4 \mathrm{pm}$ and $4 \mathrm{am}$. It is very likely that this explains the large variation in patient LOS during the day for patients admitted from the ED (described in the previous section).

\subsubsection{Interviews with management in the wards and the ED}

The opinion of the internal medicine supervisors and heads of the wards about implementing an observation unit was primarily ward-oriented. They thought that an observation unit would prevent unnecessary admissions and remove disturbances during the evening and night. It might also reduce patient LOS in the ED. The opinion of the medical director of the ED was primarily patient-oriented. He thought that an observation unit would provide a safer and better environment for patients to be observed in. It might reduce patient LOS in the ED, but not necessarily in the entire chain of acute care: an observation unit implies an extra step for the patients. He also stated that decisions about the results of diagnostics started in the ED should be finished in the ED as well-these should not be delayed to a next morning in an observation unit. All of the stakeholders agreed that an observation unit would benefit the quality of medical care. None took a fixed standpoint by fully opposing or supporting the observation unit as a solution.

\subsubsection{Presentation of key insights and follow-up decisions in the study setting}

The results of the analyses were presented to members of the study setting during meetings and in written reports. The key insights about the problematic flow of 


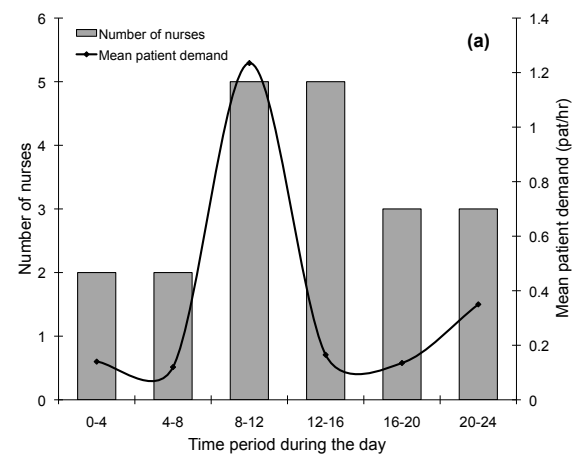

(a) Wards with primarily scheduled admissions

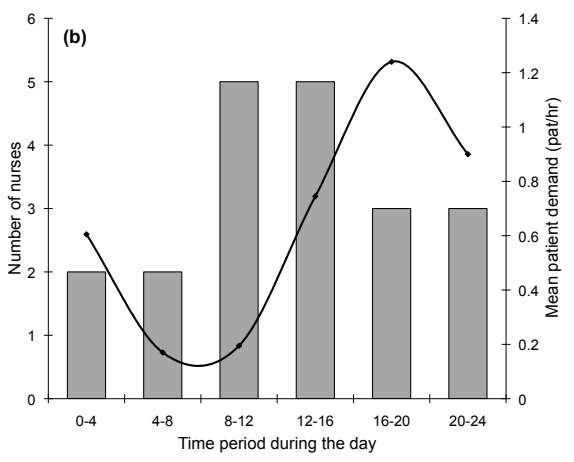

(b) Wards with primarily acute admissions

Figure 8.4: Comparison of nurse staffing levels in the wards (capacity) to patient inflow into the wards (demand)

acute admissions for internal medicine were as follows. On average, the problem is not so large, as shown by the relatively small delay for admission compared to discharge-certainly when compared to settings in the United States (e.g., Hoffenberg et al., 2001). During evening and night times, however, the acute admissions are disturbing, resulting in extended patient LOS in the ED and admissions to other wards and hospitals. Admissions to other places certainly do not improve the patients' care; they also consume extra time, which adds to blocking in the ED, and result in missed revenue for the hospital. Likely cause of the problems during the evening and night are the staffing levels in the internal medicine wards. These do not fit the outflow pattern of admissions from the ED. Dedicating five beds in the wards would suffice to handle 90 percent of acute admissions. The admission process itself contains many inefficiencies as well as improvement opportunities that are currently being missed. The main conclusion of the study was that an observation unit is not the first choice to solve the problems in the acute admissions flow. There are other, less extensive options available.

Ultimately, hospital management decided not to implement an observation unit between the ED and the wards. Through considering the insights from this study, it was realised that the problems in the acute patient flow were likely to persist - they would only be moved from the ED to the observation unit. It was also considered that the investment involved in the implementation is typically large and that the operating costs are higher than those of a regular nursing ward (Zun, 1990); the nursing staff needs additional training to know about patients' symptoms from many specialities (Scott et al., 2009). In addition, the observation unit requires its own decision-making and management, with the associated problems in stakeholder responsibilities (Graff et al., 2000; Daly et al., 2003; Scott et al., 2009). Hospital 
management, instead, used the key insights from the analyses to optimise the outflow of ED patients into the wards. A plan was laid out for the three main "ED-outflow" specialties of internal medicine, surgery, and neurology. For each specialty, one of its nursing wards would be dedicated to receive the acute admissions from the ED. The nurse staffing levels in this ward would be matched with the outflow pattern of admissions from the ED. During the morning, the patients would if necessary be transferred from this "acute ward" to another ward within the specialty. Admission of patients to beds of another specialty was prevented as much as possible, as the nurses and specialists know the way best around their own specialty. The plan was feasible because the number of patients was manageable: only up to five or six beds would be needed per specialty, which could be accommodated within the existing nursing ward configuration. The plans have currently been implemented for internal medicine, showing promising initial results. Finally, hospital management used the key insights from the analyses to address the inefficiencies in the admission process.

\subsection{Discussion}

This study presented an operations management analysis of patient flow in a university hospital's emergency department. The study concentrated on the admission of patients from the ED to the nursing wards of internal medicine. The steps in the patients' care delivery process were analysed, as well as the relation between staffing levels in the wards and the varying number of arrivals from the ED during the day. In addition, managers in the nursing wards and the ED were asked for their opinion about an observation unit as a possible solution. The results of the analyses show many steps in the admission process that do not add to the patients' care delivery, and that the staffing levels in the wards do not match the outflow pattern from the ED. This increases patients' length of stay in the ED during evenings and night times. The managers agreed that an observation unit would benefit the quality of medical care, but did not indicate fixed preferences in favour of or against the solution. The results from the study helped hospital management to decide about implementing an observation unit. They realised that they had better options available to address the patient flow problem in their setting than to implement an observation unit between the ED and the wards. The key insights were used instead to rethink the outflow into the wards. A plan was made that changed the configuration of nursing wards for each of the major specialties by dedicating one to receive acute admissions from the ED. This freed up the other wards within the specialty from disturbances during inconvenient times.

The central message of this study is that in decisions such as implementing an observation unit, "technical" operations management aspects such as flow and resource planning need to play a role, next to the "social" aspects such as the experiences and opinions of the various stakeholders involved. Through the action research approach, this study explicitly sought to combine the researchers' knowledge about analysing 
patient flow with the knowledge of the practitioners about their local work processes. Full benefit was made of the opportunities provided by the AR methodology to combine data from multiple sources and viewpoints (Eden and Huxham, 1996). Throughout the analysis, the importance of observing the situation from the perspective of the patients was stressed continually. This ensured that all the different stakeholders understood the whole picture-they usually tend to see only their own contribution to the patient flow. A shared insight into the main problem solving options thus emerged.

From an operations management point of view, an observation unit addresses symptoms instead of causes. Adding an extra station to problematic patient flow will only provide safer and more pleasant waiting, instead of preventing the waiting altogether. It is also likely that an observation unit only complicates the existing organisation. Many hospitals have experienced in practice that their observation units created more problems when they were not properly managed (Brillman et al., 1995; Graff et al., 2000; Daly et al., 2003; Scott et al., 2009). Especially in academic settings, conflicts over patients are likely to occur because there are so many specialties and sub-specialties. The task of reconciling the conflicts then often falls to the nursing staff, which reduces medical decision-making power. This makes it likely to render the observation unit unmanageable.

This article described how an operations management analysis provided hospital management with valuable information to facilitate decision-making. The recommendations of this study are therefore as follows: next to using the experience, opinions and emotions of the various stakeholders, analyse the acute patient flow and the related levels of staffing and resources. Involve representatives from all the staff in the process mapping sessions. Think about whether to complicate the existing organisation or to simplify it. In considering the goals that an observation unit should serve, distinguish between the orientations of the patients, the ED, and the wards. Finally, we encourage managers in other hospitals who face similar decisions to incorporate operations management aspects into their decision-making processes.

\section{Acknowledgements}

The authors thank Professor Koos Krabbendam for his contributions to the research. This article is an illustration of his passion: to better organise care processes using successful concepts from industry. Many thanks also go out to Stefan Roskam.

\section{References}

Asplin B, Magid D, Rhodes K, Solberg L, Lurie N, Camargo C (2003). A conceptual model of emergency department crowding. Annals of Emergency Medicine. 42:173-80.

Bazarian J, Schneider S, Newman V, Chodosh J (1996). Do admitted patients held in the ED impact the throughput of treat and release patients? Academic Emergency Medicine. 3:1113-8.

Brillman J, Mathers-Dunbar L, Graff L, Joseph T, Leikin J, Schultz C, Severance H, Werne C (1995). Management of observation units. Annals of Emergency Medicine. 25:823-30. 
Cardin S, Afilalo M, Lang E, Collet J, Colacone A, Tselios C, Dankoff J, Guttman A (2003). Intervention to decrease emergency department crowding: does it have an effect on return visits and hospital readmissions? Annals of Emergency Medicine. 41:173-85.

Checkland P, Scholes J (1990). Soft systems methodology in action. John Wiley \& Sons, Chichester.

Coughlan P, Coghlan D (2002). Action research for operations management. International Journal of Operations \& Production Management. 22:220-40.

Daly S, Campbell D, Cameron P (2003). Short-stay units and observation medicine: a systematic review. The Medical Journal of Australia. 178:559-63.

Derlet R, Richards J (2000). Overcrowding in the nation's emergency departments: complex causes and disturbing effects. Annals of Emergency Medicine. 35:63-8.

Dick R (2004). The role of the emergency department observational unit. American Journal of Therapeutics. 11:S15-7.

Eden C, Huxham C (1996). Action research for management research. British Journal of Management. 7:75-86.

French W, Bell Jr C (1990). Organization development: behavioral science interventions for organization improvement. Prentice-Hall International, Englewood Cliffs, 4th edn.

Gouin S, Macarthur C, Parkin P, Schuh S (1997). Effect of a pediatric observation unit on the rate of hospitalization for asthma. Annals of Emergency Medicine. 29:218-22.

Graff L, Prete M, Werdmann M, Monico E, Smothers K, Krivenko C, Maag R, Joseph A (2000). Implementing emergency department observation units within a multihospital network. Joint Commission Journal of Quality Improvement. 26:421-7.

Hayes R, Pisano G, Upton D, Wheelwright S (2005). Operations, strategy, and technology: pursuing the competitive edge. Wiley, Hoboken.

Hoffenberg S, Hill M, Houry D (2001). Does sharing process differences reduce patient length of stay in the emergency department? Annals of Emergency Medicine. 38:533-40.

Hopp W, Spearman M (2000). Factory physics. McGraw-Hill, Singapore, 2nd edn.

Kyriacou D, Ricketts V, Dyne P, McCollough M, Talan D (1999). A 5-year time study analysis of emergency department patient care efficiency. Annals of Emergency Medicine. 34:326-35.

Mace S, Graff L, Mikhail M, Ross M (2003). A national survey of observation units in the United States. American Journal of Emergency Medicine. 21:529-33.

NHS Institute for Innovation and Improvement (2007). Improvement leader's guide to process mapping, analysis and redesign. http://www.institute.nhs.uk/index.php?option=com content\&task=view\&id=134\&Itemid $=35$.

Rosmulder R, Krabbendam J, Kerkhoff A, Luitse J (2009). Action research and soft systems methodology for studying problems in emergency care delivery. International Journal of Healthcare Technology and Management. 10:289-302.

Rydman R, Roberts R, Albrecht G, Zalenski R, McDermott M (1999). Patient satisfaction with an emergency department asthma observation unit. Academic Emergency Medicine. 6:178-83.

Scott I, Vaughan L, Bell D (2009). Effectiveness of acute medical units in hospitals: a systematic review. International Journal for Quality in Health Care. 21:397-407.

Slack N, Chambers J, Johnston S (2004). Operations management. Prentice Hall, Harlow, 4th edn.

Spaite D, Bartholomeaux F, Guisto J, Lindberg E, Hull B, Eyherabide A, Lanyon S, Criss E, 
Valenzuela T, Conroy C (2002). Rapid process redesign in a university-based emergency department: decreasing waiting time intervals and improving patient satisfaction. Annals of Emergency Medicine. 39:168-77.

Susman G, Evered R (1978). An assessment of the scientific merits of action research. Administrative Science Quarterly. 23:582-603.

Zun L (1990). Observation units: boom or bust for emergency medicine. Journal of Emergency Medicine. 8:485-90. 



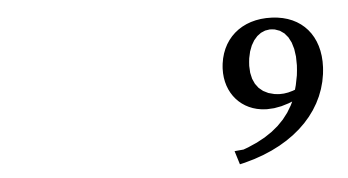

\section{Conclusions}

The healthcare sector faces a big challenge: delivering more and better patient care with the same means. This thesis deals with the question if industrial engineers can help with this challenge by applying process improvement concepts that were successful in industry. In this thesis, the principles of lean thinking (see chapters 1 and 2) were used to improve healthcare delivery. The research was carried out in the emergency department (ED) of the Academic Medical Centre in Amsterdam (see chapter 3 ). The managers of this department requested our help to address problematic patient flow in the ED. Given the fact that healthcare is an entirely different context than industry, we first carried out an exploratory research about applying lean thinking in the ED (see chapters 1 and 4). Based on the experiences in the pilot project, we chose a soft systems strategy to continue the research (see chapters 2 and 5). We collaborated with ED managers and healthcare professionals in the ED to diagnose the problematic patient flow, find feasible actions to take and study the effects. This joint process of enquiry and action became the subject of investigation. Five action research (AR) projects were carried out (see chapters 5 to 8).

This chapter presents the conclusions of the $\mathrm{PhD}$ research. We answer three central questions:

1. Were the industrial engineers able to have the other participants in the AR look at the healthcare delivery using the principles of lean thinking?

2. When looking at it in this way, were the AR participants then able to experiment with making the healthcare delivery more lean?

3. To what extent did the experiments result in measureable improvement of patient flow?

The answers to these questions are presented in three separate sections (9.1 to 9.3). Each section includes the main findings from the AR projects, a conclusion, and a discussion. Then we propose a new set of lean thinking principles, specifically intended 
for use in healthcare (9.4). This thesis ends with recommendations for further research and for practice (9.5).

\subsection{Conclusion and discussion for central question one}

Were the industrial engineers able to have the other participants in the AR look at the healthcare delivery using the principles of lean thinking?

\subsubsection{Main findings from the AR projects}

- Radiology project (chapter 5). Yes, we ${ }^{1}$ were able to have the ED managers and healthcare professionals look at the healthcare delivery from a lean thinking perspective after a while. Initially, they focused on their own activities from the perspective of their own profession. They did not fully understand how all of their activities contributed to the entire transformation process for the patients. Neither were they aware of the waste inherent in this process. By mapping the patient flow between the ED and radiology, this insight soon came. To do this, we focused on having the healthcare professionals identify what they do in $80 \%$ of cases for $80 \%$ of the patients - there was no such thing as one transformation process. The participants in the AR team were now able to identify quickly which activities actually contributed to the patient care and which did not. They were amazed at the large amount of time patients were waiting while nothing happened (waste). The AR team designed several interventions to improve patient flow.

- Planning board project (chapter 5). Yes, now that the ED managers and healthcare professionals were used to the perspective of lean thinking, they were able to design a planning board to improve the overview of patient flow.

- Computer simulation project (chapter 6). Yes, we were able to work with the medical director of the ED to model and animate the patient flow for self-referred patients on the computer. Members from the medical and nursing staff helped to approve and modify the flowcharts in the conceptual model. When we presented the working computer simulation model to the medical and nursing staff in the ED, they judged that the displayed movements and working order accurately represented the actual patient flow. They also brought up several ideas for improving the healthcare delivery.

- Advanced triage project (chapter 7). Yes, the computer simulation model was an excellent tool to look at the patient flow together with the participants in the AR team. The team was able to design an improvement scenario that fundamentally rearranged the task division between the staff physicians and the emergency

\footnotetext{
${ }^{1}$ For the sake of clarity: "we" means the (action) researchers. The researchers were industrial engineers.
} 
nurses. The effects of this scenario on the patient flow were projected in the computer model.

- Nursing wards project (chapter 8). Yes, through analysis of patient flow, patient volume and availability of beds, the participants in the AR team understood that an observation unit would not tackle the causes of problematic patient flow between the ED and the nursing wards.

\subsubsection{Conclusion}

The principles of lean thinking presented a perspective that was different from what the other participants in the AR team were used to. In all five projects, the industrial engineers were nevertheless able to have the ED managers and other healthcare professionals look at the healthcare delivery from the perspective of lean thinking. Together, they developed a shared understanding of the patient flow and the inherent waste.

\subsubsection{Discussion}

Especially at the beginning of the $\mathrm{PhD}$ research, there were sceptical reactions in the ED about the research intentions of using industrial principles such as lean thinking in healthcare. In the practice of this research, however, the AR participants proved very able to use lean thinking as a perspective to look at the healthcare delivery. In all projects, the industrial engineers (from students to professors) made an effort to first understand the current way of working of the professionals by joining them to observe their work. After this, the practitioners were invited to adopt a lean thinking perspective. The process mapping sessions served to make patient flow and waste visible to the AR participants. The computer simulation model provided an additional facility of studying the patient flow in animation.

The principles of lean thinking were designed to be applicable across industries. Our findings confirm that they can be applied in healthcare-although we propose to slightly change the original principles for use in healthcare, see section 9.4. By now, this is not a new conclusion anymore. Especially over the last few years, many studies became available about applications of lean thinking in healthcare (Harders et al., 2006; van den Heuvel et al., 2006; King et al., 2006; Parks et al., 2008; Dickson et al., 2009a;b). Tools and workshops are available for all kinds of topics including process mapping, understanding patient flow, matching capacity and demand, etc. (e.g. Rother and Shook, 1999; Institute for Healthcare Improvement, 2005a;b; NHS Institute for Innovation and Improvement, 2005; 2007). Lean thinking is also a popular tool of management consultants in healthcare.

Limitations. The results are based on the experiences and observations of the action researchers in one setting. 


\subsection{Conclusion and discussion for central question two}

When looking at the healthcare delivery from a lean thinking perspective, were the AR participants then able to experiment with making it more lean?

\subsubsection{Main findings from the AR projects}

- Radiology project. Yes, the AR team decided to experiment with performing all acute radiology examinations in one location instead of two for a number of weeks; this way of working was maintained since then (see also van Tuijn et al., 2010). Several other ideas to improve the collaboration between the emergency nurses and the radiology technicians failed to receive sufficient support for implementation.

- Planning board project. Yes, the team successfully replaced the existing planning board with the newly designed, more comprehensive version. After an initial period of getting used to it, the board was used by all the staff working in the ED. It became the foundation for an electronic version.

- Computer simulation project. There was no experimentation in this project. The computer simulation model was used to facilitate the experiment in the next project.

- Advanced triage project. Yes, the team was able to experiment-only just but nevertheless successfully-with the new professional task division; the experiment generated much discussion in the ED. Motivated by the positive projections of the computer model, the AR team carried out a pilot of the improvement scenario. This created a practice that had never before happened in the ED of the Academic Medical Centre: emergency nurses initiated diagnostic examinations from the triage- a task normally performed by the staff physicians. In response, several staff physicians and members of the radiology department expressed concerns regarding the quality of care. A full-scale experiment was set up next, in which two other staff physicians agreed to participate. The experiment was halted after a few test shifts because these staff physicians did not follow the new way of working. Eventually, the one staff physician in the AR team completed the experiment with several emergency nurses. After the experiment, several nurses reported trying the new task division on their own initiative. Over time, other staff physicians indicated their support for the new task division.

- Nursing wards project. Yes, it was decided by hospital management to change the configuration of the nursing wards for each of the major specialties receiving patient admissions from the ED. The nurse staffing levels in the wards were better matched with the actual outflow pattern of patients admitted from the ED. These changes were introduced when the $\mathrm{PhD}$ research had already ended. 


\subsubsection{Conclusion}

Considered over all projects, the participants in the AR team were able to experiment with making the healthcare delivery more lean. Several times, the experiments conflicted with the existing practice in the ED. People who had not directly participated in the AR team were not always willing to support new ways of working. This made experimentation difficult. The industrial engineers were able to complete all experiments using a soft systems strategy.

\subsubsection{Discussion}

Based on our experiences in the pilot project, we hoped to carry out a number of AR projects following a soft systems strategy. After first looking at healthcare delivery using a lean thinking perspective, the participants in the AR team were now able to successfully experiment with making it more lean. On close inspection, it appears that the collaboration of ED managers and healthcare professionals in the AR created the organisational arrangements required for lean healthcare delivery, mentioned in section 2.5.1:

1. Representatives from all three worlds of management in healthcare-cure, care, and control—collaborated to improve the healthcare delivery. The department managers of the ED played an important role: they deliberately collaborated to disrupt established routines in the ED, thereby accepting discussion to be generated in response. They enforced that experimentation took place by supporting it when necessary.

2. The healthcare professionals were given time and responsibility to experiment with different ways of working.

3. The participants in the AR learned to use lean thinking principles to tackle problematic patient flow (see section 9.1).

4. Data collection in the AR created insight into the sources of problematic patient flow. The computer simulation model created an additional facility of predicting the effects of interventions before implementation. By evaluating the effects of interventions based on data about the patient flow, the AR worked as a method of continuous improvement.

5. Many of the proposed ideas evolved around improving teamwork around the patients. See section 7.2.2 for example.

At the same time, a sharp distinction emerged between those people who were directly involved in the experiment and those who were not. It makes sense for the latter group to express concerns; this shows the reality of carrying out action research in the real life situation.

Our findings confirm the suitability of using a soft systems strategy to arrive at feasible improvement actions in unstructured problem situations such as tackling 
problematic patient flow in the ED. To our knowledge, this research was the first where industrial engineers used such a strategy for improving healthcare delivery with lean thinking.

Recent studies suggest that creating organisational arrangements similar to those described above is a necessary condition for improving healthcare delivery. For instance, Ham (2003, p. 1980) and Grol et al. (2005, p. 208) mention the conditions of engaging clinicians to bring about changes, developing clinical leadership, providing professionals with time and skills, and strengthening collaboration. Pines and Yealy (2009) mention that ED leaders, in order to successfully affect change, should create a culture of process improvement in which all stakeholders become invested. Considering the improvement of teamwork around patients, King et al. (2006) report on implementing a teamwork format in an application of lean thinking in the ED. Two teams were formed; one to treat patients likely to be discharged, the other to treat patients likely to be admitted. The format was found to impact patient flow positively and remained operational after it was introduced. Dickson et al. (2009b, p. 180) report the institution of similar interventions in the ED after applying lean thinking; one of these included a "team approach whereby a registered nurse, a resident, and the attending physician get the patient's history at the same time when possible, thus reducing duplication of history and saving staff time".

Dickson et al. (2009a) mention a slightly different method to experiment with making healthcare delivery more lean in the ED. They report successful behavioural changes with so-called kaizen events, intensive multiple day workshops as a beginning of continuous improvement. They also found that improvements were affected by leadership and engagement of the frontline workforce. Compared to the kaizen events, the AR in this research was more gradual and took place over a longer period.

Limitations. The same limitations apply as described for central question one. In addition, we point out that changes were made to specific procedures and routines in one setting. All changes included multiple interventions at the same time, taking place in a social situation of interacting people. In this situation, the "material" is not homogeneous in time (Checkland and Holwell, 1998), making exact replication impossible. It is therefore not possible to identify a single cause for success or to generalise from the results (McGrath, 1982). Action research is an approach to research which is unclear and imprecise compared to other approaches (Coughlan and Coghlan, 2002).

If our findings are indeed not the result of coincidence, we may explain them as follows in terms of a soft systems perspective on organisations (section 2.6). We believe that the collaboration in the AR created a new social structure, parallel to the existing one in the ED (see also Shani and Eberhardt, 1987). By using lean thinking as a new perspective to look at the healthcare delivery, the actors in this new social structure changed their conceptions (see also Susman and Evered, 1978; Bhaskar, 1998). Next, they designed experiments using these new conceptions. The experiments included taking different actions-making healthcare delivery more lean-in the existing social structure of the ED. The people who were not directly involved in the AR had not 
changed their conceptions about their actions. This makes it understandable that they expressed concerns (or even refused to cooperate) after observing the AR participants working together differently in the experiments. The AR participants functioned as role models for the people who were not directly involved.

Our explanation presents opportunities for further research regarding decisions about whom to involve in the AR and when, see section 9.5.1. We chose a relatively small group, with only one or two professionals representing each discipline.

\subsection{Conclusion and discussion for central question three}

To what extent did the experiments result in measureable improvement of patient flow?

\subsubsection{Main findings from the AR projects}

1. Radiology project. A baseline and a second time study showed that waiting time for patients and the total processing time remained the same. Though the intervention did simplify the patient flow, it did not reduce unnecessary waiting time as we hoped.

2. Planning board project. A baseline and a second survey showed that the planning board improved the overview of patient flow and the feeling of control for the ED staff. It is imaginable that this promoted the patient flow. We did not measure patient flow directly.

3. Computer simulation project. As there was no experimentation in this project, there were no improvements to be measured.

4. Advanced triage project. A baseline and a second time study showed a 14 minute (14 percent) reduction in the length of stay for self-referred patients. The intervention achieved the goal of better utilising patient waiting time by bringing operating activities forward. The quality of care was maintained with advanced triage in terms of diagnostic procedures ordered.

5. Nursing wards project. As the changes were made after the $\mathrm{PhD}$ research, it is unknown if patient flow was improved. It is imaginable that the patient flow was promoted by better matching staffing levels with patient demand.

\subsubsection{Conclusion}

We found a clear improvement of patient flow in one project. The other projects produced promising clues of improvement. Through careful application of lean thinking principles, industrial engineers can make a valuable contribution to the present challenge in healthcare of doing more with the same means. 


\subsubsection{Discussion}

To us, the findings in the advanced triage project are a clear illustration that a different architecture of the operating activities in a transformation process can improve the output of that process. In other words, that the same healthcare professionals can work together differently to significantly improve patient flow. We had not expected to measure improvement in only one out of four successful experiments-especially because this was the result of incomplete data collection.

Compared to the dramatic improvements promised to be possible from applying lean thinking by Womack and Jones (2003), our finding of 14 percent reduction in the advanced triage project was small. However, the finding is in line with other empirical research in healthcare. Chan et al. (2005), Pedersen and Storm (2009), and Retezar et al. (2011) found reductions in patient length of stay of similar order as we found. Dickson et al. (2009a) also found comparable improvements from applications of lean thinking in four EDs.

Limitations. Considering the finding in the advanced triage project, the same limitations apply as described for central question two. Susman and Evered (1978, p. 601) state that in action research, the ultimate sanction is in the perceived functionality of chosen actions to produce desirable consequences for an organisation. We can say that these desirable consequences were achieved. Considering the incomplete data collection, it is important to note that patient flow was not measured continuously in the study setting during the research period. Data were only available on printed medical records, requiring separate efforts to collect the required data. For the planning board project, we judged that the efforts required to collect data outweighed the chance of first measuring a significant effect and then being able to attribute it to the introduction of the new planning board. Naturally, clear recommendations for future research follow from the data collection in this study.

Evidently, improving transformation processes in healthcare does work differently than in industry. Although healthcare delivery contains much waste when analysed from a lean thinking perspective, removing it is a different story (Dickson et al., 2009b; Pines and Yealy, 2009). The value stream in the ED consists of many different professionals from different departments and specialties working together according to individual preferences and routines embedded in the hospital culture. Experimenting to have the professionals change their collaboration around patients using a lean thinking perspective does not directly improve the entire organisation. The strict professional task division, specialised departments and disconnected hierarchies in the different worlds of management all interfere with making healthcare delivery improvement one shared goal. 
Table 9.1: Original principles of lean thinking and a new set for use in healthcare

\begin{tabular}{ll}
\hline Original principles & New principles for use in healthcare \\
\hline $\begin{array}{l}\text { Specify value from the standpoint of the } \\
\text { end customer in terms of a specific product }\end{array}$ & $\begin{array}{l}\text { Specify value from the standpoint of the } \\
\text { patient in terms of a specific healthcare } \\
\text { service delivered }\end{array}$ \\
$\begin{array}{l}\text { Identify all the steps in the value stream for } \\
\text { each product family, eliminating whenever } \\
\text { possible those steps that do not create }\end{array}$ & $\begin{array}{l}\text { Identify all the steps in the value stream for } \\
\text { groups of patients sharing similar needs, } \\
\text { clearly marking all steps that do not create } \\
\text { value }\end{array}$ \\
$\begin{array}{l}\text { Make the value-creating steps occur in } \\
\text { tight sequence so the product will flow } \\
\text { smoothly toward the customer }\end{array}$ & $\begin{array}{l}\text { Make the value-creating steps occur in } \\
\text { tight sequence so the patient will flow } \\
\text { smoothly through the value stream }\end{array}$ \\
$\begin{array}{l}\text { As flow is introduced, let customers pull } \\
\text { value from the next upstream activity }\end{array}$ & $\begin{array}{l}\text { Have all healthcare professionals across } \\
\text { departments collaborate to pull patients } \\
\text { through the value stream }\end{array}$ \\
Pursue perfection & Pursue perfection \\
\hline
\end{tabular}

\subsection{A new set of lean thinking principles for use in healthcare}

Based on our research, we propose a new set of slightly changed lean thinking principles. These are specifically aimed for application in healthcare. See table 9.1.

\subsection{Recommendations}

Several recommendations for further research follow from the conclusions and discussion in this study. We also provide a number of recommendations for improving practice, based on our own experiences in the AR.

\subsubsection{Further research}

Industrial engineers should continue with soft systems strategies to help people in organisations find feasible improvement actions in unstructured problem situations. In the evaluation of changes, collaborating with practitioners to ensure proper and continuous data collection should be a first priority. Especially for improving healthcare delivery, it is important for industrial engineers to see the organisation as a social structure rather than a production system. Within such a perspective, computer 
simulation models can serve as great tools to facilitate the implementation of changes. Design and use of these models for the specific purpose of affecting change is still little reported in the healthcare literature.

It is worthwhile to experiment with different setups of participants in the AR. More people could be involved directly from the start in the diagnosis and action planning phases of the AR (e.g. van der Zouwen, 2011); more people may then change their conceptions about their actions. Another opportunity is to repeat the same experiment in one setting with more than one AR team; in addition, comparable AR projects in multiple settings would strengthen the generalisability of findings. For the ED, decisions about involving more people need to be weighed against their availability within the context of continuous care delivery. The chance of finding an action that everyone can live with is probably highest in the smallest possible group as defined by the actors in the part of the care delivery under study.

\subsubsection{Improving practice}

Specialisation is a central quality of the healthcare sector. In the ED, it becomes directly visible how this complicates coordination and continuous improvement. Rather than narrowing existing specialties by creating new subspecialties around non-core activities, we should extend the existing ones. In this respect, the introduction of emergency physicians in the Netherlands may help to reduce the complexities in the patient flow and guarantee continuous improvement of patient care. In addition, responsibilities for emergency nurses can be enlarged safely, as our own advanced triage project demonstrated.

Healthcare delivery improvement should be deliberately organised as a goal. A great source of knowledge is the expertise of the healthcare professionals, who already need to improvise to do their work. This goal requires the creation of the organisational arrangements as described in sections 9.2.3 and 2.5.1. Healthcare managers and healthcare professionals should be able to adopt a lean thinking perspective. This helps them understand the inherent waste in the care delivery experienced by their patients daily.

Next to using lean thinking as a perspective for improving healthcare delivery, it should also be used to enable lean healthcare delivery, for example by designing staffing levels, information systems and new hospitals around continuous patient flow.

\section{References}

Bhaskar R (1998). The possibility of naturalism. A philosophical critique of the contemporary human sciences. Routledge, London, 3rd edn.

Chan T, Killeen J, Kelly D, Guss D (2005). Impact of rapid entry and accelerated care at triage on reducing emergency department patient wait times, lengths of stay, and rate of left without being seen. Annals of Emergency Medicine. 46:491-7. 
Checkland P, Holwell S (1998). Action research: its nature and validity. Systemic Practice and Action Research. 11:9-21.

Coughlan P, Coghlan D (2002). Action research for operations management. International Journal of Operations \& Production Management. 22:220-40.

Dickson E, Anguelov Z, Vetterick D, Eller A, Singh S (2009a). Use of lean in the emergency department: a case series of 4 hospitals. Annals of Emergency Medicine. 54:504-10.

Dickson E, Singh S, Cheung D, Wyatt C, Nugent A (2009b). Application of lean manufacturing techniques in the emergency department. Journal of Emergency Medicine. 37:177-82.

Grol R, Wensing M, Eccles M (2005). Improving patient care. The implementation of change in clinical practice. Elsevier, Edinburgh.

Ham C (2003). Improving the performance of health services: the role of clinical leadership. The Lancet. 361:1978-80.

Harders M, Malangoni M, Weight S, Sidhu T (2006). Improving operating room efficiency through process redesign. Surgery. 140:509-16.

van den Heuvel J, Does R, Bogers A, Berg M (2006). Implementing six sigma in the netherlands. Joint Commission Journal on Quality and Patient Safety. 32:393-9.

Institute for Healthcare Improvement (2005a). Decrease and smooth variation. http://www.ihi. org/knowledge/pages/changes/decreaseandsmoothvariation.aspx.

Institute for Healthcare Improvement (2005b). Match capacity and demand. http://www.ihi. org/knowledge/pages/changes/matchcapacityanddemand.aspx.

King D, Ben-Tovim D, Bassham J (2006). Redesigning emergency department patient flows: application of lean thinking to health care. Emergency Medicine Australasia. 18:391-7.

McGrath J (1982). Dilemmatics. the choice of research problems and dilemmas. In McGrath J, Martin J, Kulka R (eds.) Judgment calls in research, pp. 69-102, Sage, London.

NHS Institute for Innovation and Improvement (2005). Improvement leaders' guide: Improving flow. http://www.institute.nhs.uk/quality_and_service_improvement_tools/quality_and_ service_improvement_tools/patient_flow.html.

NHS Institute for Innovation and Improvement (2007). Improvement leader's guide to process mapping, analysis and redesign. http://www.institute.nhs.uk/index.php?option=com content\&task $=$ view\&id $=134 \&$ Itemid $=35$.

Parks J, Klein J, Frankel H, Friese R, Shafi S (2008). Dissecting delays in trauma care using corporate lean six sigma methodology. The Journal of Trauma. 65:1098-105.

Pedersen G, Storm J (2009). Emergency department x-rays requested by physicians or nurses. Ugeskrift for Laeger. 171:1747-51.

Pines J, Yealy D (2009). Advancing the science of emergency department crowding: measurement and solutions. Annals of Emergency Medicine. 54:511-3.

Retezar R, Bessman E, Ding R, Zeger S, McCarthy M (2011). The effect of triage diagnostic standing orders on emergency department treatment time. Annals of Emergency Medicine. 57:89-99.e2.

Rother M, Shook J (1999). Learning to see: value stream mapping to add value and eliminate muda. Lean Enterprise Institute, Brookline.

Shani A, Eberhardt B (1987). Parallel organization in a health care institution. Group and Organization Studies. 12:147-73. 
Susman G, Evered R (1978). An assessment of the scientific merits of action research. Administrative Science Quarterly. 23:582-603.

van Tuijn C, Luitse J, van der Valk M, van Wissen S, Prins M, Rosmulder R, Geerlings S (2010). Reduction of the door-to-needle time for administration of antibiotics in patients with a severe infection: a tailored intervention project. Netherlands Journal of Medicine. 68:123-7.

Womack J, Jones D (2003). Lean thinking. Simon \& Schuster, London, 2nd edn.

van der Zouwen T (2011). Building an evidence based practical guide to large scale interventions. $\mathrm{PhD}$ thesis, Tilburg University, Tilburg. 


\section{Dankwoord}

In de film Groundhog Day beleeft hoofdrolspeler Phil Connors (Bill Murray) iedere keer dezelfde dag. Als hij 's avonds gaat slapen, wordt hij weer wakker op de vorige ochtend. Na vele varianten van dezelfde dag te hebben beleefd en duizend doden te zijn gestorven, wordt hij dan eindelijk wakker op de volgende ochtend, samen met zijn geliefde. Ik herken me sterk in de belevenissen van Phil. Weer een afgewezen publicatie, weer een nieuwe versie van het simulatieartikel, weer een dag waarop er nog iets moest $-\mathrm{o}$ ja, promoveren. Het is geweldig maar ook ietwat beangstigend dat er nu eindelijk een nieuwe dag aanbreekt.

Ik wil een aantal mensen bedanken voor hun bijdragen in de afgelopen periode. Allereerst mijn promotoren aan de Universiteit Twente, Koos Krabbendam en Toon Kerkhoff. Beste Koos, mijn dank voor je vertrouwen, je toegankelijkheid en je persoonlijke belangstelling. Je was aanwezig wanneer het moest. Jouw overtuiging dat zorgprocessen gewoon goed moeten verlopen, blijft onverminderd van kracht. We weten nu een stuk beter hoe technisch bedrijfskundigen daaraan kunnen bijdragen. Beste Toon, je hebt me verschrikkelijk uitgedaagd met je kritische blik en je geweldige kennis. Je hebt mij op weg gestuurd om een antwoord te vinden op de vraag hoe je als ingenieur mensen verbindt met systemen. Dit heeft mij verrijkt en heeft dit boek-samen met de begeleiding van Koos-gemaakt tot wat het nu is.

In het AMC ben ik veel dank verschuldigd aan het medisch hoofd van de afdeling Spoedeisende Hulp (SEH), Jan Luitse. Beste Jan, bedankt voor je aanhoudend enthousiasme en onverwoestbaar geloof in een goede afronding. Je hebt me steeds opnieuw weten te motiveren. Bedankt voor je sterke overtuiging dat de gezondheidszorg baat heeft bij de technische bedrijfskunde. Inmiddels begrijpen we beter wat dat in de praktijk betekent en hoe het zich zelfs kan doorvertalen in het ontwerp voor een nieuwe afdeling. Beste Els en Verica, bedankt voor de vele plezierige en persoonlijke gesprekken en voor jullie hulp bij mijn onderzoek. Verica, ik ben vereerd dat je mijn paranimf bent, ook namens de afdeling en het AMC. Ik dank de SEH-verpleegkundigen, $\mathrm{SEH}$-artsen, radiologisch laboranten, radiologen, arts-assistenten, specialisten, receptionisten en alle anderen voor hun medewerking aan het onderzoek. Met name noem ik diegenen met wie ik direct heb samengewerkt: Anieke, Bea, Christine, Erik, Eva, Hans, Harry, Jurriaan, Karine, Ludo, Marcel, Marja, Marleen, Nicole, Piet, Rob, Willeke en Wouter. 
Ik bedank mijn collega's aan de Universiteit Twente voor hun wijze woorden, luisterend oor en welkome afleiding. Speciale dank gaat uit naar Anna, Annemien, Jasper, Jeroen, Liqin, Marie-Christine, Martijn, Matthias, Patricia, Petra, Rauf en Waling. Beste Anna, ik voel me vereerd en gesteund om jou als paranimf te hebben. Mijn dank aan jou en Ger voor de vele keren dat ik bij jullie mocht logeren. Ik bedank ook Erwin Hans voor zijn enthousiasme en gedeelde passie voor de gezondheidszorg. Eelco, ik zie uit naar jouw proefschrift. Ik heb veel geleerd van de studenten die ik de afgelopen jaren bij hun afstudeeronderzoeken heb mogen begeleiden. Bedankt voor jullie bijdragen aan dit onderzoek.

Bij Sioo ben ik de leden van het onderzoeksplatform dankbaar voor het meedenken en het geven van feedback op mijn werk. Speciale dank gaat uit naar Gerhard en Jaap.

Met mijn vrienden heb ik fijne tijden beleefd tijdens feesten, pokeravonden, zeilen, weekenden weg, verhuizen, afzien in de bergen, etc. Derk-Jan en Dorus dank ik voor de vele jaren van gastvrijheid op "ons" Calslaan 14b. Beste Dolf, ik ben je zeer dankbaar dat je de opmaak en vormgeving van mijn proefschrift hebt willen verzorgen. Wat een enorme klus-maar wat een prachtig resultaat! Dank voor de vriendschap van jou en Elske en voor de vele keren dat ik bij jullie mocht logeren. Luuk, ik dank je voor onze goede gesprekken en ik dank je vooral niet voor het net iets vaker winnen met poolen. Ik bedank Karen voor haar jaren van liefde en steun.

Er zijn inmiddels vele families die ik mag bedanken voor de gezelligheid en hulp bij allerlei zaken de afgelopen tijd. Beste Margriet, Henk, Rian en Peter, dank voor jullie aandacht en interesse en voor de prettige momenten van samenzijn. Peter, hartelijk dank voor het ontwerpen van de omslag van dit proefschrift. Lieve Ellie, $\mathrm{ik}$ voelde mij al snel thuis in jouw gezin. Ik vind het fijn om Harrie nog ontmoet te hebben. Harm, bedankt voor het vertalen van hoofdstuk zeven van dit boek. Hardcore never dies. Lieve Anne-loes en Wim, het is fijn om te zien hoe gelukkig jullie zijn met elkaar. Ik dank jullie zeer voor het feit dat jullie zo betrokken zijn en me ondersteunen waar het kan. Met onuitputtelijke energie en plezier doen jullie dit niet alleen voor mij, maar voor alle naaste familie. Dit boek is opgedragen aan mijn moeder Anne. Ik weet dat ze trots is. Haar eigengereide geest leeft in mij voort.

In vergelijking met Phil uit de film heb ik gelukkig al veel langer het genoegen om iedere dag opnieuw wakker te worden naast mijn geliefde. Lieve Maaike, zonder jou had ik mijn promotie niet kunnen afronden. Ik dank je voor de geweldige schop die af en toe nodig was en ook handig bleek voor in de tuin. Ik ben een trots man met jou naast me. Ik ben blij om met jou samen de nieuwe dag in te gaan.

Utrecht, september 2011 


\section{Over de auteur}

Remco Rosmulder (1981) groeide op in Eindhoven. Hij studeerde in 2004 af als bedrijfskundig ingenieur aan de Universiteit Twente. Daarna diepte hij zijn belangstelling voor het beter organiseren van zorgprocessen uit in een promotieonderzoek. Tevens begeleidde hij studenten bij bedrijfskundige afstudeeropdrachten in verschillende Nederlandse ziekenhuizen. Sinds 2009 werkt hij als zelfstandig organisatieadviseur.

Remco doet vrijwilligerswerk in een verzorgingshuis. Hij was eerder vrijwilliger in een hospice. In zijn vrije tijd speelt hij jazzmuziek op de hoorn. Hij woont samen met Maaike in Utrecht. 



\section{Index}

Action research, 6, 58, 65, 71

Action research team, 61, 75, 80

Admission process, 112

Advanced triage, 85, 93

Advanced triage protocol, 95

AMC, 33-45

Architecture, 12, 14

Care, 22

Care delivery, 41, 77, 94

Computer simulation, 71

Control, 22

Cure, 22

Emergency department, 33-45

Environment, 12

Flow, 2, 17, 40, 127, 129

Goals, 12

Hard systems approach, 27

Improvement scenario, 74, 80

Industrial engineers, 11, 26, 121, 129

Job shop organisation, 37, 38, 40

Kaizen, 17

Lean production, 1,13

critiques of, 17

Lean thinking, 2, 16, 123 new principles, 129

Machine bureaucracy, 20, 21

Muda, 16

Muddling through, 6, 62

Operating activities, 13

Operations management, 55, 105

Organisational arrangements, 13, 15, 20, 38, 39, 125

Participants, 12

Patient flow, 33, 34

Patients

critical, 34

GP-referred, 34, 49

self-referred, 35, 76

Perfection, 2, 17, 129

Piecemeal engineering, 62

Planning, see Scheduling

Production system, 12

Professional bureaucracy, 20, 21

Project organisation, 37, 38

Pull, 2, 17, 129

Referral process, 50

Research projects, 6, 43 advanced triage project, 91-102 computer simulation project, 69-89 main findings, 122, 124, 127 nursing wards project, 103-119 planning board project, 63-64 
radiology project, 62-63

Scheduling, 49

Social structure, 12, 28, 126

Soft systems methodology, 27, 59

Soft systems strategy, 29, 125

Systems engineering, 27

Technology, 12, 19

Transformation process, 13,14

Transforming resources, 13, 36

Triage, 39

Value, 2, 16, 129

Value stream, 2, 17, 39, 129

Waiting, 39

Waste, 2, 17 